CARLOS NAOMI TANAKA

\title{
METODOLOGIA DE DIMENSIONAMENTO DO SISTEMA DE TRAÇÃO PARA VEÍCULOS ELÉTRICOS
}

Dissertação de Mestrado apresentada à Escola Politécnica da Universidade de São Paulo para a obtenção do título de Mestre em Ciências. 


\section{METODOLOGIA DE DIMENSIONAMENTO DO SISTEMA DE TRAÇÃO PARA VEÍCULOS ELÉTRICOS}

Dissertação de Mestrado apresentada à Escola Politécnica da Universidade de São Paulo para a obtenção do título de Mestre em Ciências.

Área de concentração:

Sistemas de potência

Orientador: Prof. Dr. Silvio Ikuyo Nabeta

São Paulo

2013 
Este exemplar foi revisado e alterado em relação à versão original, sob responsabilidade única do autor e com a anuência de seu orientador.

São Paulo, 15 de fevereiro de 2013.

Assinatura do autor

Assinatura do orientador

FICHA CATALOGRÁFICA

Tanaka, Carlos Naomi

Metodologia de dimensionamento do sistema de tração para veículos elétricos / C.N. Tanaka. -- ed.rev. -- São Paulo, 2013. $106 \mathrm{p}$.

Dissertação (Mestrado) - Escola Politécnica da Universidade de São Paulo. Departamento de Engenharia de Energia e Automação Elétricas.

1. Veículos especiais 2 . Motores elétricos 3 . Sistema de tração (Metodologia; Dimensionamento) I. Universidade de São Paulo. Escola Politécnica. Departamento de Engenharia de Energia e Automação Elétricas II. t. 


\section{DEDICATÓRIA}

Aos meus pais, aos meus filhos e à Márcia. A todos que ao meu lado me incentivaram e apoiaram. Àqueles que se empenham para a realização de seus sonhos... 


\section{AGRADECIMENTOS}

Ao Professor Doutor Clovis Goldemberg (in memoriam) pelo incentivo.

Ao Professor Doutor Ivan Chabu e ao Eng. Doutor Cassiano Lobo Pires pelas valiosas contribuições e comentários.

Ao orientador Professor Doutor Silvio Ikuyo Nabeta por tornar possível. 


\section{RESUMO}

O interesse por veículos elétricos voltou a crescer nos últimos anos, principalmente, devido às questões ambientais e de eficiência energética. Aliado ao desenvolvimento de fontes e acumuladores de energia com densidades de energia e potência maiores que viabilizam a utilização de veículos elétricos em substituição parcial dos veículos com motores a combustão interna, já surgem comercialmente no mercado alguns modelos de veículos elétricos. Neste contexto, também cresce a necessidade de recursos humanos capacitados e ferramentas auxiliares para o dimensionamento dos componentes dessa nova geração de veículos automotores. Este trabalho apresenta uma metodologia simples e direta de dimensionamento do sistema de tração para veículos elétricos autônomos, bem como os resultados de uma aplicação prática da utilização desta metodologia no desenvolvimento de veículos elétricos fora de estrada para transporte de pessoas e de material. A comparação entre os resultados práticos obtidos com os cálculos realizados mostra que a metodologia, com o equacionamento completo e abrangente apresentado, fornece resultados com excelente exatidão.

Palavras-chave: Veículos elétricos. Sistemas de tração de veículos elétricos. Dimensionamento de sistemas de tração. Metodologia de dimensionamento de sistemas de tração. 


\begin{abstract}
The interest in electric vehicles is growing again in recent years, mainly due to environmental concerns and energy efficiency issues. Combined with the development of energy storage devices with higher power and energy densities that enable the use of electric vehicles, some models already appear commercially in the market replacing vehicles with internal combustion engines in specific applications. In this context, it also increases the need for trained human resources and auxiliary tools for designing the components of this new vehicles generation. This dissertation presents a simple and direct methodology of propulsion system design for autonomous electric vehicles as well as the results of a practical application of using this methodology in the development of off-road electric vehicles for people and material transport. The comparison between the practical results obtained with the calculations shows that the methodology, with the complete and comprehensive equations presented, provides results with excellent accuracy.
\end{abstract}

Keywords: Electric vehicles. Propulsion system of electric vehicles. Propulsion system design. Methodology of propulsion system design. 


\section{LISTA DE FIGURAS}

Figura 1.1 - Comparação de energia a partir do petróleo e bateria chumbo-ácido ...18

Figura 1.2 - cadeira de rodas elétrica 20

Figura 3.1 - Curvas ideais de torque e potência .32

Figura 3.2 - Estrutura de quatro máquinas elétricas tradicionais. .33

Figura 4.1 - Conceito de veículo elétrico com baterias recarregáveis .44

Figura 4.2 - Configurações para veículos elétricos puros 45

Figura 4.3 - Forças atuando em um veículo .48

Figura 4.4 - Arrasto de forma na resistência aerodinâmica 51

Figura 4.5 - Ciclo de condução ECE 15 .57

Figura 4.6 - Ciclo de condução EUDC .57

Figura 4.7 - Ciclo de condução EUDCL .58

Figura 4.8 - Ciclo de condução FTP 75 .59

Figura 4.9 - Ciclo de condução NYCC .60

Figura 4.10 - Ciclo de condução 10-15 MODE 61

Figura 4.11 - Novo ciclo de condução europeu (NEDC) ........................................62

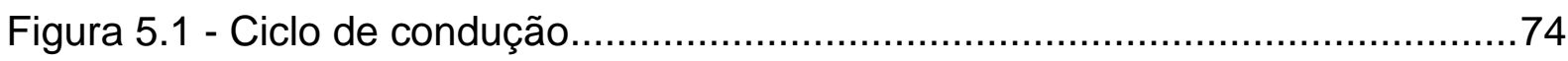

Figura 5.2 - Potência e energia consumida no ciclo de condução ............................74

Figura 5.3 - Algoritmo para planilha de cálculos................................................76

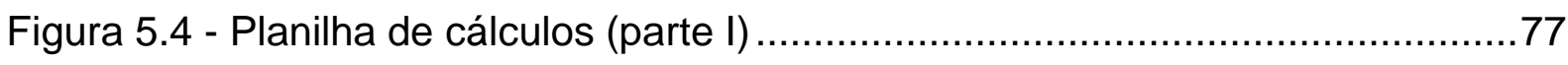

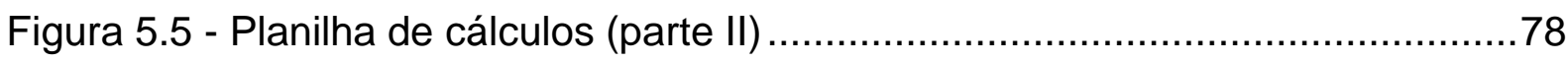

Figura 5.6 - Planilha de cálculos (parte III) ........................................................ 79

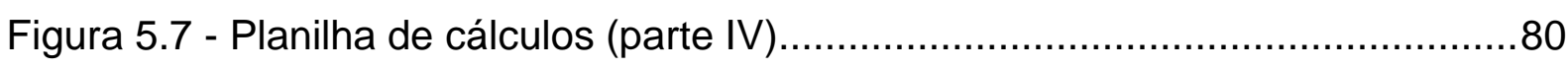

Figura 5.8 - Potência, torque e rotação no motor ………………….....................81

Figura 5.9 - Curvas características do motor ADCM AC1-4001 …...........................82

Figura 5.10 - Potência no controlador/conversor de potência ....................................83 
Figura 5.11 - Capac. potência do controlador/conversor de potência Curtis 1204-0XX

Figura 5.12 - Potência e energia consumida das baterias em um ciclo de condução

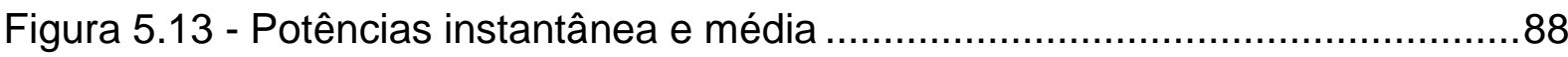

Figura 5.14 - Veículo elétrico (distribuição de bebidas) ............................................94

Figura 5.15 - Veículo elétrico (transporte de pessoas) ………...............................94

Figura 5.16 - Motores elétricos de tração ...........................................................94

Figura 5.17 - Motor acoplado à transmissão e diferencial no eixo de tração .............94

Figura 5.18 - Controlador/conversor de potência montado com contator e fusíveis..94

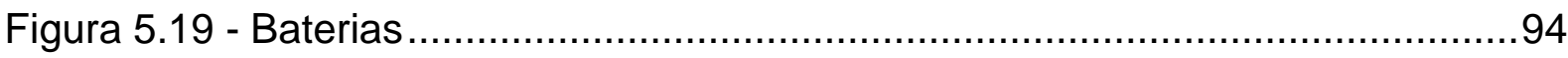

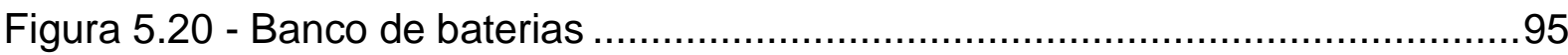

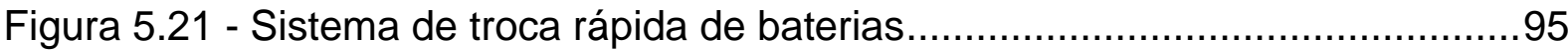




\section{LISTA DE TABELAS}

Tabela 3.1 - Valores típicos para o fator de massa ................................................28

Tabela 3.2 - Aplicações de motores em veículos elétricos ........................................34

Tabela 3.3 - Avaliação de motores com acionamentos para veículos elétricos .........35

Tabela 3.4 - Características de baterias de lítio e NiMH ..........................................38

Tabela 3.5 - Características de ultracapacitores ……………...............................40

Tabela 4.1 - Valores típicos para o coeficiente de resistência ao rolamento ...............50

Tabela 4.2 - Coeficientes de arrasto em função da forma do veículo ........................52

Tabela 5.1 - Especificação técnica......................................................................

Tabela 5.2 - Dados definidos pelo projeto …………................................................

Tabela 5.3 - Ciclo de condução..............................................................................

Tabela 5.4 - Requisitos para o motor de tração ………............................................ 81

Tabela 5.5 - Principais características do motor CC c/ escovas ADCM AC1-4001 ...82

Tabela 5.6 - Requisitos para o controlador/conversor de potência ..............................83

Tabela 5.7 - Características do controlador/conversor de potência Curtis 1204-0XX

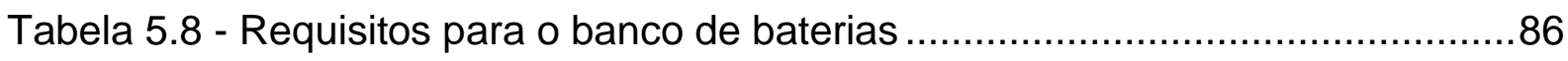

Tabela 5.9 - características do banco de baterias (Trojan T-105) .............................. 86

Tabela 5.10 - Requisitos para o banco de ultracapacitores ....................................8

Tabela 5.11 - Principais características dos ultracapacitores escolhidos ...................89

Tabela 5.12 - Medições efetuadas na fábrica com o veículo ………………….......90

Tabela 5.13 - Características reais de desempenho e especificações de projeto .....92 


\section{LISTA DE ABREVIATURAS}

\section{Abreviatura Significado}

$\begin{array}{ll}\text { BEV } & \text { Veículo elétrico a bateria } \\ \text { DCM } & \text { Máquina de corrente contínua } \\ \text { EV } & \text { Veículo elétrico (vide VE) } \\ \text { HEV } & \text { Veículo elétrico híbrido (vide VEH) } \\ \text { IEEE } & \text { Institute of Electric and Electronic Engineers } \\ \text { IM } & \text { Máquina de indução } \\ \text { NiMH } & \text { Hidreto metálico de níquel } \\ \text { Plug-in } & \text { (Veículo elétrico híbrido) plug-in é aquele que pode recarregar suas } \\ \text { (PHEV) } & \text { baterias através da rede elétrica ou outra fonte de energia elétrica } \\ & \text { externa ao veículo. } \\ \text { PMBM } & \text { Máquina de imãs permanentes sem escovas } \\ \text { PWM } & \text { Modulação de largura de pulso (Pulse Width Modulation) } \\ \text { SRM } & \text { Máquina de relutância chaveada } \\ \text { VE } & \text { Veículo elétrico } \\ \text { VEB } & \text { Veículo elétrico a bateria } \\ \text { VEH } & \text { Veículo elétrico híbrido } \\ \text { VEHP } & \text { Veículo elétrico híbrido plug-in }\end{array}$




\section{LISTA DE SÍMBOLOS}

\begin{tabular}{|c|c|c|}
\hline Símbolo & Variável & Unidade \\
\hline$A_{f}$ & $\begin{array}{l}\text { Área frontal do veículo (projeção em plano perpendicular } \\
\text { ao movimento) }\end{array}$ & {$\left[m^{2}\right]$} \\
\hline$C_{D}$ & Coeficiente aerodinâmico & Adimensional \\
\hline$C_{u c}$ & Capacitância do ultracapacitor & {$[F]$} \\
\hline$d$ & Fator de desempenho do veículo & Adimensional \\
\hline$E_{\text {out }}$ & Energia consumida das baterias & {$[\mathrm{Wh}]^{1}$} \\
\hline$E_{\text {out_acum }}$ & Energia consumida das baterias acumulada & {$[\mathrm{Wh}]$} \\
\hline$E_{u c}$ & Energia do ultracapacitor & {$[\mathrm{Wh}]$} \\
\hline$F_{g}$ & Força de resistência ao aclive & {$[N]$} \\
\hline$F_{l a}$ & Força de aceleração linear & {$[N]$} \\
\hline$f_{r}$ & Coeficiente de resistência ao rolamento & Adimensional \\
\hline$F_{r}$ & Força de resistência ao rolamento & {$[N]$} \\
\hline$F_{t}$ & Força de tração & {$[\mathrm{N}]$} \\
\hline$F_{w}$ & Força de resistência aerodinâmica & {$[N]$} \\
\hline$F_{w a}$ & Força de aceleração angular & {$[N]$} \\
\hline$g$ & Aceleração da gravidade & {$\left[\mathrm{m} / \mathrm{s}^{2}\right]$} \\
\hline$i$ & Inclinação do terreno $(\tan \alpha \sim \operatorname{sen} \alpha)$ & Adimensional \\
\hline$i_{0}$ & Relação do acionamento final (quando existir) & Adimensional \\
\hline$i_{g}$ & Relação do sistema de transmissão & Adimensional \\
\hline$i_{g \min }$ & Relação mínima do sistema de transmissão & Adimensional \\
\hline$I$ & $\begin{array}{l}\text { Momento de inércia das partes girantes do sistema de } \\
\text { tração referidos ao motor }\end{array}$ & {$\left[\mathrm{kg} \cdot \mathrm{m}^{2}\right]$} \\
\hline$I_{W}$ & Momento de inércia das rodas/pneus & {$\left[\mathrm{kg} \cdot \mathrm{m}^{2}\right]$} \\
\hline M & Massa do veículo & {$[\mathrm{kg}]$} \\
\hline$N_{m}$ & Rotação do motor de tração & [rpm] \\
\hline$N_{\max }$ & Rotação máxima do motor de tração & [rpm] \\
\hline$N_{t}$ & Rotação da roda/pneu & [rpm] \\
\hline$P_{\text {bat }}$ & Potência da bateria & {$[\mathrm{W}]$} \\
\hline Preg & Potência regenerada & {$[\mathrm{W}]$} \\
\hline$P_{t o t}$ & Potência total consumida & {$[\mathrm{W}]$} \\
\hline
\end{tabular}

${ }^{1}$ No SI a unidade para energia é o Joule [J], mas neste trabalho será utilizado o [Wh] por ser de uso frequente em tração elétrica. 


\begin{tabular}{|c|c|c|}
\hline Símbolo & Variável & Unidade \\
\hline$P_{\text {tot_med }}$ & Potência total consumida média & {$[\mathrm{W}]$} \\
\hline$P_{c c}$ & Potência de saída do controlador/conversor de potência & {$[\mathrm{W}]$} \\
\hline$P_{m}$ & Potência (no eixo) do motor & {$[\mathrm{W}]$} \\
\hline$P_{t}$ & Potência de tração & {$[\mathrm{W}]$} \\
\hline$P_{u c}$ & Potência do ultracapacitor & {$[\mathrm{W}]$} \\
\hline$r$ & Raio do pneu & [m] \\
\hline$r_{d}$ & Raio efetivo do pneu & {$[\mathrm{m}]$} \\
\hline$t$ & Tempo, período de tempo. & {$[\mathrm{s}]$} \\
\hline$t_{0}$ & Tempo no instante zero no ciclo de condução & {$[\mathrm{s}]$} \\
\hline$t_{1}$ & Tempo no instante um. & {$[\mathrm{s}]$} \\
\hline$t_{2}$ & Tempo no instante dois. & {$[\mathrm{s}]$} \\
\hline$t_{a}$ & Tempo de aceleração & [s] \\
\hline$t_{f}$ & Tempo no instante final no ciclo de condução & {$[\mathrm{s}]$} \\
\hline$t_{n}$ & Tempo no instante $n$ no ciclo de condução & {$[\mathrm{s}]$} \\
\hline$t_{n-1}$ & Tempo no instante $n-1$ no ciclo de condução & [s] \\
\hline$T_{m}$ & Torque do motor de tração & {$[\mathrm{N} . \mathrm{m}]$} \\
\hline$T_{t}$ & Torque de tração nas rodas/pneus & {$[\mathrm{N} . \mathrm{m}]$} \\
\hline$U_{\text {ucmin }}$ & Tensão mínima no ultracapacitor & {$[\mathrm{V}]$} \\
\hline$U_{\text {ucmax }}$ & Tensão máxima no ultracapacitor & {$[\mathrm{V}]$} \\
\hline $\mathrm{V}$ & Velocidade do veículo & {$[\mathrm{m} / \mathrm{s}]$} \\
\hline$V_{b}$ & Velocidade do veículo na rotação de base do motor & {$[\mathrm{m} / \mathrm{s}]$} \\
\hline$V_{f}$ & Velocidade final do veículo & {$[\mathrm{m} / \mathrm{s}]$} \\
\hline$V_{k}$ & Velocidade do veículo & {$[\mathrm{km} / \mathrm{h}]$} \\
\hline$V_{W}$ & $\begin{array}{l}\text { Componente da velocidade do vento na direção do } \\
\text { movimento (positiva no mesmo sentido do veículo) }\end{array}$ & {$[\mathrm{m} / \mathrm{s}]$} \\
\hline$\alpha$ & Inclinação do terreno & {$[\stackrel{\circ}{]}$} \\
\hline$\delta$ & Coeficiente de momento de inércia & Adimensional \\
\hline$\eta_{c c}$ & Rendimento do controlador/conversor de potência & Adimensional \\
\hline$\eta_{m}$ & Rendimento do motor & Adimensional \\
\hline$\eta_{t}$ & Rendimento da transmissão total & Adimensional \\
\hline$\xi$ & Fator de frenagem regenerativa & Adimensional \\
\hline$\rho_{a}$ & Densidade do ar & {$\left[\mathrm{kg} / \mathrm{m}^{3}\right]$} \\
\hline
\end{tabular}




\section{SUMÁRIO}

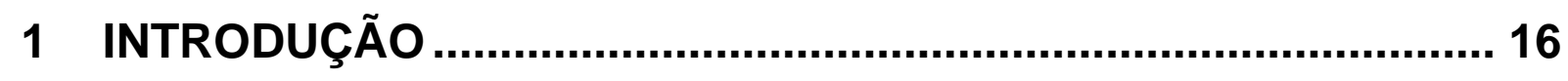

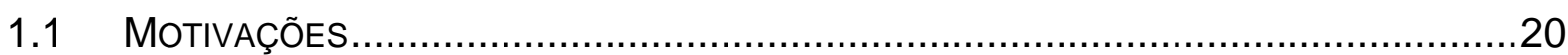

2 OBJETIVOS........................................................................ 23

3 REVISÃO BIBLIOGRÁFICA ..................................................... 24

3.1 DimENSIONAMENTO DO SISTEMA DE TRAÇÃO PARA VEÍCULOS ELÉTRICOS................24

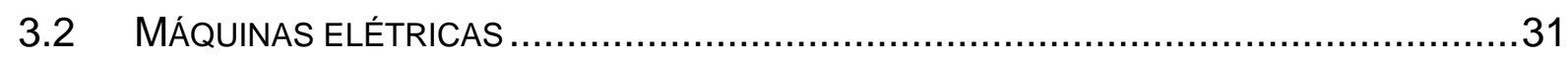

3.3 ESTRUTURAS DE MÁQUINAS ELÉTRICAS TRADICIONAIS EM VEÍCULOS ELÉTRICOS......33

3.4 COMPARAÇÃO DE DESEMPENHO DAS MÁQ. ELÉTRICAS TRADICIONAIS EM VE'S ........34

3.5 BATERIAS E ULTRACAPACITORES PARA VEÍCULOS ELÉTRICOS ............................36

3.5.1 Requisitos de armazenamento de energia para veículos elétricos...............36

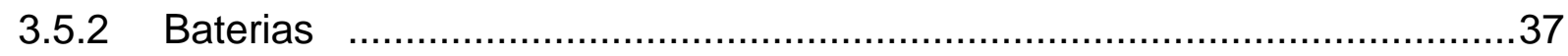

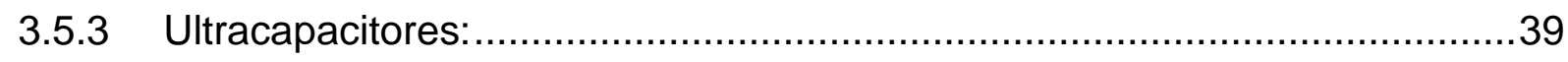

4 DIMENSIONAMENTO DE SISTEMAS DE TRAÇÃO.................... 43

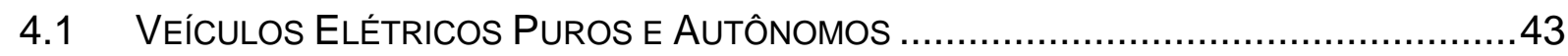

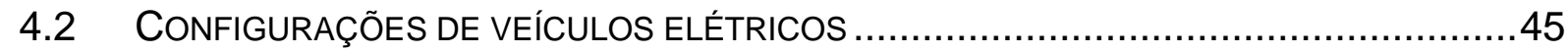

4.3 SISTEMAS DE TRAÇÃO PARA VEÍCULOS ELÉTRICOS PUROS ...............................47

4.4 PRINCÍPIOS BÁSICOS DE VEÍCULOS AUTOMOTIVOS ....................................47

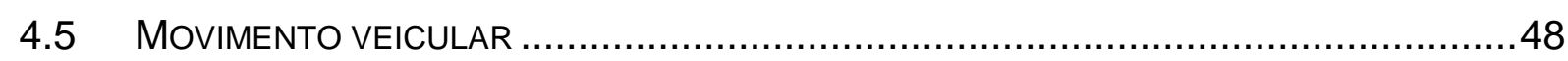

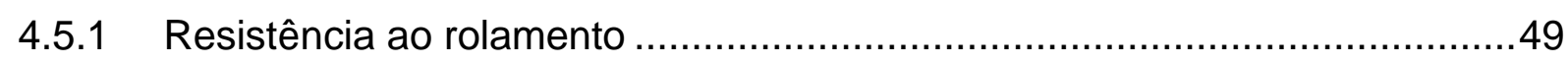

4.5.2 Resistência aerodinâmica.......................................................... 50

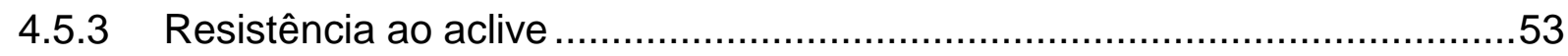

4.5.4 Força de aceleração linear ..........................................................53

4.5.5 Força de aceleração angular .......................................................... 54

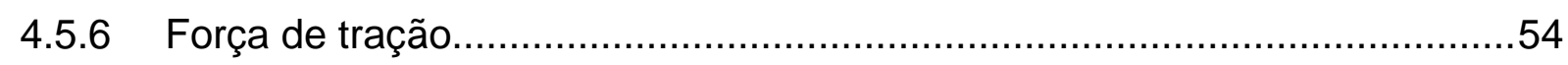

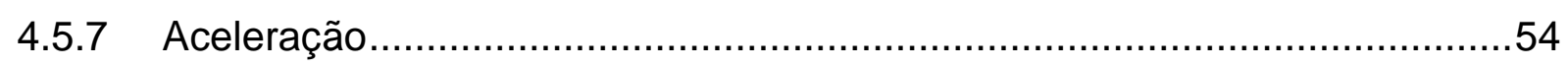

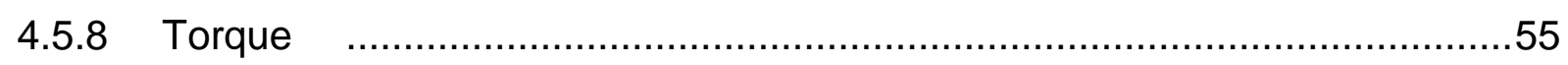

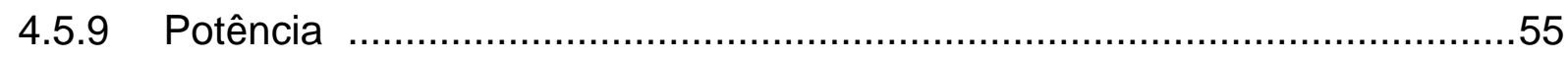

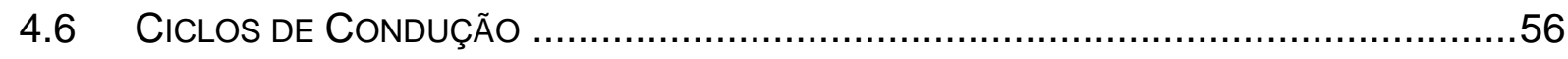

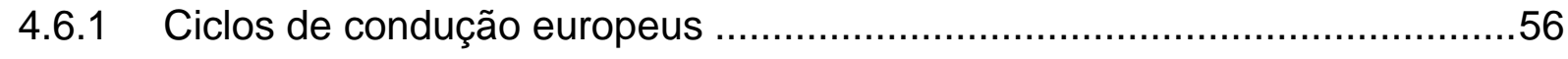


4.6.2 Ciclos de condução norte-americanos...............................................59

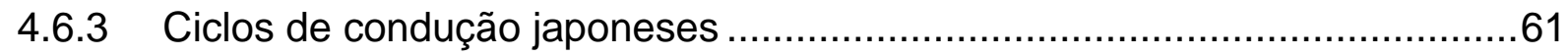

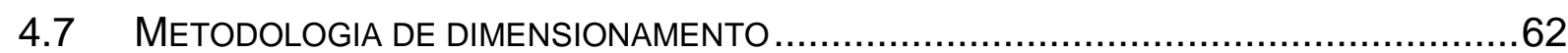

4.7.1 Determinação da potência necessária (nas rodas):................................63

4.7.2 Dimensionamento do motor elétrico ...............................................64

4.7.3 Dimensionamento do controlador /conversor de potência .........................66

4.7.4 Dimensionamento da capacidade das baterias ....................................67

4.7.5 Dimensionamento do banco de ultracapacitores ..................................68

5 APLICAÇÃO E RESULTADOS ................................................. 70

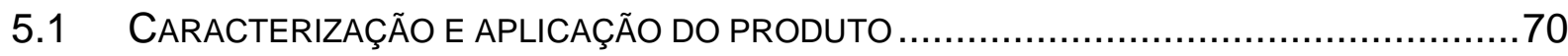

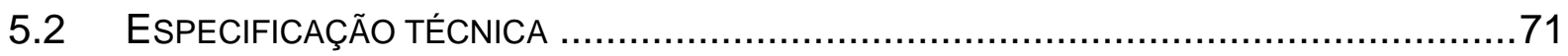

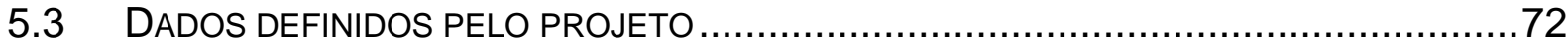

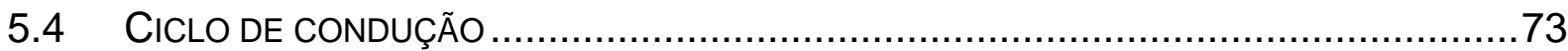

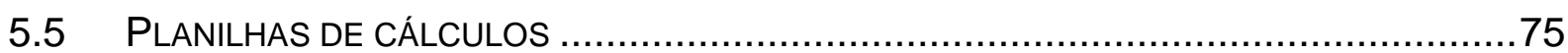

5.6 DETERMINAÇÃO DO MOTOR ELÉTRICO ................................................... 81

5.7 DETERMINAÇÃO DO CONTROLADOR/CONVERSOR DE POTÊNCIA ...........................83

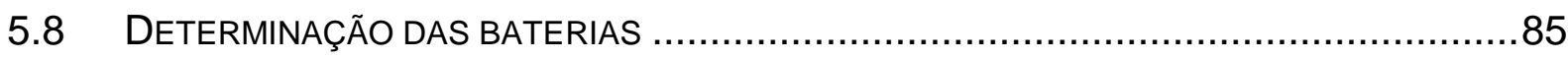

5.9 DETERMINAÇÃO DO BANCO DE ULTRACAPACITORES ........................................87

5.10 RESUltAdOS DE DESEMPENHO OBTIDOS ..............................................90

5.11 AVALIAÇÃO dOS RESULTADOS PRÁTICOS ................................................... 93

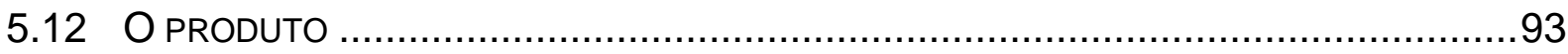

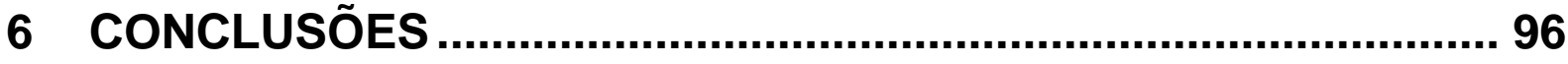

7 DESENVOLVIMENTOS FUTUROS .............................................. 98

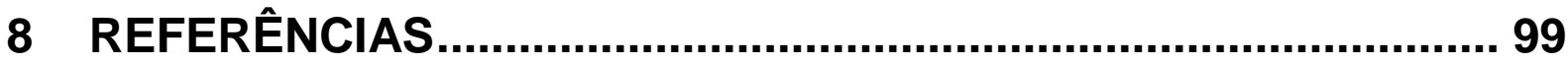




\section{INTRODUÇÃO}

O conceito de veículos elétricos não é algo recente, tendo surgido em meados do século 19. Mesmo após a introdução dos motores a combustão interna, os veículos elétricos permaneceram lado a lado por vários anos, especialmente nas áreas urbanas onde a autonomia das baterias era suficiente para os curtos trajetos e em função da capacidade de autopartida (BOTTURA; BARRETO, 1989; EHSANI; RAHMAN; TOLIYAT, 1997; NANDA; KAR, 2006).

Entretanto, com o rápido avanço dos veículos baseados em motores a combustão interna, inclusive com a introdução da partida elétrica no início do século 20, a demanda por veículos elétricos caiu drasticamente devido à limitada autonomia e ao desempenho inferior, mesmo sendo mais eficientes e não poluentes (SHACKET, 1979).

Outro fato que contribuiu de forma significativa na mesma época foi a produção em série do Modelo T por Henry Ford que era vendido inicialmente por US\$850 em 1909 e por US\$ 260 em 1925. Ironicamente, quase todos os cerca de 15 milhões de Modelo T vendidos tinham partida manual e não elétrica. Desde então, os veículos com motor a combustão interna têm evoluído, melhorado em projeto e recebido larga aceitação e respeito (ANDERSON; ANDERSON, 2005; BRANT, 1993; SHACKET, 1979).

A densidade energética da gasolina é muito superior ao que uma bateria eletroquímica pode fornecer, mas o interesse por veículos elétricos nunca pereceu totalmente e pode aumentar sempre que há alguma crise em relação à operação de veículos com motores a combustão interna, como elevação nos preços dos combustíveis e questões ambientais: emissão de gases poluentes, efeito estufa, poluição sonora, etc. (EHSANI; RAHMAN; TOLIYAT, 1997; LARMINIE; LOWRY, 2003).

As razões para o maior sucesso até hoje de veículos com motor a combustão interna são facilmente compreendidas quando se compara a energia específica do combustível de petróleo com a das baterias. A energia específica de combustíveis para motores a combustão interna varia, mas está em torno de 
$9000 \mathrm{Wh} / \mathrm{kg}$, enquanto a energia específica de uma bateria chumbo-ácido é cerca de $30 \mathrm{Wh} / \mathrm{kg}$ (LARMINIE; LOWRY, 2003) ${ }^{2}$.

Uma vez que a eficiência do motor de combustão interna, caixa de velocidades e transmissão (normalmente em torno de $20 \%$ ) é contabilizada, isto significa que $1800 \mathrm{Wh} / \mathrm{kg}$ de energia útil (no eixo) podem ser obtidos a partir da gasolina. Com $90 \%$ de eficiência no motor elétrico, apenas $27 \mathrm{Wh} / \mathrm{kg}$ de energia útil (no eixo do motor) podem ser obtidos a partir de uma bateria chumbo-ácido (LARMINIE; LOWRY, 2003).

A título de ilustração, 4,5 litros (1 galão) de gasolina com uma massa de cerca de 4 $\mathrm{kg}$ resulta em uma autonomia de aproximadamente $50 \mathrm{~km}$ em um carro típico. Para armazenar a mesma quantidade de energia elétrica útil requer-se uma bateria chumbo-ácido com uma massa de cerca de $200 \mathrm{~kg}$ conforme apresentada na Figura 1.1. Duplicar o armazenamento de energia e, portanto, a autonomia do veículo com motor a gasolina requer 0 armazenamento de mais 4,5 litros de combustível com uma massa adicional de cerca de $4 \mathrm{~kg}$ apenas. Para fazer 0 mesmo em um veículo com bateria chumbo-ácido é necessária uma massa adicional de baterias de cerca de $200 \mathrm{~kg}$.

$\mathrm{Na}$ prática, isso não vai dobrar a autonomia do veículo elétrico, uma vez que uma quantidade considerável da energia extra é necessária para acelerar e desacelerar os $200 \mathrm{~kg}$ adicionais de bateria e transportá-los nas subidas. Parte dessa energia pode ser recuperada através de frenagem regenerativa, um sistema onde 0 motor funciona como um gerador, freando o veículo e convertendo a energia cinética do veículo em energia elétrica, que é devolvida à bateria, de onde ela pode ser reutilizada. Na prática quando a eficiência de geração, controle, armazenamento e passagem da corrente elétrica de volta através do motor e controlador são contabilizadas, apenas uma parcela da energia é susceptível de ser recuperada.

A frenagem regenerativa tende a ser usada como uma maneira conveniente de frenagem de veículos pesados, mas naturalmente, do ponto de vista da eficiência energética, é importante aproveitar ao máximo toda a energia regenerada.

\footnotetext{
${ }^{2}$ Baterias de lítio com eletrodos a base de oxido de níquel cobalto $(\mathrm{NiCo})$ e de oxido de níquel manganês $\left(\mathrm{NiMnO}_{2}\right)$ apresentam densidade de energia de $170 \mathrm{Wh} / \mathrm{kg}$ (BURKE; MILLER; ZHAO, 2010; BURKE; ZHAO, 2012).
} 
Veículo com autonomia de aprox. $50 \mathrm{~km}$

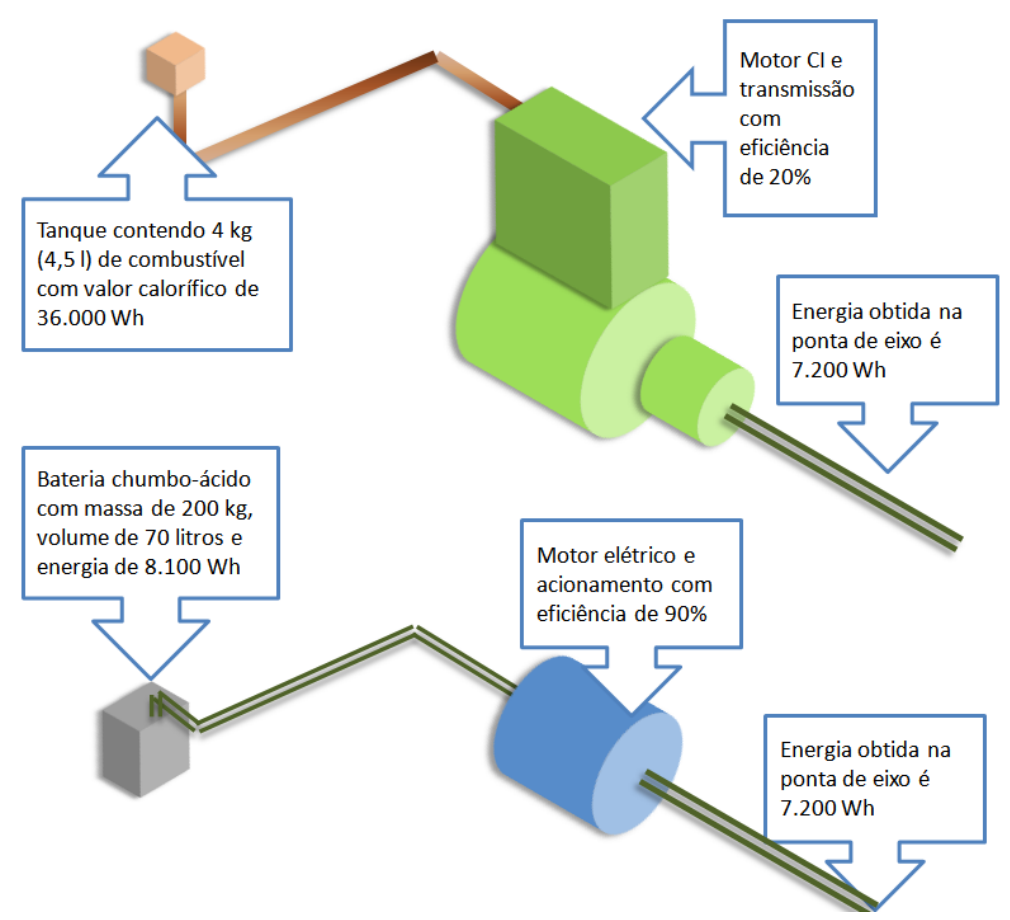

Veículo com autonomia de aprox. $500 \mathrm{~km}$

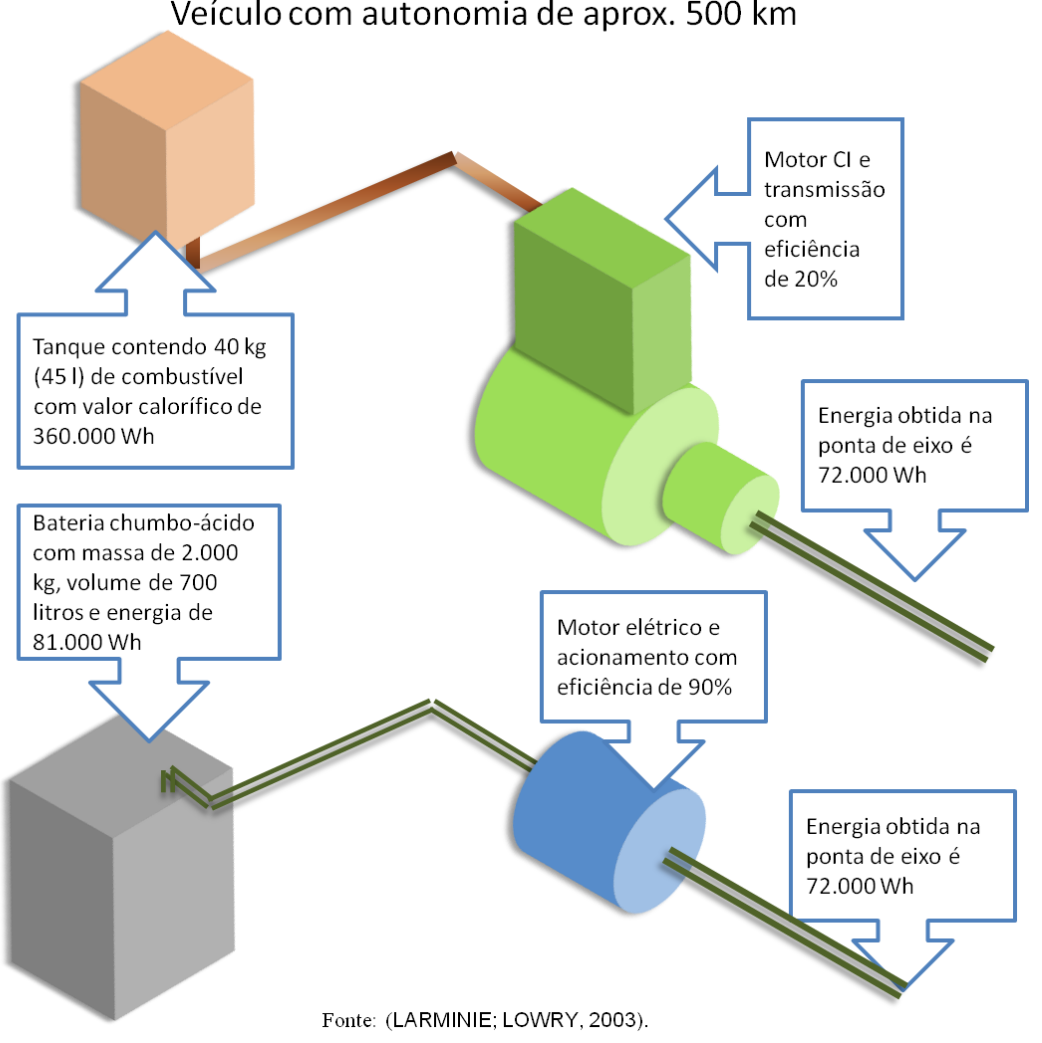

Figura 1.1 - Comparação de energia a partir do petróleo e bateria chumbo-ácido

É interessante observar que para um banco de baterias de chumbo ácido ter a capacidade de energia efetiva de 45 litros ( 10 galões) de gasolina, seriam necessárias duas toneladas delas! 
Outro grande problema que surge com as baterias é o tempo para recarregá-las. Mesmo quando a energia elétrica adequada está disponível, há um tempo mínimo, normalmente de várias horas, necessário para recarregar uma bateria eletroquímica, enquanto que 45 litros de gasolina podem ser colocados em um veículo em aproximadamente um minuto. O tempo de recarga de alguns dos novos tipos de baterias foi reduzido para cerca de dez minutos, mas isso ainda é consideravelmente mais tempo do que se leva para encher um tanque de gasolina (BURKE; ZHAO, 2012).

Ainda outro parâmetro limitante com veículos elétricos é que as baterias são caras, então é provável que qualquer veículo com baterias elétricas não apenas tenha autonomia menor, mas também seja mais caro que um veículo com motor a combustão interna de tamanho similar e qualidade de construção.

Por exemplo, as duas toneladas de baterias chumbo ácido que fornecem a mesma energia efetiva que os 45 litros de gasolina custam em torno de US\$ 6000 ao preço atual. As baterias também têm a vida limitada, tipicamente cinco anos, o que significa que outro grande investimento será necessário para renovar as baterias periodicamente.

Quando esses fatores são levados em consideração, as razões para a predominância dos veículos com motor a combustão interna durante a maior parte do século 20 tornam-se claras.

Desde o século 19, diversas maneiras de superar o limitado armazenamento de energia das baterias têm sido utilizadas. A primeira foi fornecer a energia elétrica através de cabos aéreos, sendo o trólebus o melhor exemplo. Este foi amplamente utilizado durante $\mathrm{o}$ século $20 \mathrm{e}$ permitiu que ônibus não poluentes $\mathrm{e}$ silenciosos fossem utilizados nas cidades. Quando afastados da rede elétrica os ônibus podem rodar a partir de suas próprias baterias. As desvantagens são as caras e feias linhas aéreas de abastecimento que são necessárias e, talvez por essas razões, uma parte dos sistemas de bondes e trólebus foi retirada de serviço. Modernos sistemas de transferência de energia por indução podem superar este problema. $\cdot$ 


\subsection{MOTIVAÇÕES}

Apesar dos problemas anteriormente descritos, sempre existiram aplicações para veículos elétricos desde o início do século 20. Eles têm algumas vantagens sobre os veículos com motor a combustão, principalmente por não produzirem emissões de escape em seu ambiente imediato, e em segundo lugar porque eles são inerentemente silenciosos. Isso torna os veículos elétricos ideais em aplicações como movimentação de materiais em fábricas e depósitos utilizando empilhadeiras e rebocadores elétricos. Também as plataformas de trabalho aéreas nos setores de serviço e construção, carros de golfe e similares no setor de lazer, e equipamentos de mobilidade para os idosos e deficientes físicos, como o mostrado na Figura 1.2, que podem ser conduzidos em calçadas, lojas e muitos edifícios.

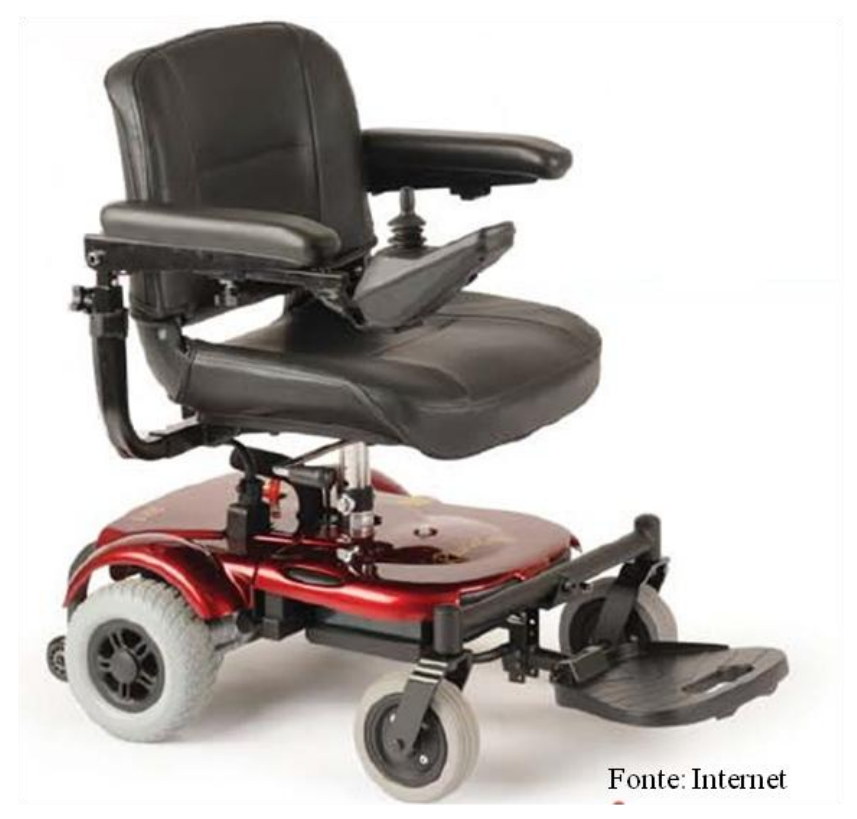

Figura 1.2 - cadeira de rodas elétrica

Os veículos elétricos também mantêm a sua eficiência na condução anda e para (start-stop), quando um motor a combustão interna torna-se muito ineficiente e poluente. Isso faz com que os primeiros sejam atraentes para uso como veículos de entrega. Em alguns países isso tem sido ajudado pelo fato de que deixar um veículo 
com o motor ligado em frente de uma casa, por exemplo, para efetuar uma coleta ou entrega, é ilegal.

Além dessas, novas aplicações, como os carros urbanos (city cars), vêm sendo introduzidas em centros urbanos onde veículos elétricos circulam sem restrições e sem pagar pedágio, ou os carros de comutação (commuter cars) que são aqueles utilizados, geralmente, em subúrbios, para o deslocamento de ida e de volta da residência a uma estação de ônibus, trem ou metrô. Nessas aplicações o percurso total diário é relativamente curto, $50 \mathrm{~km}$ a $100 \mathrm{~km}$ no máximo, viabilizando a utilização de carros elétricos puros.

A utilização dos carros de comutação é uma aplicação com algumas características importantes, tais como:

Permitir a recarga das baterias através de fontes alternativas de energia como a eólica, das marés, a solar e a hídrica;

A recarga pode ser programada para horários de maior disponibilidade de energia, de madrugada, por exemplo, não comprometendo a demanda das concessionárias.

Podem contribuir para a estabilidade da rede elétrica através das redes inteligentes (smart grids), onde além de consumidores, podem assumir o papel de supridores de energia.

Nos últimos anos, tem havido mudanças que podem fazer o veículo elétrico uma proposta mais atraente. Primeiramente, há a crescente preocupação com o meio ambiente, tanto em termos de emissões globais de dióxido de carbono e também a emissão local de gases de escape, que contribuem para tornar as grandes cidades em locais não saudáveis para se viver. Em segundo lugar, tem havido desenvolvimentos técnicos na concepção dos veículos e melhorias nos motores, controladores e nas fontes e acumuladores de energia como baterias, células combustíveis e ultracapacitores.

As questões ambientais podem muito bem serem fatores decisivos na adoção de veículos elétricos para utilização urbana. A gasolina com chumbo tem sido banida e algumas cidades como Londres têm incentivado a introdução de veículos com emissão zero, com desconto na taxa de congestionamento (pedágio) e subsídio para aquisição de veículos elétricos. 
Os veículos elétricos não necessariamente reduzem o montante global de energia utilizada, mas vão acabar com energia gerada a bordo dos motores a combustão interna instalados nos veículos e transferir o problema para as usinas, que podem usar uma grande variedade de combustíveis e onde as emissões de escape podem ser manuseadas de forma mais responsável.

A eficiência global do fornecimento de energia para o carro onde os combustíveis fósseis são queimados para produzir energia elétrica não é necessariamente muito melhor do que usar um motor a diesel ou a gasolina mais moderno e de alta eficiência. No entanto, há mais flexibilidade na escolha de combustíveis nas usinas geradoras. Parte ou toda a energia pode ser obtida a partir de fontes alternativas, tais como hídrica, solar, eólica ou das marés, o que garantiria menor emissão em geral.

Tem havido crescentes tentativas de rodar veículos a partir de células fotovoltaicas. Veículos cruzaram a Austrália durante o World Solar Challenge, com velocidades superiores a $85 \mathrm{~km} / \mathrm{h}$ (50 mph), utilizando energia inteiramente obtida a partir de radiação solar. Embora as células solares sejam caras e de potência limitada (100W/m2 é tipicamente obtida na luz do sol forte), elas podem trazer algum impacto no futuro. O preço de células fotovoltaicas está constantemente caindo, enquanto a eficiência é crescente. Elas podem muito bem se tornar úteis, particularmente para recarregar veículos suburbanos e, como tais, são dignas de consideração. 


\section{OBJETIVOS}

Atualmente, centenas de pessoas no Brasil, milhares ao redor do mundo estão em suas empresas, nas escolas, em órgãos governamentais ou em seus lares desenvolvendo algum tipo de veículo elétrico.

Contribuindo para a solução dessa necessidade não apenas brasileira, mas global, o objetivo central deste trabalho é disponibilizar uma metodologia simples e direta de dimensionamento do sistema de tração para veículos elétricos puros e autônomos, isto é, desconectados de trilhos ou linhas aéreas para suprimento de energia.

Complementarmente, também serão apresentadas algumas alternativas de componentes para o sistema de tração aplicáveis à metodologia em questão e tema deste trabalho, e as principais vantagens e desvantagens de se utilizar múltiplas fontes de energia em veículos elétricos, especificamente, os ultracapacitores com as baterias eletroquímicas. 


\section{REVISÃO BIBLIOGRÁFICA}

Basicamente, o dimensionamento do sistema de tração de um veículo consiste em atender as especificações de desempenho estabelecidas no projeto de acordo com as leis físicas que regem a dinâmica veicular.

Neste capítulo serão apresentados e comentados alguns trabalhos recentes com o estado da arte e outros trabalhos já consagrados, publicados em forma de artigos técnicos ou livros, onde se poderão buscar maiores detalhes.

Ainda com foco no estado da arte serão apresentadas e comparadas algumas topologias de máquinas elétricas com características que favorecem a sua utilização como motores de tração e, finalizando, será mostrado o estado da arte das baterias e ultracapacitores utilizados como armazenadores de energia em veículos elétricos puros.

\subsection{DIMENSIONAMENTO DO SISTEMA DE TRAÇÃO PARA VEÍCULOS ELÉTRICOS}

No artigo Propulsion System Design of Electric and Hybrid Vehicles (EHSANI et al., 1997), os autores descrevem uma metodologia para o dimensionamento de sistemas de tração para veículos elétricos e híbridos baseada na dinâmica veicular e considerando três condições de operação:

a) Aceleração inicial;

b) Velocidade nominal do veículo;

c) Velocidade máxima do veículo.

Afirmam que estas três condições de operação fornecem as restrições de projeto básicas para os sistemas de tração para veículos elétricos e híbridos, e que um sistema de tração capaz de atender essas restrições funcionará adequadamente nos demais regimes de operação.

Os parâmetros que definem as restrições de projeto são:

a) Velocidade nominal do veículo; 
b) Tempo especificado para o veículo atingir a velocidade nominal;

c) Velocidade máxima do veículo;

d) Massa do veículo (e outras grandezas físicas).

O objetivo é atender às restrições de projeto com o menor requerimento de potência, ou seja, obter um perfil de torque-velocidade ótimo para o sistema de tração elétrica e que atenda às condições operacionais com o mínimo peso, volume e custo.

Os parâmetros de projeto do sistema de tração são:

a) Potência nominal do motor elétrico;

b) Velocidade nominal do motor;

c) Velocidade máxima do motor;

d) Extensão além da velocidade nominal do motor na faixa de operação a potência constante.

e) Relação de transmissão entre a ponta de eixo do motor e o eixo das rodas.

Com relação às forças resistentes ao movimento foram consideradas:

a) Resistência ao rolamento dada pela expressão:

$$
\mathrm{F}_{\mathrm{r}}=\mathrm{f}_{\mathrm{r}} \mathrm{Mg} \cos (\alpha)
$$

b) Resistência aerodinâmica dada pela expressão:

$$
\mathrm{F}_{\mathrm{w}}=\frac{1}{2} \rho_{\mathrm{a}} \mathrm{A}_{\mathrm{f}} \mathrm{C}_{\mathrm{D}}\left(\mathrm{V}-\mathrm{V}_{\mathrm{w}}\right)^{2}
$$

c) Resistência ao aclive dada pela expressão:

$$
F_{g}=M g \operatorname{sen}(\propto)
$$

d) Aceleração dada pela expressão:

$$
\mathrm{a}=\frac{\mathrm{F}_{\mathrm{t}}-\left(\mathrm{F}_{\mathrm{r}}+\mathrm{F}_{\mathrm{w}}+\mathrm{F}_{\mathrm{g}}\right)}{\delta \mathrm{M}}
$$

onde $\delta$ é o coeficiente de momento de inércia para compensar o aparente aumento na massa do veículo devido ao momento de inércia das massas girantes do sistema de tração. 
No artigo Step by step design procedure of an Independent-Wheeled Small EV applying EVLS (PINAL et al., 2006), o objetivo dos autores é apresentar um procedimento, passo a passo, para projeto de um pequeno veículo elétrico com tração independente em duas rodas.

Os passos são:

a) Determinar a relação entre o torque mecânico e o estágio eletrônico de potência incluindo o motor elétrico;

b) Determinar a potência mecânica requerida;

c) Determinar a potência elétrica necessária ao estágio eletrônico de potência;

Para a determinação da potência mecânica, os autores descrevem duas técnicas: a primeira através da potência máxima necessária baseada no ciclo de condução do veículo elétrico. A segunda técnica pela determinação da potência mecânica média necessária em função de uma velocidade inicial, tempo de aceleração e velocidade máxima.

O cálculo da potência mecânica através do ciclo de condução do veículo é realizado através da determinação das forças de resistência ao rolamento, resistência aerodinâmica e resistência ao aclive utilizando-se expressões equivalentes àquelas utilizadas por (EHSANI et al., 1997). Entretanto, no calculo da aceleração não se considerou o efeito das massas rotativas.

O cálculo da potência mecânica pela potência mecânica média é feito em quatro etapas:

a) Determinar (estimando) a potência nominal do acionamento do motor através da seguinte expressão:

$$
P_{t}=\frac{\delta M}{2 t_{a}}\left(V_{f}^{2}+V_{b}^{2}\right)+\frac{2}{3} M g f_{r} V_{f}+\frac{1}{5} \rho_{a} C_{D} A_{f} V_{f}^{3}
$$

onde $P_{t}$ é a potência de tração total para acelerar o veículo de zero a velocidade $V_{f}$ em $t_{a}$ segundos e $\delta$ é o coeficiente de momento de inércia.

b) Determinar o tempo de aceleração usando a seguinte expressão:

$$
t_{a}=\int_{0}^{V_{b}} \frac{\delta M}{P_{t} / V_{b}-M g f_{r}-\frac{1}{2} \rho_{a} C_{D} A_{f} V^{2}} \boldsymbol{d} v+\int_{V_{b}}^{V_{f}} \frac{\delta M}{P_{t} / V_{f}-M g f_{r}-\frac{1}{2} \rho_{a} C_{D} A_{f} V^{2}} \boldsymbol{d} v
$$


c) Determinar a distância de aceleração expressa pela equação:

$$
S_{a}=\int_{V_{1}}^{V_{2}} \frac{\delta M}{P_{t}-M g f_{r}-\frac{1}{2} \rho_{a} C_{D} A_{f} V^{2}} d v
$$

d) A relação de transmissão é projetada de forma que o veículo atinja a máxima velocidade na máxima rotação do motor. De acordo com os autores, utilizando esse critério, a mínima potência de motor é necessária, conforme descrito em Handbook of Automotive Power Electronics And Motor Drives (EMADI, 2005).

No livro Modern Electric, Hybrid Electric, and Fuel Cell Vehicles (EHSANI; GAO; EMADI, 2010), é apresentada a descrição geral para o movimento veicular através da equação:

$$
\frac{d V}{d t}=\frac{\sum F_{t}-\sum F_{r}}{\delta M}
$$

onde $\sum F_{t}$ é a força de tração total e $\sum F_{r}$ é a força resistente total (não confundir com $F_{r}$ que é a força de resistência ao rolamento) e $\delta$ é o chamado fator de momento de inércia. $O$ fator de momento de inércia ou fator de massa pode ser escrito como:

$$
\delta=1+\frac{I W}{M r_{d}^{2}}+\frac{i_{0}^{2} i_{g}^{2} I}{M r^{2}}
$$

onde $I_{W}$ é o momento de inércia total das rodas e $I$ é o momento de inércia total dos componentes girantes do sistema de transmissão, incluindo o rotor do motor.

O cálculo do fator de massa, $\delta$, requer o conhecimento dos momentos de inércia de todas as partes rotativas. Nos casos onde esses valores não são conhecidos, o fator de massa, para automóveis de passageiros seriam estimados usando a seguinte relação empírica:

$$
\delta=1+\delta_{1}+\delta_{2} i_{g}^{2} i_{0}^{2}
$$

onde $\delta_{1}$ é o termo correspondente ao efeito devido à massa das rodas e $\delta_{2}$ é o termo correspondente ao efeito devido à massa das partes girantes do sistema de tração, inclusive o rotor do motor. Valores razoáveis para $\delta_{1}$ e $\delta_{2}$ são: 0.04 e 0.0025 e a equação fica: 


$$
\delta=1+0.04+0,0025 i_{g}^{2} i_{0}^{2}
$$

Que é a mesma equação apresentada em Fundamentals of Vehicles Dynamics (GILLESPIE, 1992) onde também se chama a atenção para o fato de o coeficiente de massa depender da marcha utilizada (quando se utiliza uma caixa de marchas evidentemente).

A Tabela 3.1 mostra valores típicos para o fator de massa em função da marcha utilizada e do porte do veículo:

Tabela 3.1 - Valores típicos para o fator de massa

\begin{tabular}{lcccc}
\hline & \multicolumn{4}{c}{ Fator de Massa } \\
\hline Marcha alta & $\begin{array}{c}\text { Segunda } \\
\text { marcha }\end{array}$ & $\begin{array}{c}\text { Primeira } \\
\text { marcha }\end{array}$ & Marcha lenta \\
\hline Veículo Pequeno & 1.11 & 1.20 & 1.50 & 2.40 \\
\hline Veículo Grande & 1.09 & 1.14 & 1.30 & - \\
\hline Caminhão & 1.09 & 1.20 & 1.60 & 2.50 \\
\hline
\end{tabular}

Em (EHSANI; GAO; EMADI, 2010; GUZZELLA; SCIARRETTA, 2005) o desempenho veicular é caracterizado por três variáveis. As equações apresentadas são de (EHSANI; GAO; EMADI, 2010):

a) Velocidade máxima dada pela equação:

$$
V_{\max }=\frac{\pi N_{\max } r_{d}}{30 i_{\operatorname{gmin}} i_{0}}
$$

b) Capacidade de aclive dada pela equação:

$$
i=\frac{F_{t}-\left(F_{r}+F_{w}\right)}{M g}
$$


onde:

$$
F_{t}=\frac{T_{m} i_{g} i_{0} \eta_{t}}{r_{d}}
$$

É a força de tração nas rodas do veículo na velocidade considerada. Entretanto, a baixas velocidades, a capacidade de aclive é muito grande. Cálculos baseados na equação (3.13) resultarão em erros significativos e a equação a seguir deve ser usada:

$$
\operatorname{sen} \alpha=\frac{d-f_{r} \sqrt{1-d^{2}+f_{r}^{2}}}{1+f_{r}^{2}}
$$

onde: $\quad d=\frac{F_{t}-F_{W}}{M g}$

É o fator de desempenho do veículo.

c) Aceleração dada pela equação:

A aceleração é avaliada pelo tempo usado para acelerar o veículo de uma velocidade $V_{1}$ (geralmente zero) a uma velocidade maior $V_{f}$ (geralmente 65 $\mathrm{km} / \mathrm{h}$ ou $100 \mathrm{~km} / \mathrm{h}$ para automóveis de passageiros).

$$
t_{a}=\int_{0}^{V_{b}} \frac{\delta M}{P_{t} / V_{b}-M g f_{r}-\frac{1}{2} \rho_{a} C_{D} A_{f} V^{2}} d v+\int_{V_{b}}^{V_{f}} \frac{\delta M}{P_{t} / V_{f}-M g f_{r}-\frac{1}{2} \rho_{a} C_{D} A_{f} V^{2}} d v
$$

E a potência de tração total para acelerar o veículo de zero a velocidade $V_{f}$ em $t_{a}$ segundos pode ser obtida por:

$$
P_{t}=\frac{\delta M}{2 t_{a}}\left(V_{f}^{2}+V_{b}^{2}\right)+\frac{2}{3} M g f_{r} V_{f}+\frac{1}{5} \rho_{a} C_{D} A_{f} V_{f}^{3}
$$

Ou, conforme descrito no artigo Metodologia para Dimensionar Múltiplas Fontes de Suprimento de Energia de Veículos Elétricos (FERREIRA et al., 2007):

$$
P_{t}=\left[M \frac{d V}{d t}+M g \operatorname{sen} \propto+M g f_{r} \cos \propto+\frac{1}{2} \rho A_{f} C_{D}\left(V-V_{w}\right)^{2}\right] V
$$

Observar que nesta equação não se considerou o fator de massa $\delta$. Se for considerado, a equação será:

$$
P_{t}=\left[\delta M \frac{d V}{d t}+M g \operatorname{sen} \propto+M g f_{r} \cos \propto+\frac{1}{2} \rho A_{f} C_{D}\left(V-V_{w}\right)^{2}\right] V
$$


O consumo de energia em um período de tempo, como durante um ciclo de condução, é obtido integrando-se a potência total consumida no tempo. A potência total consumida, em um determinado instante, é dada por:

$$
P_{\text {tot }}=\frac{V}{\eta_{t} \eta_{m} \eta_{c c}}\left[M g\left(f_{r} \cos \propto+\operatorname{sen} \propto\right)+\frac{1}{2} \rho_{a} C_{D} A_{f}\left(V-V_{w}\right)^{2}+M \delta \frac{d V}{d t}\right]
$$

E a potência regenerada, devido à frenagem regenerativa, é dada por:

$$
P_{\text {reg }}=\frac{\xi V}{\eta_{t} \eta_{m} \eta_{c c}}\left[M g\left(f_{r} \cos \propto+\operatorname{sen} \propto\right)+\frac{1}{2} \rho_{a} C_{D} A_{f}\left(V-V_{w}\right)^{2}+M \delta \frac{d V}{d t}\right]
$$

onde $\xi(0<\xi<1)$ é o fator de frenagem regenerativa e representa a porcentagem da energia total de frenagem que pode ser regenerada.

O balanço do consumo de energia é dado por:

$$
E_{\text {out }}=\int_{\text {tração }} P_{\text {tot }} d t+\int_{\text {frenagem }} P_{\text {reg }} d t
$$

Observar que nesta equação a potência de frenagem é negativa. 


\subsection{MÁQUINAS ELÉTRICAS}

No artigo Survey on Electrical Machines in Electrical Vehicles (XU et al., 2009) os autores apresentam e discutem a topologia e o desempenho de quatro tipos tradicionais e de outros quatro tipos especiais de maquinas, estas visando, principalmente, melhorar as densidades de potência e de torque.

Com relação às máquinas tradicionais parece haver certo consenso quanto aos quatro tipos de máquinas elétricas mais aplicáveis em tração elétrica, ou seja, a máquina de corrente contínua (DCM), a máquina de indução (IM), a máquina de relutância chaveada (SRM) e a máquina de imãs permanentes sem escovas (PMBM). Além de (XU et al., 2009), outros autores como (XUE; CHENG; CHEUNG, 2008), (NANDA; KAR, 2006) e (WEST, 1994) pesquisaram e publicaram artigos sobre esses quatro tipos de máquinas tradicionais. Também, um capítulo do livro Modern Electric, Hybrid Electric, and Fuel Cell Vehicles foi dedicado a esses quatro tipos de máquinas elétricas por (EHSANI; GAO; EMADI, 2010) e, praticamente, sete capítulos em Handbook of Automotive Power Electronics and Motor Drives (EMADI, 2005).

No sistema de tração, a tecnologia de máquinas elétricas é um dos fatores cruciais para a eficiência e o desempenho do sistema (XU et al., 2009).

As exigências sobre as características básicas de uma máquina elétrica em um sistema de acionamento de veículo elétrico estão indicados a seguir ( $\mathrm{XU}$ et al., 2009):

a) Altas densidades de potência e de torque;

b) Ampla faixa de velocidade de operação com potência constante em torno de 3-4 vezes a velocidade de base (ver Figura 3.1);

c) Elevado torque de partida e alta potência em velocidade de cruzeiro;

d) Alta eficiência em amplas faixas de velocidade e torque;

e) Alta confiabilidade e robustez adequadas ao meio ambiente;

f) Capacidade de sobrecarga intermitente e de custo aceitável;

g) Baixo ruído acústico e baixa ondulação (ripple) de torque; 
h) Boa regulação de tensão sobre ampla faixa de velocidade.

Curvas ideais de torque e potência em função da velocidade para uma máquina de tração são mostradas na Figura 3.1. Na região I de torque constante, a capacidade de torque máximo é definida pela corrente nominal do conversor de potência. $\mathrm{Na}$ região de potência constante $I I$, enfraquecimento de fluxo é empregado devido às limitações de tensão e corrente do conversor de potência. Na região III, redução de torque e potência devido ao aumento da força eletromotriz.

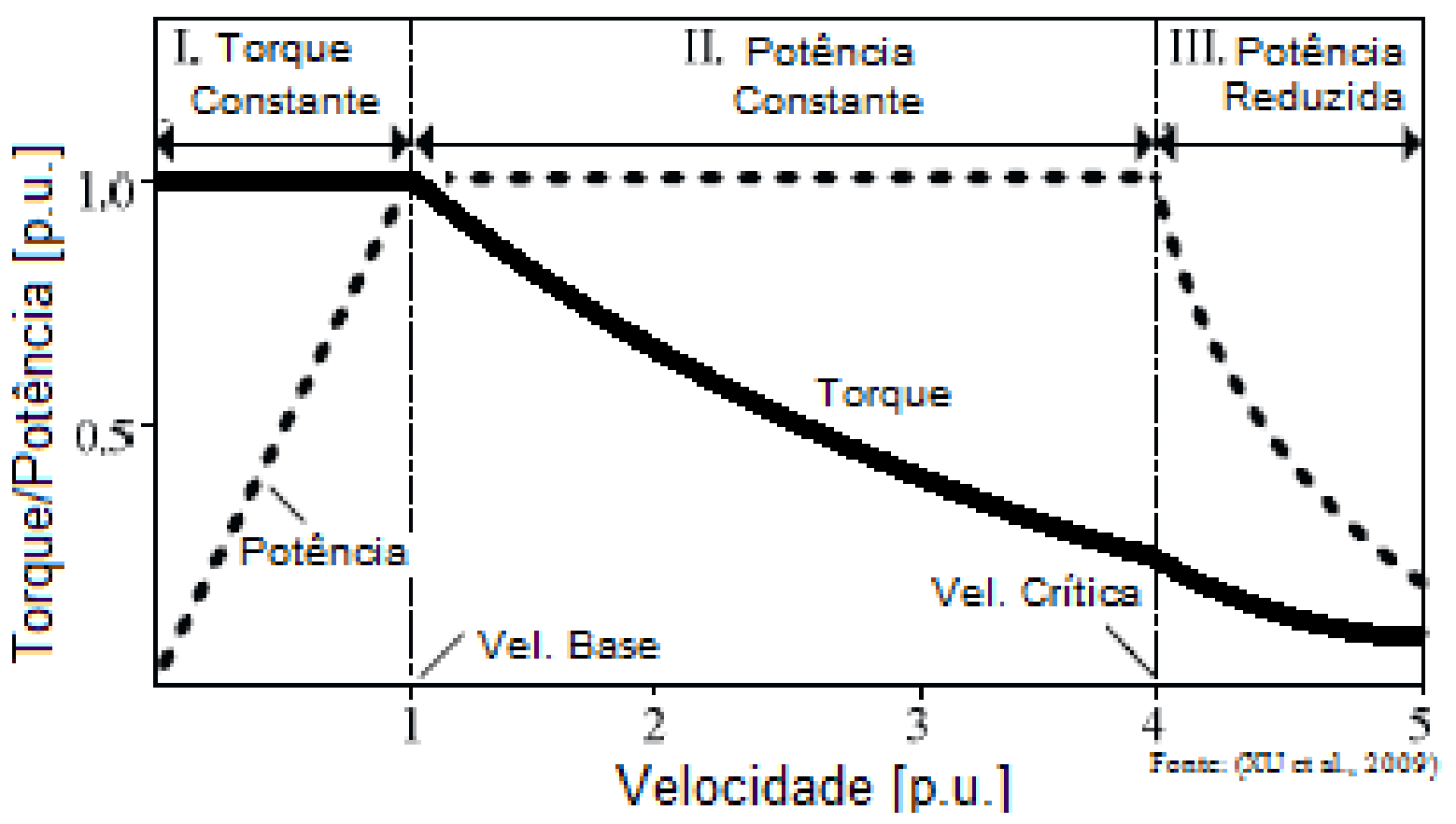

Figura 3.1 - Curvas ideais de torque e potência 


\subsection{ESTRUTURAS DE MÁQUINAS ELÉTRICAS TRADICIONAIS EM VEÍCULOS ELÉTRICOS}

De acordo com (XU et al., 2009), entre os diferentes tipos de motores elétricos, existem essencialmente duas classes de máquinas: com escovas e sem escovas. Incluem quatro tipos principais, a saber, máquina de corrente contínua (DCM), máquina de indução (IM), máquina de relutância chaveada (SRM) e máquina de imã permanente sem escovas (PMBM), conforme ilustrado na

Figura 3.2.

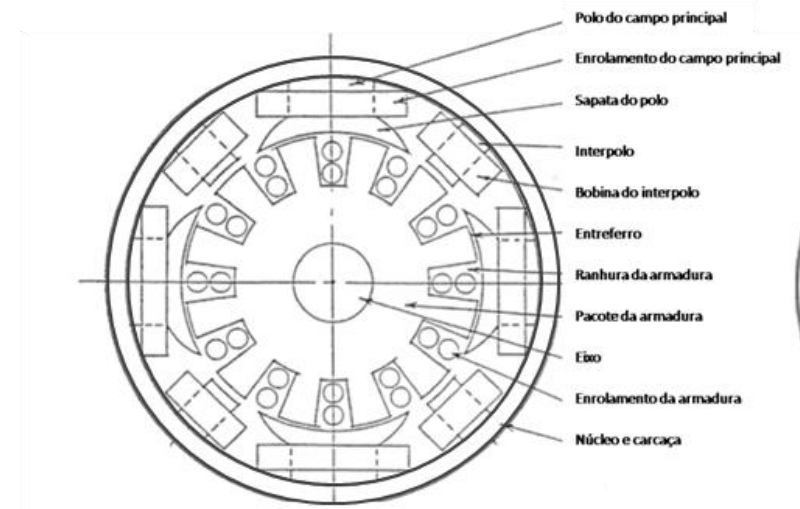

(a)

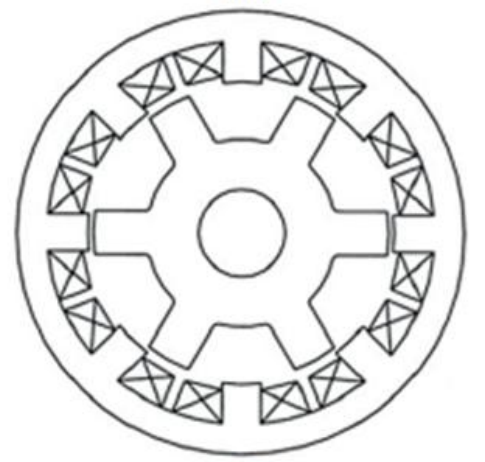

(c)

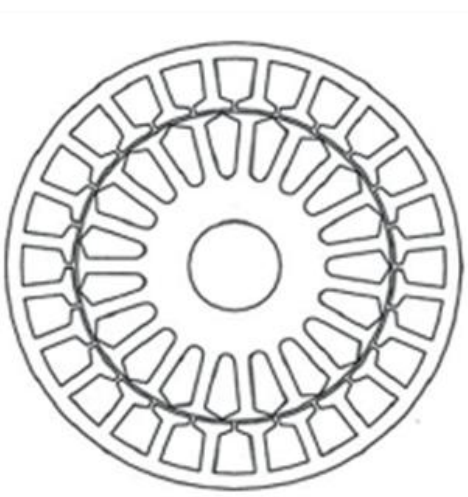

(b)

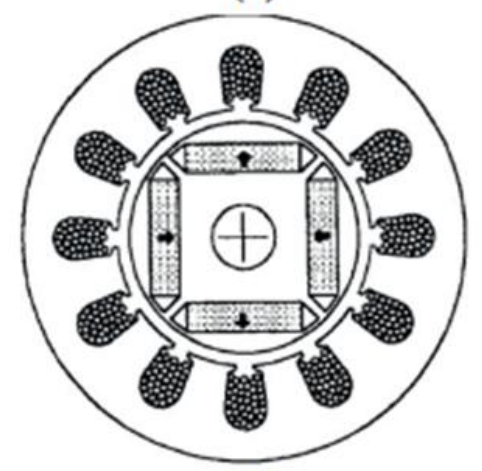

(d)

Fonte: (XU et al., 2009)

(a) DCM, (b) IM, (c) SRM, (d) PMBM.

Figura 3.2 - Estrutura de quatro máquinas elétricas tradicionais 


\subsection{COMPARAÇÃO DE DESEMPENHO DAS MÁQ. ELÉTRICAS TRADICIONAIS EM VE'S}

Os diferentes tipos de máquinas elétricas utilizados nos principais veículos elétricos são mostrados na Tabela 3.2. A avaliação dos motores para veículos elétricos é mostrada na Tabela 3.3 onde é adotado um sistema de pontuação. O sistema de pontuação é composto por seis características principais e cada uma delas é graduada de 1 a 10 pontos, sendo 10 pontos, o melhor. Pode ser visto que os acionamentos com IM e PMBM são as principais tendências na propulsão de veículos elétricos de hoje.

Tabela 3.2 - Aplicações de motores em veículos elétricos

\begin{tabular}{cc}
\hline Modelos VE & Motores \\
\hline Fiat Panda Elettra & DCM \\
\hline Mazda Bongo & DCM \\
\hline Conceptor G-Van & DCM \\
\hline Fiat Seicento Elettra & IM \\
\hline Ford Think City & IM \\
\hline GM EV1 & IM \\
\hline Choride Lucas & SRM \\
\hline Honda EV Plus & PMBM \\
\hline Nissan Altra & PMBM \\
\hline Toyota RAV4 & PMBM \\
\hline Suzuki Senior Tricycle & PMBM \\
\hline
\end{tabular}


Tabela 3.3 - Avaliação de motores com acionamentos para veículos elétricos

\begin{tabular}{lcccc}
\hline & DCM & IM & PMBM & SRM \\
\hline Densidade de potência & 5 & 7 & 10 & 7 \\
\hline Eficiência & 5 & 7 & 10 & 7 \\
\hline Controle & 10 & 7 & 8 & 7 \\
\hline Confiabilidade & 5 & 10 & 8 & 10 \\
\hline Maturidade & 10 & 10 & 8 & 8 \\
\hline Custo & 8 & 10 & 6 & 7 \\
\hline Total & $\mathbf{4 3}$ & $\mathbf{5 1}$ & $\mathbf{5 0}$ & $\mathbf{4 6}$ \\
\hline & & & \multicolumn{2}{l}{ Fonte: (XU et al., 2009) }
\end{tabular}

Na maioria dos casos, é importante a relação de velocidade, que é definida como a razão entre a velocidade máxima e a velocidade nominal. Cada tipo de motor tem a sua limitação máxima de relação de velocidade. O motor de imã permanente tem uma pequena relação $(<=2)$, porque é difícil empregar 0 controle de enfraquecimento de campo. O motor de relutância chaveada tem a maior relação (> = 6), enquanto um motor de indução pode atingir uma relação de 4 (XU et al., 2009).

De modo geral, todas as quatro tecnologias de máquina podem cumprir os requisitos de desempenho dos sistemas de tração, e cada um tem o seu mérito. Com o rápido desenvolvimento de materiais magnéticos, os motores de imãs permanentes sem escovas, que tem elevadas eficiência e densidade de torque, tem sido o foco de muita atenção (XU et al., 2009).

A partir das características apresentadas, tenta-se dar uma melhor perspectiva dos principais acionamentos utilizados nos sistemas de propulsão para veículos elétricos que é sumarizado como segue (NANDA; KAR, 2006):

a) Os motores mais amplamente utilizados são o de indução e o de imãs permanentes sem escovas.

b) IM são os mais baratos;

c) PMBM são os mais eficientes; 
d) DCM são tecnologicamente mais maduros;

e) IM e SRM são mais confiáveis e necessitam menos manutenção.

\subsection{BATERIAS E ULTRACAPACITORES PARA VEÍCULOS ELÉTRICOS}

Nesta seção será apresentado o estado da tecnologia de baterias e de ultracapacitores. No caso das baterias, as tecnologias consideradas são hidreto metálico de níquel e lítio-íon. Para ultracapacitores, dispositivos de carbono/carbono de dupla camada e híbridos são considerados.

\subsubsection{Requisitos de armazenamento de energia para veículos elétricos}

De acordo com (BURKE, 2007), as unidades de armazenamento de energia elétrica devem ser dimensionadas de forma a armazenar energia suficiente $(\mathrm{kWh})$ e fornecer potência de pico adequada $(\mathrm{kW})$ para que o veículo atenda à especificação de desempenho de aceleração e tenha capacidade apropriada de atingir os ciclos de condução. Para aqueles projetos de veículo destinados a ter autonomia puramente elétrica, a unidade de armazenamento de energia deve armazenar energia suficiente para satisfazer a exigência de autonomia da aplicação do veículo. Além disso, a unidade de armazenamento de energia deve atender aos requisitos apropriados de número de ciclos e de tempo de vida.

O peso e o volume da bateria podem ser facilmente calculados a partir do consumo de energia $(\mathrm{Wh} / \mathrm{km})$ do veículo e da densidade de energia $(\mathrm{Wh} / \mathrm{kg}, \mathrm{Wh} / \mathrm{L})$ da bateria descarregada sobre o ciclo de teste adequado (potência versus tempo). Na maioria dos casos, para o veículo alimentado a bateria, a bateria dimensionada por autonomia pode facilmente atender o requisito de potência $(\mathrm{kW})$ para um desempenho de aceleração especificado, capacidade de inclinação, e velocidade de cruzeiro do veículo. As baterias nesta aplicação são regularmente descarregadas e recarregadas profundamente usando a eletricidade da rede ou de uma fonte alternativa de suprimento de energia. Portanto, um ciclo de vida para descargas profundas é uma questão fundamental e é essencial que a bateria atenda a uma exigência mínima especificada. 
A nanotecnologia tem feito grandes progressos e introduzido novos materiais com potencial de aumentar significativamente as densidades de potência e de energia das baterias e ultracapacitores (PESARAN et al., 2007)

\subsubsection{Baterias}

Como descrito no artigo Batteries and Ultracapacitor for Electric, Hybrid, and Fuel Cell Vehicles (BURKE, 2007), até 2006 a maioria dos veículos alimentados por bateria e híbridos testados e comercializados usavam baterias de hidreto metálico de níquel (NiMH). Estudos atuais, com projeções até 2030, consideram as baterias de óxido de lítio níquel manganês e titanato de lítio para os veículos elétricos puros/plug in e híbridos, respectivamente (BURKE; ZHAO, 2012).

De acordo com (BURKE, 2007), as baterias para veículos elétricos híbridos são dimensionadas de acordo com os requisitos de potência com muito menos ênfase na densidade de energia. Baterias para veículos elétricos híbridos plug-in (que podem recarregar as baterias conectando-os a uma tomada da rede ou outra fonte de energia elétrica externa ao veículo) requerem tanto a capacidade de alta potência como de alta densidade energética.

Um resumo das características de baterias de lítio e NiMH para aplicações em veículos elétricos e veículos elétricos híbridos pode ser visto na Tabela 3.4.

Também fica evidente a partir da Tabela 3.4, que a capacidade de potência das baterias concebidas para veículos elétricos híbridos é muito maior do que aquelas projetadas para veículos elétricos a bateria. Esta exigência decorre diretamente do menor peso das baterias para veículos elétricos híbridos e da necessidade de transferir energia para dentro e para fora das baterias com uma alta eficiência (BURKE, 2007).

A capacidade de alta potência exige que a resistência da bateria seja baixa, e consequentemente, o conhecimento da resistência de uma bateria é crítico para a habilidade de avaliar a sua capacidade de potência. 
Observa-se também que as densidades de energia das baterias para veículos elétricos híbridos são mais baixas do que as baterias de mesma tecnologia e química para veículos elétricos puros.

O compromisso entre a densidade de energia e a densidade de potência é uma característica chave na otimização de baterias para aplicações de determinados veículos.

Tabela 3.4 - Características de baterias de lítio e $\mathrm{NiMH}$

\begin{tabular}{|c|c|c|c|c|c|c|}
\hline Bateria & Eletrodo & $\begin{array}{l}\text { Faixa de } \\
\text { Tensão }\end{array}$ & Ah & Wh/kg & $\begin{array}{c}\text { W/kg } \\
90 \% \text { ef. }\end{array}$ & $\begin{array}{c}\text { W/kg } \\
\text { imped. } \\
\text { casada }\end{array}$ \\
\hline Enerdel & $\mathrm{NiMnO}_{2}$ & $4,1-2,5$ & 15 & 115 & 2010 & 6420 \\
\hline Enerdel & $\mathrm{NiMnO}_{2}$ & $4,1-2,5$ & 15 & 127 & 1076 & 3494 \\
\hline Kokam & $\mathrm{NiCoMnO}_{2}$ & $4,1-3,2$ & 30 & 140 & 1220 & 3388 \\
\hline Saft & NiCoAl & $4,0-2,5$ & 6,5 & 63 & 1225 & 3571 \\
\hline GAIA & $\mathrm{NiCoMnO}_{2}$ & $4,1-2,5$ & 40 & 96 & 2063 & 5446 \\
\hline A123 & $\mathrm{FePO}_{4}$ & $3,6-2,0$ & 2,2 & 90 & 1393 & 3857 \\
\hline Altairnano & LiTiO & $2,8-1,5$ & 11 & 70 & 990 & 2620 \\
\hline Altairnano & LiTiO & $2,8-1,5$ & 3,8 & 35 & 2460 & 6555 \\
\hline Quallion & $\mathrm{NiCo}$ & $4,2-2,7$ & 1,8 & 144 & 577 & 1550 \\
\hline Quallion & $\mathrm{NiCo}$ & $4,2-2,7$ & 2,3 & 170 & 445 & 1182 \\
\hline EIG & $\mathrm{NiCoMnO}_{2}$ & $4,2-3,0$ & 20 & 165 & 1278 & 3147 \\
\hline EIG & $\mathrm{FePO}_{4}$ & $3,65-2,0$ & 15 & 113 & 1100 & 3085 \\
\hline Panasonic & $\mathrm{NiMH}$ & $7,2-5,4$ & 6,5 & 46 & 395 & 1093 \\
\hline
\end{tabular}




\subsubsection{Ultracapacitores:}

Ultracapacitores para aplicações em veículos já estão sendo desenvolvidos desde 1990. A maior parte do desenvolvimento tem sido em capacitores de dupla-camada usando carbono microporoso em ambos os eletrodos. Mais recentes, os ultracapacitores híbridos também tem ganhado atenção em pesquisa e desenvolvimento (BURKE, 2007; BURKE; MILLER; ZHAO, 2012).

Desde o início, o duplo objetivo era alcançar uma densidade de energia de pelo menos $5 \mathrm{Wh} / \mathrm{kg}$ para as descargas de alta densidade de potência e ciclo de vida de pelo menos 500000 ciclos de descarga profunda (BURKE, 2007).

A fim de justificar o desenvolvimento de ultracapacitores como uma tecnologia distinta, separada das baterias de alta potência, é fundamental que as suas características de potência e de ciclo de vida sejam significativamente melhores que as das baterias de alta potência porque a densidade de energia dos capacitores será significativamente menor (BURKE, 2007).

Recentemente, tem havido considerável pesquisa em ultracapacitores que utilizam materiais pseudo capacitivos ou materiais equivalentes ao das baterias em um dos eletrodos, com carbono microporoso no outro eletrodo. Isto está sendo feito para aumentar a densidade de energia dos dispositivos (BURKE, 2007; BURKE; MILLER; ZHAO, 2012).

Atualmente, existem disponíveis comercialmente dispositivos ultracapacitores de carbono/carbono (células individuais e módulos) de várias empresas. Todas estas empresas comercializam dispositivos de grande porte com capacitância de $1000 \mathrm{~F} \mathrm{a}$ 7000 F. Estes dispositivos são adequados para aplicações em veículos de alta potência (BURKE, 2007; BURKE; MILLER; ZHAO, 2012).

O desempenho dos vários dispositivos é dado na Tabela 3.5. As densidades de energia $(\mathrm{Wh} / \mathrm{kg})$ descritas correspondem à energia utilizável a partir dos dispositivos baseada em testes de descarga de potência constante de $V_{0}$ a $1 / 2 V_{0}$. Densidades de potência de pico são dadas tanto para impedância casada como para pulsos de eficiência a 95\%.

Para a maioria das aplicações com ultracapacitores, a densidade de potência de alta eficiência é a medida adequada da capacidade de potência do dispositivo. 
Tabela 3.5 - Características de ultracapacitores

\begin{tabular}{|c|c|c|c|c|c|c|c|c|}
\hline & $\begin{array}{c}\mathbf{V} \\
{[\mathrm{V}]}\end{array}$ & $\begin{array}{c}\mathrm{C} \\
{[\mathrm{F}]}\end{array}$ & $\begin{array}{c}\mathbf{R} \\
{[\mathrm{mOhm}]}\end{array}$ & $\begin{array}{l}\mathrm{RC} \\
{[\mathrm{s}]}\end{array}$ & $\begin{array}{c}\text { Wh/kg } \\
\text { (1) }\end{array}$ & $\begin{array}{c}\mathrm{W} / \mathbf{k g} \\
(95 \%) \\
(2)\end{array}$ & $\begin{array}{c}\text { W/kg } \\
\text { imped. } \\
\text { casada }\end{array}$ & $\begin{array}{c}\text { Massa } \\
{[\mathrm{kg}]}\end{array}$ \\
\hline Maxwell & 2,7 & 2885 & 0,375 & 1,1 & 4,2 & 994 & 8836 & 0,55 \\
\hline Maxwell & 2,7 & 605 & 0,90 & 0,55 & 2,35 & 1139 & 9597 & 0,20 \\
\hline Vinhatech & 2,7 & 336 & 3,5 & 1,2 & 4,5 & 1085 & 9656 & 0,054 \\
\hline Vinhatech & 3,0 & 342 & 6,6 & 2,25 & 5,6 & 710 & 6321 & 0,054 \\
\hline loxus & 2,7 & 3000 & 0,45 & 1,4 & 4,0 & 828 & 7364 & 0,55 \\
\hline loxus & 2,7 & 2000 & 0,54 & 1,1 & 4,0 & 923 & 8210 & 0,37 \\
\hline Skeleton & 2,85 & 350 & 1,2 & 0,42 & 4,0 & 2714 & 24200 & 0,07 \\
\hline Skeleton & 3,4 & 850 & 0,8 & 0,68 & 6,9 & 2796 & 24879 & 0,145 \\
\hline Yunasko & 2,7 & 510 & 0,9 & 0,46 & 5,0 & 2919 & 25962 & 0,078 \\
\hline Yunasko & 2,75 & 480 & 0,25 & 0,12 & 4,45 & 10241 & 91115 & 0,060 \\
\hline Yunasko & 2,75 & 1275 & 0,11 & 0,13 & 4,55 & 8791 & 78125 & 0,22 \\
\hline Yunasko & 2,7 & 7200 & 1,4 & 10 & 26 & 1230 & 10947 & 0,119 \\
\hline Yunasko & 2,7 & 5200 & 1,5 & 7,8 & 30 & 3395 & 30200 & 0,068 \\
\hline Ness & 2,7 & 1800 & 0,55 & 1,00 & 3,6 & 975 & 8674 & 0,38 \\
\hline Ness & 2,7 & 3640 & 0,4 & 1,3 & 4,4 & 982 & 8728 & 0,522 \\
\hline Ness & 2,7 & 3160 & 0,24 & 1,22 & 4,3 & 958 & 8532 & 0,89 \\
\hline LS Cable & 2,8 & 3200 & 0,25 & 0,80 & 3,7 & 1400 & 12400 & 0,63 \\
\hline BatScap & 2,7 & 2680 & 0,20 & 0,54 & 4,2 & 2050 & 18225 & 0,50 \\
\hline JME & 3,8 & 1100 & 1,15 & 1,21 & 10 & 2450 & 21880 & 0,144 \\
\hline JME & 3,8 & 2300 & 0,77 & 1,6 & 7,6 & 1366 & 12200 & 0,387 \\
\hline
\end{tabular}


Notas:

(1) Densidade de energia a $400 \mathrm{~W} / \mathrm{kg}$ potência constante, $V_{\text {nom }}-\frac{1}{2} V_{\text {nom }}$

(2) Potência baseada em $P=\frac{9}{16}(1-E F) \frac{V^{2}}{R}, \quad E F=$ eficiência da descarga

Nos últimos anos, a densidade de energia dos dispositivos tem sido gradualmente aumentada com a tecnologia de dupla-camada carbono/carbono e as tensões de células aumentaram para 2,7 $\sim 3,8$ V/célula usando acetonitrila e compostos orgânicos como eletrólito (BURKE, 2007; BURKE; MILLER; ZHAO, 2012).

O desempenho atual da ultracapacitores é adequado para uso em veículos elétricos híbridos leves usando motores a combustão interna ou células de combustível como conversor de energia primária. Entende-se por híbridos leves projetos em que a potência nominal do motor a combustão interna ou da célula de combustível é grande o suficiente para proporcionar um desempenho satisfatório ao veículo, mesmo se a unidade de armazenamento de energia estiver esgotada.

Ultracapacitores não são adequados para uso em veículos elétricos híbridos plug-in como tecnologia de armazenamento de energia principal, mas podem vir a ser valiosos se combinados com baterias para projetos de veículos elétricos híbridos plug-in de autonomia puramente elétrica de curta autonomia. Nesses casos, a bateria seria tão pequena que não poderia por si só fornecer a energia elétrica necessária para acelerar o veículo ou recuperar toda a energia disponível durante a frenagem (BURKE, 2007).

De acordo com (JINRUI et al., 2006) em "Simulation and Analysis of Performance of a Pure Electric Vehicle with a Super-capacitor", através de simulações e testes em campo, os resultados mostraram que o desempenho do veículo melhorou nos seguintes aspectos: melhoraram as condições de trabalho das baterias prolongando a vida operacional, melhorou o desempenho de aceleração do veículo e reduziu o consumo médio de energia.

Entretanto, de acordo com (SIMPSON; WALKER, 2002), apesar dos aparentes ganhos de eficiência do sistema e de autonomia do veículo, os estudos sugerem que a inclusão de ultracapacitores nos veículos elétricos puros não faz sentido do ponto de vista de custos no ciclo de vida. 
Similarmente, (BURKE, 2007) conclui que é improvável que ultracapacitores sejam usados em veículos elétricos puros. Entretanto, em trabalho posterior conclui que a utilização de ultracapacitores contribui para o aumento da eficiência e melhora as condições de operação das baterias com capacidade de potência moderada (300 a $1000 \mathrm{~W} / \mathrm{kg}$ ), reduzindo os pulsos de corrente e o esforço dinâmico nas mesmas, resultando em aumento no ciclo de vida (BURKE; MILLER; ZHAO, 2010). 


\section{DIMENSIONAMENTO DE SISTEMAS DE TRAÇÃO}

\subsection{VEÍCULOS ELÉTRICOS PUROS E AUTÔNOMOS}

Os veículos elétricos puros e autônomos, escopo deste trabalho e denominados apenas veículos elétricos ou veículos elétricos puros, utilizam motores elétricos para a tração e baterias eletroquímicas como fontes de energia. Os veículos elétricos têm muitas vantagens sobre os veículos com motor de combustão interna convencionais, tais como:
a) Maior eficiência energética
b) Menor produção de poluentes
c) Podem ser utilizados em ambientes fechados
d) Mais silenciosos
e) Simplicidade e facilidade de manutenção
f) Capacidade de desenvolver alto torque em baixa rotação
g) Causam menos fadiga ao motorista devido à menor vibração do motor
h) Não consomem energia quando parados

Algumas desvantagens são:
a) Menor autonomia
b) Preço elevado
c) Substituição das baterias ao final do ciclo de vida
d) Tempo de reabastecimento

O conceito do veículo elétrico a bateria é essencialmente simples e é mostrado na Figura 4.1. O seu sistema de tração consiste em uma bateria eletroquímica para o armazenamento de energia, um motor elétrico, e um controlador/conversor de potência. A bateria é recarregada normalmente a partir de rede elétrica, ou outra fonte de energia elétrica, e uma unidade de recarga de bateria que pode ser 
transportada a bordo do próprio veículo ou equipada no ponto de recarga. O controlador converte a energia da bateria, adequando-a as características do motor e controlando a potência fornecida e, assim, a velocidade do veículo.

Geralmente também é desejável usar a frenagem regenerativa para recuperar energia e como uma forma conveniente de frenagem sem atrito.

Há uma variedade de veículos elétricos deste tipo atualmente disponíveis no mercado. Os mais simples são pequenas bicicletas elétricas, triciclos e veículos de comutação, utilizados para realizar deslocamentos em curtos trajetos (até uma estação de trem, metrô ou ônibus, por exemplo). No mercado de lazer há carros de golfe elétrico. Há também uma gama completa de tamanhos de veículos elétricos, que incluem carros elétricos, caminhões e ônibus. Entre os mais importantes estão também aqueles de auxilio a mobilidade, como na Figura 1.2 e, também veículos de entrega e bicicletas elétricas.

Todos estes veículos têm autonomia e desempenho razoavelmente limitados, mas suficientes para os seus propósitos.

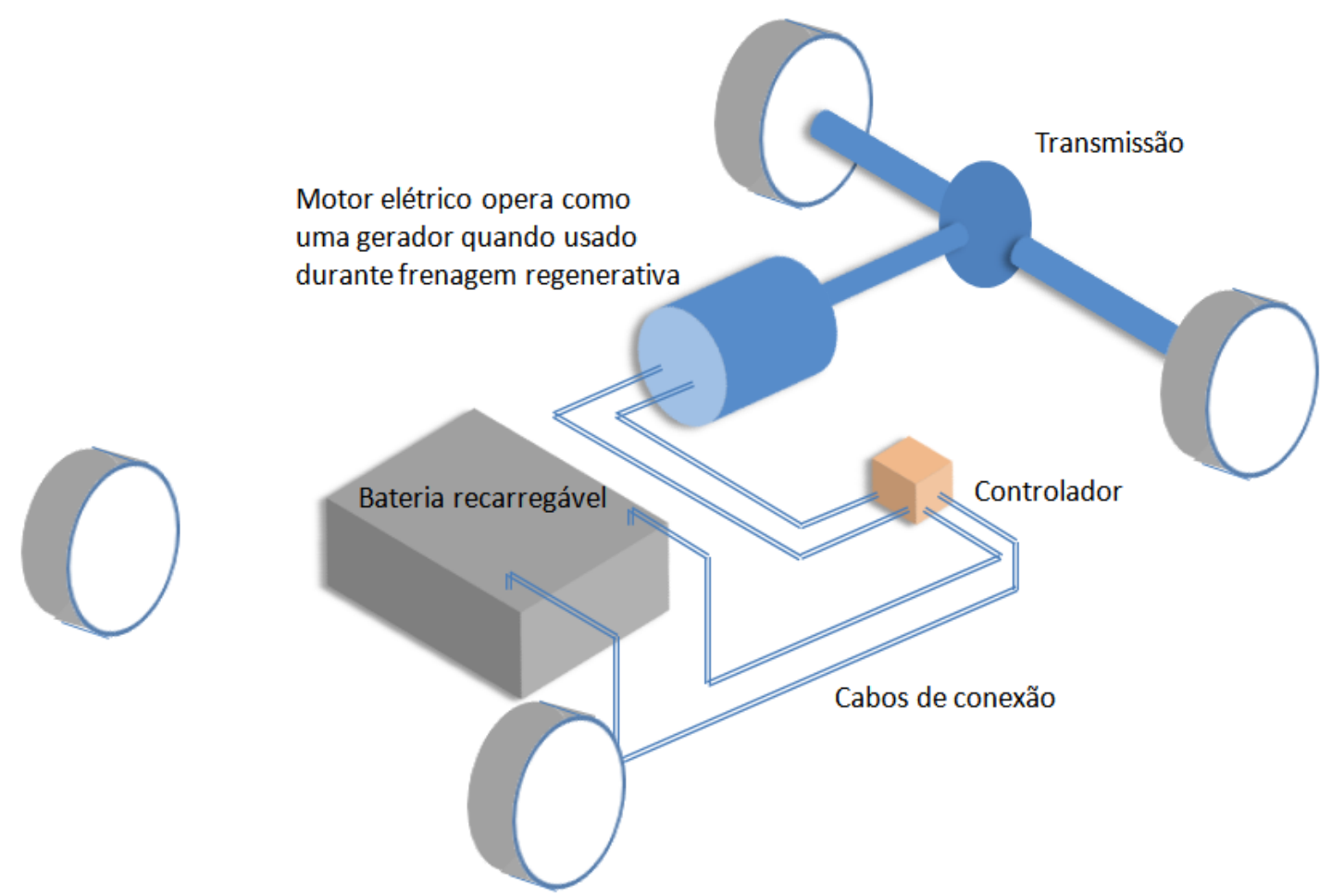

Figura 4.1 - Conceito de veículo elétrico com baterias recarregáveis 


\subsection{CONFIGURAÇÕES DE VEÍCULOS ELÉTRICOS}

(a)

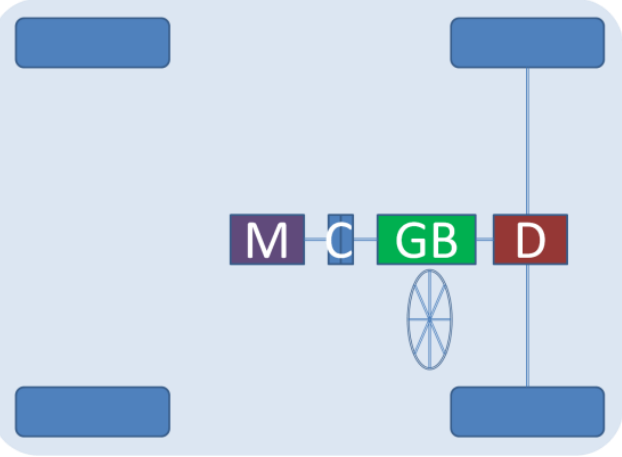

(c)

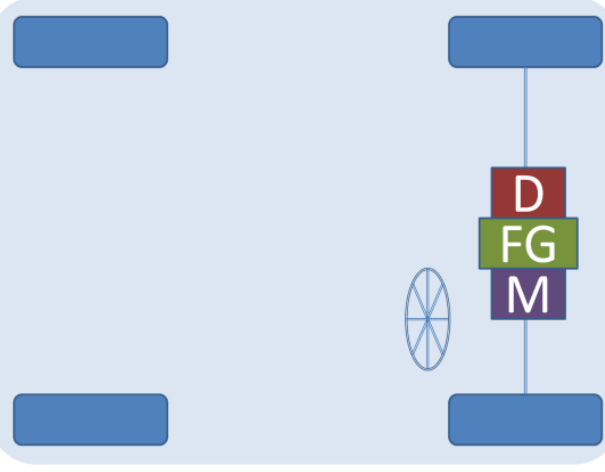

(e)

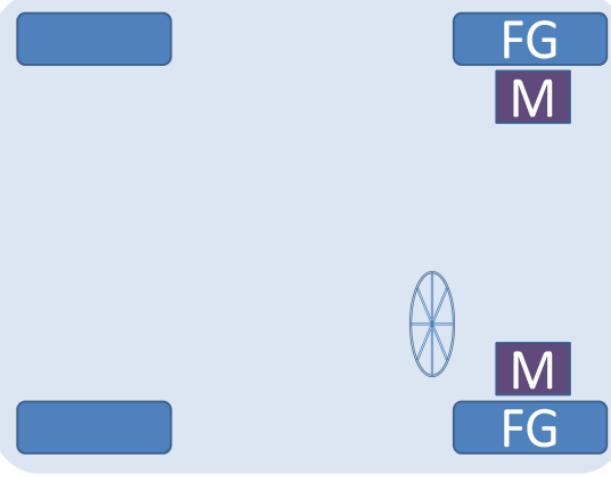

C-Embreagem

D-Diferencial

FG - Redução Fixa

$\mathrm{GB}$ - Caixa Velocidades

$\mathrm{M}$ - Motor elétrico (b)

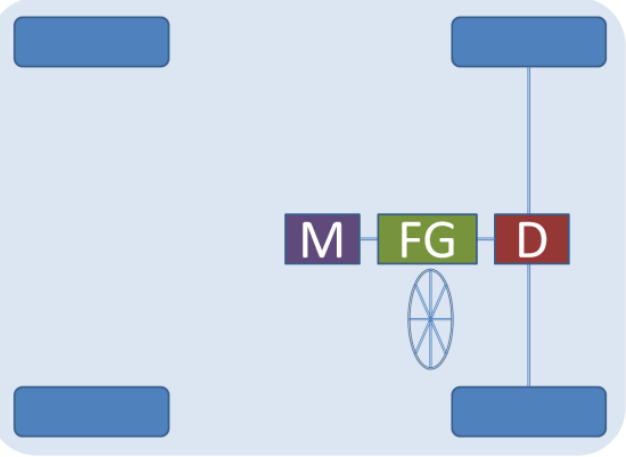

(d)

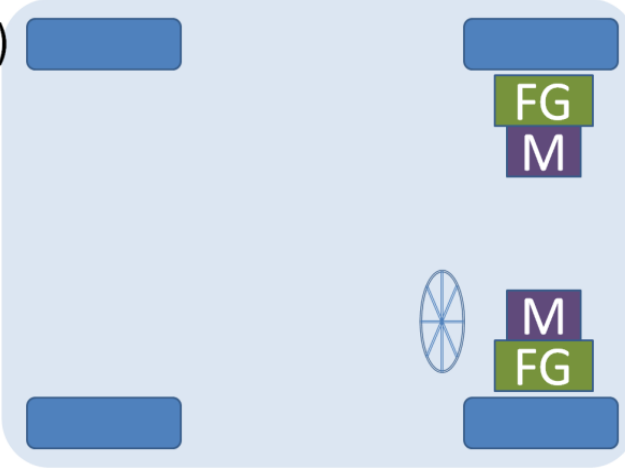

(f)
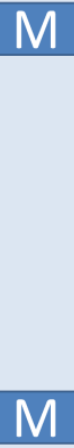

Fonte: (PINAL et al., 2006)

Figura 4.2 - Configurações para veículos elétricos puros 
Existe uma variedade de configurações de veículos elétricos possíveis devido às variações nas características de tração elétrica e fontes de energia. A Figura 4.2 apresenta algumas configurações de maior interesse:

a) A Figura 4.2 (a) mostra a configuração da primeira alternativa, em que um sistema de tração elétrica substitui o motor de combustão interna de um veículo convencional. É composto por um motor elétrico, uma embreagem, uma caixa de velocidades, e um diferencial. A embreagem e a caixa de velocidades podem ser substituídas por uma transmissão automática. A embreagem é usada para ligar ou desligar a potência do motor elétrico às rodas motrizes. A caixa de velocidades fornece um conjunto de relações de transmissão para modificar o perfil velocidade-potência (torque) para combinar com a exigência de carga. O diferencial é um dispositivo mecânico (geralmente um conjunto de engrenagens planetárias), que permite que as rodas dos dois lados sejam acionadas com velocidades diferentes quando o veículo percorre uma trajetória em curva.

b) Na Figura 4.2 (b), com um motor que opera a potência constante em uma grande faixa de velocidades, uma caixa de redução fixa pode substituir a caixa de velocidades e eliminar a necessidade da embreagem. Essa configuração não apenas reduz o tamanho e o peso da transmissão mecânica como também simplifica o controle do sistema de tração porque não é necessária a mudança de marcha.

c) Na Figura 4.2 (c), similar ao sistema de tração do item b), o motor elétrico, a caixa de redução fixa e o diferencial, podem ser integrados em um único conjunto. Todo o sistema de tração fica ainda mais simples e compacto.

d) Na Figura 4.2 (d), o diferencial mecânico é substituído pela utilização de dois motores de tração. Cada motor aciona uma roda e operam a velocidades diferentes quando o veiculo percorre uma trajetória curva.

e) Na Figura 4.2 (e), visando simplificar ainda mais o sistema de tração, o motor de tração pode ser colocado dentro da roda. Esse arranjo é denominado motor in-wheel. Um estreito conjunto de engrenagens planetárias pode ser empregado para reduzir a velocidade do motor e aumentar o torque. Esse 
sistema de planetárias oferece a vantagem de uma elevada relação de redução bem como um alinhamento dos eixos de entrada e saída.

f) Na Figura 4.2 (f), Eliminando totalmente a transmissão mecânica entre 0 motor elétrico e a roda de tração, o rotor externo de um motor elétrico inwheel de baixa rotação pode ser conectado diretamente a roda de tração. $O$ controle de velocidade do motor é equivalente ao controle da velocidade da roda e assim do veículo. Entretanto, essa configuração requer que o motor de tração tenha um torque maior para partir e acelerar o veículo.

\subsection{SISTEMAS DE TRAÇÃO PARA VEÍCULOS ELÉTRICOS PUROS}

Aqui é denominado sistema de tração elétrica o conjunto composto pelos seguintes dispositivos: motor(es) elétrico(s) de tração, controlador/conversor de potência e armazenadores de energia.

O motor elétrico converte a energia elétrica em mecânica para tracionar o veículo ou vice-versa, para realizar a frenagem ou gerar energia elétrica com o propósito de recarregar o dispositivo armazenador de energia.

O controlador/conversor de potência é usado para alimentar o motor elétrico com tensão e corrente, adequadas a cada situação, ao comando do motorista.

O dispositivo armazenador de energia, como o nome diz, é usado para armazenar energia e supri-la ao motor através do conversor de potência.

\subsection{PRINCÍPIOS BÁSICOS DE VEÍCULOS AUTOMOTIVOS}

O dimensionamento do sistema de tração é importante para a previsão do desempenho e da autonomia em qualquer veículo automotor. Neste capítulo serão apresentados os fundamentos que descrevem matematicamente o comportamento dos veículos baseados nos princípios gerais da mecânica. Parâmetros de desempenho como velocidade, capacidade de aclive, aceleração e consumo de energia serão os principais temas abordados. 
Por simplicidade e como a proposta deste trabalho é discutir os aspectos elétricos de um sistema de tração, o movimento veicular será considerado unidimensional.

Visando maximizar a eficiência energética de qualquer veículo, a massa, o coeficiente aerodinâmico e a resistência ao rolamento devem ser minimizados enquanto ao mesmo tempo as eficiências do motor/acionamento e transmissões são maximizadas. Isto é particularmente importante nos veículos elétricos puros, para reduzir a massa requerida do banco de baterias.

\subsection{MOVIMENTO VEICULAR}

As características de movimento de um veículo em uma direção específica podem ser totalmente determinadas pelas forças atuantes no veículo nessa direção. A Figura 4.3 mostra as forças que atuam em um veículo subindo uma rampa.

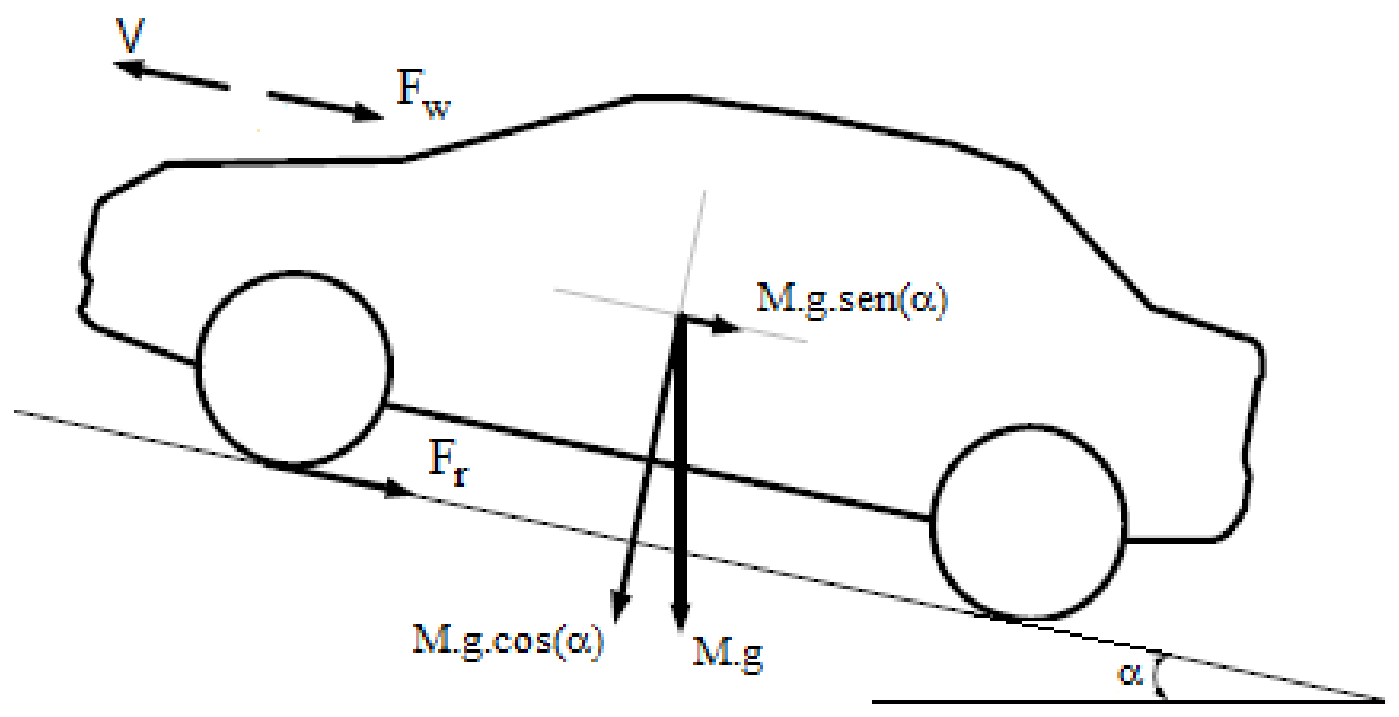

Figura 4.3 - Forças atuando em um veículo

O primeiro passo será determinar uma equação para a força de tração que é a força que propulsiona o veículo, transmitida ao solo através das rodas motrizes.

Considerando um veículo de massa $\mathrm{M}$, deslocando-se a uma velocidade $\mathrm{V}$, subindo uma rampa de ângulo $\alpha$, como na Figura 4.3. A força propulsora, que traciona o veículo, deve:

a) Superar a resistência ao rolamento; 
b) Superar a resistência aerodinâmica;

c) Superar o aclive, ou seja, fornecer a força necessária para superar a componente do peso do veículo na direção do movimento;

d) Acelerar o veículo para atingir a velocidade desejada.

A seguir a descrição de cada uma delas:

\subsubsection{Resistência ao rolamento}

Resistência ao rolamento, às vezes chamado de rolamento de fricção ou arraste de rolamento, é a resistência que ocorre quando um objeto redondo como uma bola ou pneus rolam em uma superfície plana, em linha reta e velocidade constante. É causada principalmente pela deformação do objeto, deformação da superfície, ou ambos. Fatores adicionais que contribuem incluem o raio da roda, a velocidade, adesão superficial, e relação de micro deslizamento entre as superfícies de contato. Depende do tipo de material da roda ou pneu e do tipo de solo.

Por exemplo, a borracha vai dar uma maior resistência ao rolamento que o aço em algumas superfícies (aço polido) e uma menor resistência ao rolamento em outras superfícies (pavimento / asfalto). Além disso, a areia no chão vai oferecer mais resistência ao rolamento que o concreto. Qualquer veículo com rodas em movimento irá diminuir gradualmente a velocidade devido à resistência ao rolamento. E um trem com rodas de aço sobre trilhos vai rolar mais longe que um ônibus de mesma massa com pneus de borracha no asfalto. $O$ coeficiente de resistência ao rolamento é geralmente muito menor para os pneus ou bolas que o coeficiente de atrito de deslizamento.

A resistência ao rolamento é aproximadamente constante. É proporcional ao peso do veículo e os principais fatores que o afetam são o tipo e a pressão do pneu.

A equação é, conforme visto na revisão bibliográfica:

$$
F_{r}=f_{r} M g \cos (\propto)
$$


Os valores para $f_{r}$ podem ser obtidos facilmente em livros ou manuais de mecânica ou ainda junto aos fabricantes de pneus. A Tabela 4.1 mostra alguns valores típicos.

Tabela 4.1 - Valores típicos para o coeficiente de resistência ao rolamento

\begin{tabular}{lc}
\hline \multicolumn{1}{c}{ Coeficientes de Resistência ao Rolamento } \\
Condições & $\begin{array}{c}\text { Coeficiente de Resistência ao } \\
\text { Rolamento }\end{array}$ \\
\hline Pneus de carro numa via de asfalto ou & 0,013 \\
concreto & 0,020 \\
\hline Pneus de carro numa via de cascalhos & 0,025 \\
\hline Via de macadame & 0,050 \\
\hline Via sem pavimento & $0.10-0,35$ \\
\hline Campo & $0,006-0,010$ \\
\hline Pneus de caminhão numa via de & \\
asfalto ou concreto & $0,001-0,002$ \\
\hline Roda sobre trilho & \\
\hline
\end{tabular}

Fonte: (EHSANI; GAO; EMADI, 2010)

\subsubsection{Resistência aerodinâmica}

Um veículo viajando a uma velocidade específica encontra no ar uma força de resistência ao seu movimento. Esta força é referida como o arrasto aerodinâmico. Resulta principalmente a partir de duas componentes: forma do veículo e fricção superficial.

Arrasto de forma: O movimento do veículo empurra o ar na frente dele. No entanto, o ar não pode sair instantaneamente do caminho e sua pressão, portanto, aumenta, resultando em alta pressão de ar. Além disso, o ar atrás do veículo não pode instantaneamente preencher o espaço deixado pelo movimento para frente do veículo. Isso cria uma zona de baixa pressão atmosférica. O movimento do veículo, 
portanto, cria duas zonas de pressão que se opõem ao movimento empurrando-o (alta pressão na frente) e puxando-o para trás (baixa pressão atrás), conforme mostrado na Figura 4.4. A força resultante sobre o veículo é o arrasto de forma. $\mathrm{O}$ nome arrasto de forma (shape drag) vem do fato de que este arrasto é completamente determinado pela forma do corpo do veículo.

Fricção superficial: $O$ ar próximo da superfície do veículo se move quase à velocidade do veículo enquanto $o$ ar afastado do veículo permanece parado. No meio, moléculas de ar se movem em uma ampla gama de velocidades. A diferença de velocidade entre duas moléculas de ar produz uma fricção que resulta no segundo componente do arrasto aerodinâmico.

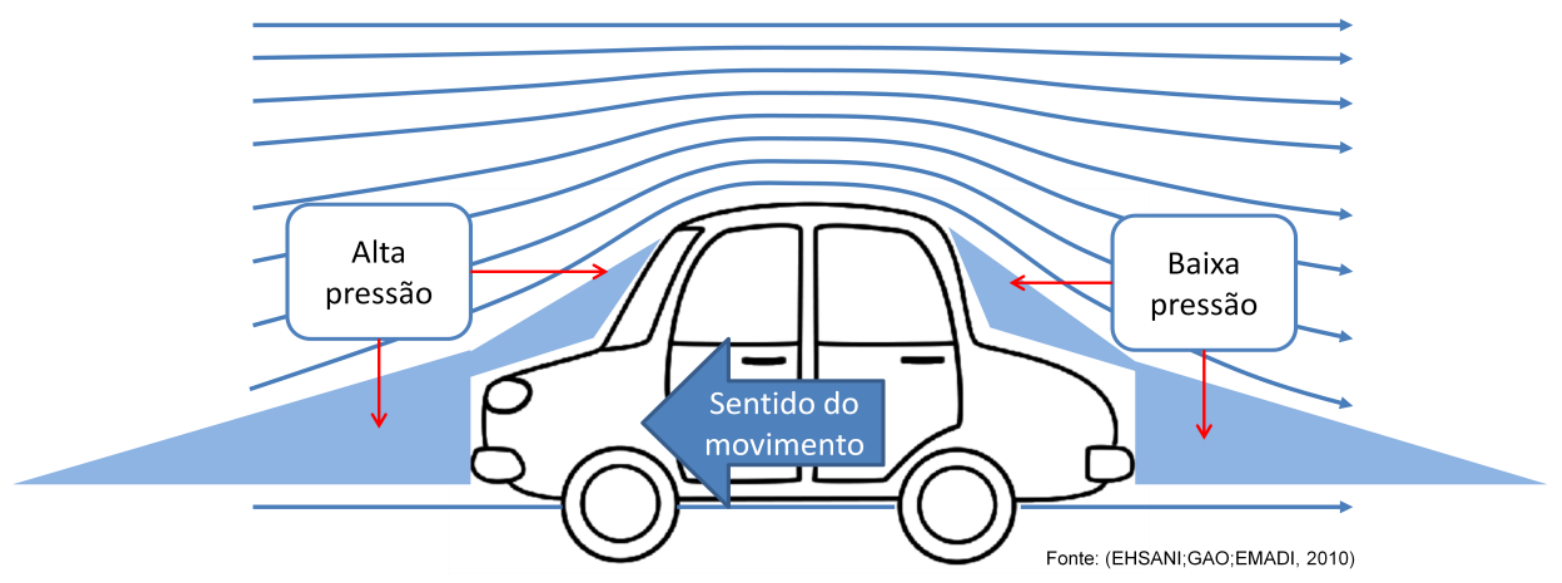

Figura 4.4 - Arrasto de forma na resistência aerodinâmica

$\mathrm{O}$ arrasto aerodinâmico é função da velocidade do veículo $\mathrm{V}$, área frontal do veículo $A_{\mathrm{f}}$, forma do corpo do veículo, e densidade do ar $\rho_{\mathrm{a}}$, conforme visto na revisão bibliográfica:

$$
\mathrm{F}_{\mathrm{w}}=\frac{1}{2} \rho_{\mathrm{a}} \mathrm{A}_{\mathrm{f}} \mathrm{C}_{\mathrm{D}}\left(\mathrm{V}-\mathrm{V}_{\mathrm{w}}\right)^{2}
$$

A densidade do ar varia com a temperatura, altitude e umidade. Entretanto, um valor de $1,25 \mathrm{~kg} / \mathrm{m}^{3}$ é um valor razoável para usar na maioria dos casos.

A Tabela 4.2 mostra alguns exemplos de coeficientes de arrasto para diferentes formas de veículos. 
Tabela 4.2 - Coeficientes de arrasto em função da forma do veículo

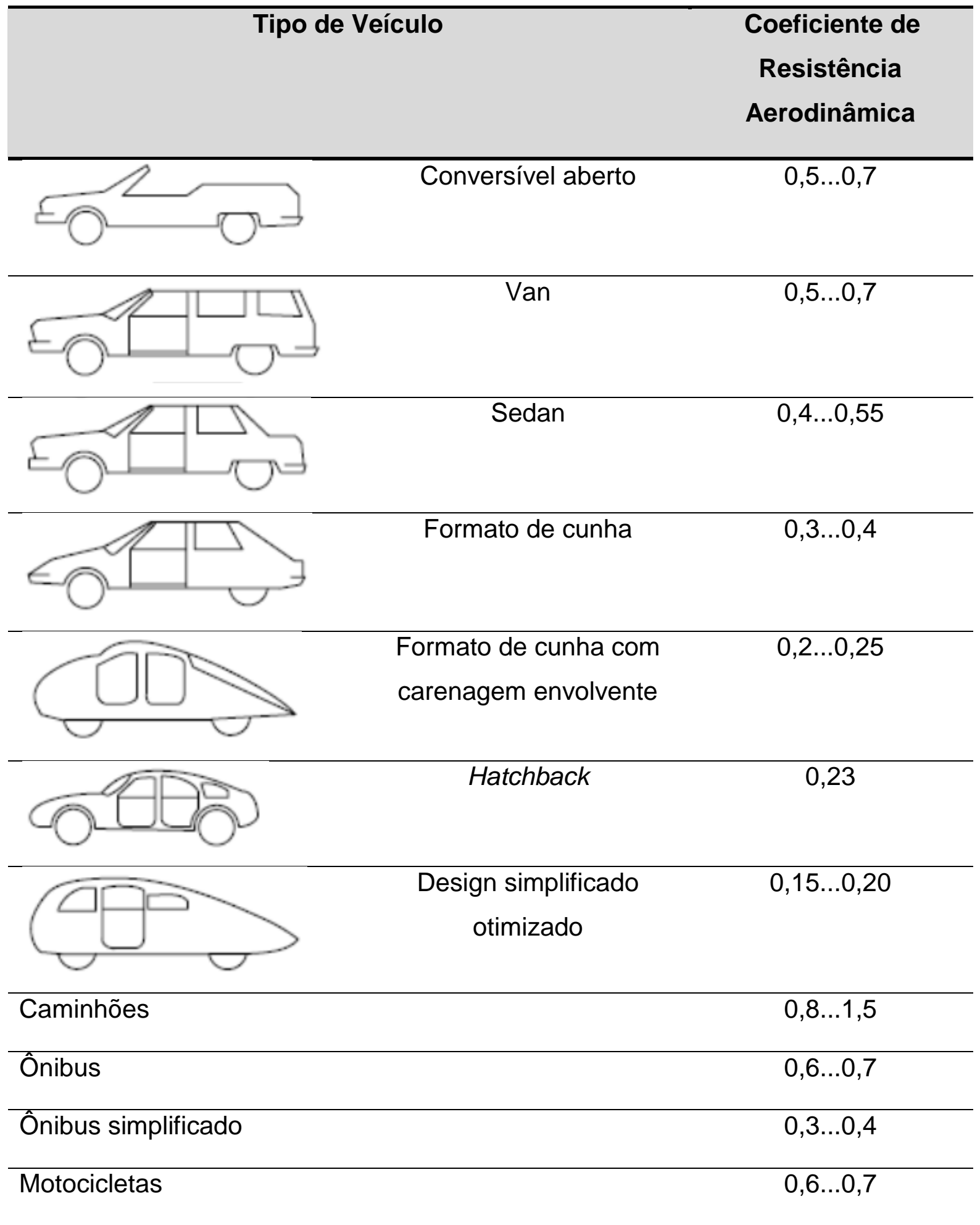




\subsubsection{Resistência ao aclive}

Quando um veículo sobe ou desce um aclive, seu peso produz uma componente que é sempre dirigida para a descida, conforme mostra a Figura 4.3. Essa componente ou se opõe ao movimento para cima ou ajuda para baixo. $\mathrm{Na}$ análise de desempenho do veículo, somente a operação de subida é considerada. Essa força normalmente é chamada de resistência ao aclive e como visto na revisão bibliográfica pode ser expressa como:

$$
F_{g}=M g \operatorname{sen}(\propto)
$$

\subsubsection{Força de aceleração linear}

Para a aceleração (mudança de velocidade) do veículo, é necessária que seja aplicada uma força em adição às de resistência ao movimento $\left(F_{r}, F_{w}\right.$ e $\left.F_{g}\right)$. Esta força fornecerá uma aceleração linear ao veículo, e é dada pela segunda lei de Newton:

$$
F_{l a}=M \frac{d V(t)}{d t}
$$

Assim, a força de tração necessária é dada por:

$$
F_{t}=F_{l a}+F_{r}+F_{w}+F_{g}
$$

No entanto, para uma imagem mais precisa da força necessária para acelerar o veículo também devemos considerar a força necessária para fazer as partes rotativas acelerarem. Em outras palavras, precisamos considerar a aceleração angular, bem como a aceleração linear. O principal problema aqui é o motor elétrico, não necessariamente por causa de seu elevado momento de inércia, mas por causa de sua maior velocidade angular. 


\subsubsection{Força de aceleração angular}

A força para a aceleração angular é:

$$
F_{w a}=\frac{\left(i_{g}^{2} I+I_{w}\right)}{r_{d}^{2}} \frac{d V(t)}{d t}
$$

Observações: (1) Considera-se de maneira conservadora que todas as massas girantes do sistema de transmissão estão no rotor do motor. (2) A força de aceleração angular está referida à roda/pneu do veículo.

\subsubsection{Força de tração}

A equação completa para a força de tração é dada por:

$$
\begin{gathered}
F_{t}=F_{r}+F_{w}+f_{g}+F_{l a}+F_{w a} \\
F_{t}=f_{r} M g \cos (\propto)+\frac{1}{2} \rho_{\mathrm{a}} \mathrm{A}_{\mathrm{f}} \mathrm{C}_{\mathrm{D}}\left(\mathrm{V}-\mathrm{V}_{\mathrm{w}}\right)^{2}+M g \operatorname{sen}(\propto)+\frac{M d V(t)}{d t}+\frac{\left(i_{g}^{2} I+I_{w}\right)}{r_{d}^{2}} \frac{d V(t)}{d t}
\end{gathered}
$$

\subsubsection{Aceleração}

A equação dinâmica do movimento linear do veículo é dada por:

$$
\begin{aligned}
& F_{l a}=F_{t}-\left(F_{r}+F_{w}+f_{g}+F_{w a}\right) \\
& \frac{M d V(t)}{d t}=F_{t}-\left[f_{r} M g \cos (\propto)+\frac{1}{2} \rho_{\mathrm{a}} \mathrm{A}_{\mathrm{f}} \mathrm{C}_{\mathrm{D}}\left(\mathrm{V}-\mathrm{V}_{\mathrm{w}}\right)^{2}+M g \operatorname{sen}(\propto)+\frac{\left(i_{g}^{2} I+I_{w}\right)}{r_{d}^{2}} \frac{d V(t)}{d t}\right] \\
& \frac{M d V(t)}{d t}+\frac{\left(i_{g}^{2} I+I_{w}\right)}{r_{d}^{2}} \frac{d V(t)}{d t}=F_{t}-\left[f_{r} M g \cos (\propto)+\frac{1}{2} \rho_{\mathrm{a}} \mathrm{A}_{\mathrm{f}} \mathrm{C}_{\mathrm{D}}\left(\mathrm{V}-\mathrm{V}_{\mathrm{w}}\right)^{2}+M g \operatorname{sen}(\propto)\right] \\
& {\left[M+\frac{\left(i_{g}^{2} I+I_{w}\right)}{r_{d}^{2}}\right] \frac{d V(t)}{d t}=F_{t}-\left[f_{r} M g \cos (\propto)+\frac{1}{2} \rho_{\mathrm{a}} \mathrm{A}_{\mathrm{f}} \mathrm{C}_{\mathrm{D}}\left(\mathrm{V}-\mathrm{V}_{\mathrm{w}}\right)^{2}+M g \operatorname{sen}(\propto)\right]} \\
& \quad \frac{d V(t)}{d t}=\frac{F_{t}-\left[f_{r} M g \cos (\propto)+\frac{1}{2} \rho_{\mathrm{a}} \mathrm{A}_{\mathrm{f}} \mathrm{C}_{\mathrm{D}}\left(\mathrm{V}-\mathrm{V}_{\mathrm{w}}\right)^{2}+M g \operatorname{sen}(\propto)\right]}{\left(M+\frac{\left(i_{g}^{2} I+I_{w}\right)}{r_{d}^{2}}\right]}
\end{aligned}
$$




\subsubsection{Torque}

O torque de tração nas rodas é obtido pelo produto da força de tração e do raio efetivo (considerando as deformações) da roda/pneu, conforme segue:

$$
\begin{aligned}
& F_{t}=f_{r} M g \cos (\propto)+\frac{1}{2} \rho_{\mathrm{a}} \mathrm{A}_{\mathrm{f}} \mathrm{C}_{\mathrm{D}}\left(\mathrm{V}-\mathrm{V}_{\mathrm{w}}\right)^{2}+M g \operatorname{sen}(\propto)+\frac{M d V(t)}{d t}+\frac{\left(i_{g}^{2} I+I_{w}\right)}{r_{d}^{2}} \frac{d V(t)}{d t} \\
& T_{t}=\mathrm{r}_{\mathrm{d}} f_{r} M g \cos (\propto)+\mathrm{r}_{\mathrm{d}} \frac{1}{2} \rho_{\mathrm{a}} \mathrm{A}_{\mathrm{f}} \mathrm{C}_{\mathrm{D}}\left(\mathrm{V}-\mathrm{V}_{\mathrm{w}}\right)^{2}+\mathrm{r}_{\mathrm{d}} M g \operatorname{sen}(\propto)+\mathrm{r}_{\mathrm{d}} \frac{M d V(t)}{d t}+\frac{\left(i_{g}^{2} I+I_{w}\right)}{r_{d}} \frac{d V(t)}{d t}
\end{aligned}
$$

E o torque no motor:

$$
T_{m}=\frac{1}{\eta_{t} i_{g}}\left[\mathrm{r}_{\mathrm{d}} f_{r} M g \cos (\propto)+\mathrm{r}_{\mathrm{d}} \frac{1}{2} \rho_{\mathrm{a}} \mathrm{A}_{\mathrm{f}} \mathrm{C}_{\mathrm{D}}\left(\mathrm{V}-\mathrm{V}_{\mathrm{w}}\right)^{2}+\mathrm{r}_{\mathrm{d}} M g \operatorname{sen}(\propto)+\mathrm{r}_{\mathrm{d}} \frac{M d V(t)}{d t}+\frac{\left(i_{g}^{2} I+I_{w}\right)}{r_{d}} \frac{d V(t)}{d t}\right](4.8)
$$

\subsubsection{Potência}

A demanda de potência para tração nas rodas do veículo é obtida pelo produto da força de tração necessária e da velocidade, como visto na revisão bibliográfica, na pagina 29 , onde o fator de massa foi utilizado ao invés da força de aceleração angular. Se a força de aceleração angular for utilizada, a equação é dada por:

$$
P_{t}=\left[f_{r} M g \cos (\propto)+\frac{1}{2} \rho_{\mathrm{a}} \mathrm{A}_{\mathrm{f}} \mathrm{C}_{\mathrm{D}}\left(\mathrm{V}-\mathrm{V}_{\mathrm{w}}\right)^{2}+M g \operatorname{sen}(\propto)+\frac{M d V(t)}{d t}+\frac{\left(i_{g}^{2} I+I_{w}\right)}{r_{d}^{2}} \frac{d V(t)}{d t}\right] V(t)
$$

A partir dessa expressão da potência, pode-se determinar a curva de demanda em um determinado ciclo de condução. 


\subsection{CICLOS DE CONDUÇÃO}

A demanda de potência de um veículo é diretamente proporcional a sua velocidade instantânea, como foi descrito em Erro! Fonte de referência não encontrada..

Foram desenvolvidas algumas curvas de ciclo de condução que representam os perfis de velocidade em determinadas aplicações e são utilizadas para verificar o desempenho do veículo nessas situações. Tais curvas de ciclo de condução foram originalmente desenvolvidas para veículos com motor de combustão interna e verificar entre outros parâmetros, o consumo de combustível e a emissão de poluentes. No caso de veículos elétricos, essas curvas são utilizadas, principalmente, para verificar o desempenho quanto à demanda de potência e consumo de energia.

Um ciclo de condução é um modelo padronizado de condução descrito por meio de uma tabela velocidade-tempo. O percurso a ser coberto é dividido em intervalos de tempo, geralmente segundos e a aceleração durante um intervalo de tempo é considerada constante. Como resultado, a velocidade durante um intervalo de tempo é uma função linear do tempo e como a velocidade e a aceleração são conhecidas para cada intervalo de tempo, a potência requerida em função do tempo pode ser determinada. Essa potência integrada no tempo de duração do ciclo de condução fornece a energia necessária para aquele ciclo de condução.

Para veículos híbridos e com motor de combustão interna, a energia consumida pode ser obtida através da medição do consumo de combustível. Para veículos elétricos e híbridos elétricos plug-in que fazem uso de uma fonte de energia externa, a energia absorvida dessa fonte é contabilizada.

Apenas como exemplo, alguns modelos dos ciclos serão ilustrados a seguir. Os ciclos de condução mais utilizados podem ser divididos em três grupos:

\subsubsection{Ciclos de condução europeus}

a) ECE 15 


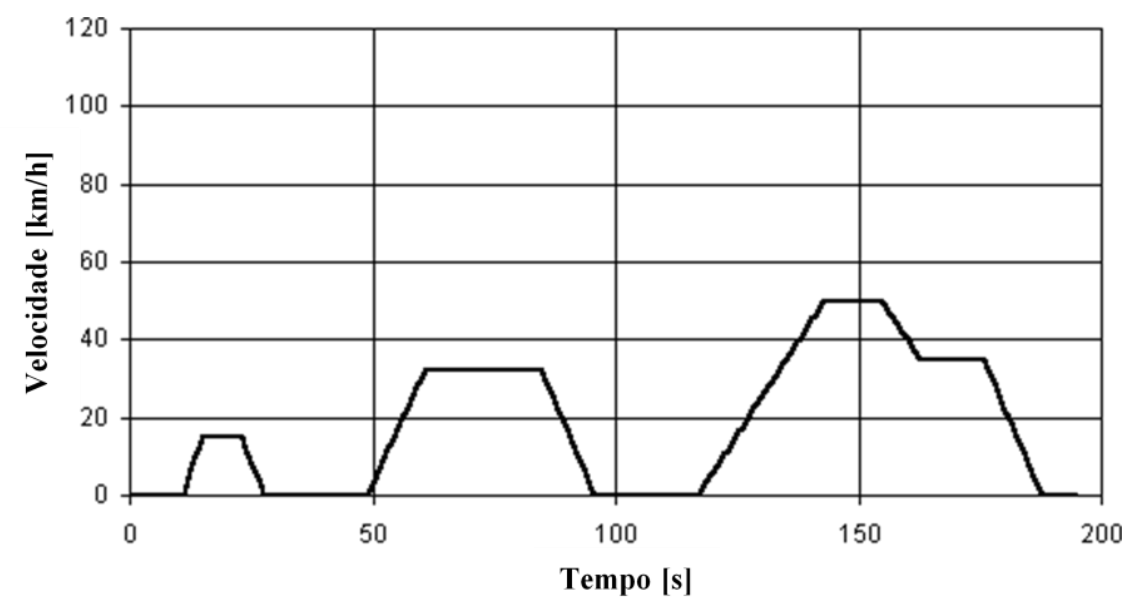

Figura 4.5 - Ciclo de condução ECE 15

Este ciclo de condução representa uma condução urbana. É caracterizada pela baixa velocidade do veículo (máximo $50 \mathrm{~km} / \mathrm{h}$ ) e baixa carga no motor.

b) EUDC

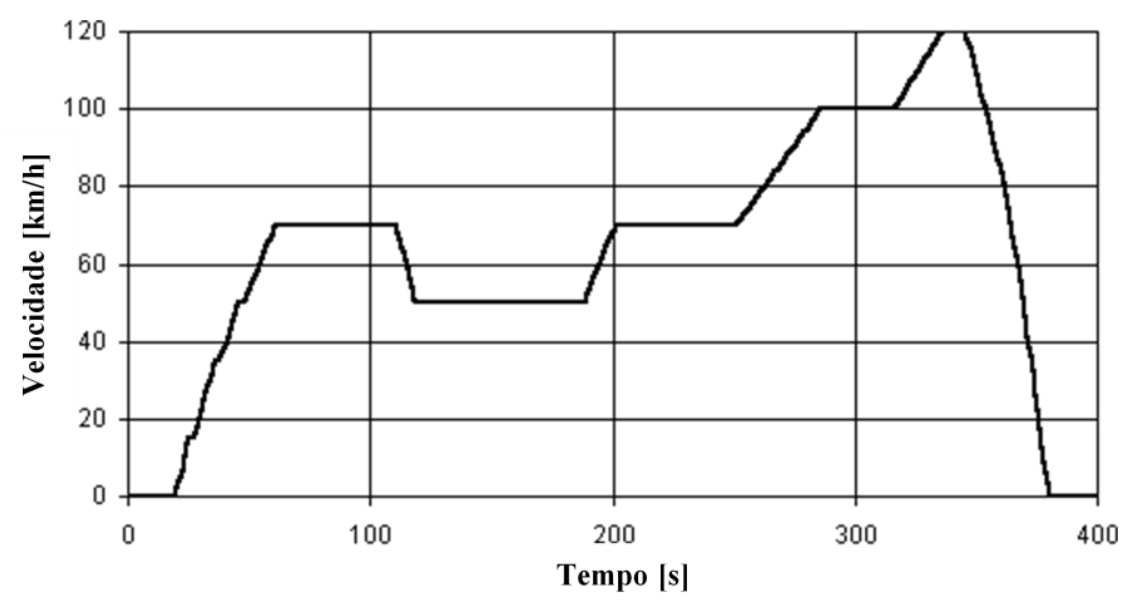

Figura 4.6 - Ciclo de condução EUDC

Este ciclo descreve uma rota suburbana. No final do ciclo o veículo acelera a velocidade de autoestrada. Tanto a velocidade como a aceleração são maiores que no ECE 15. 
c) EUDCL

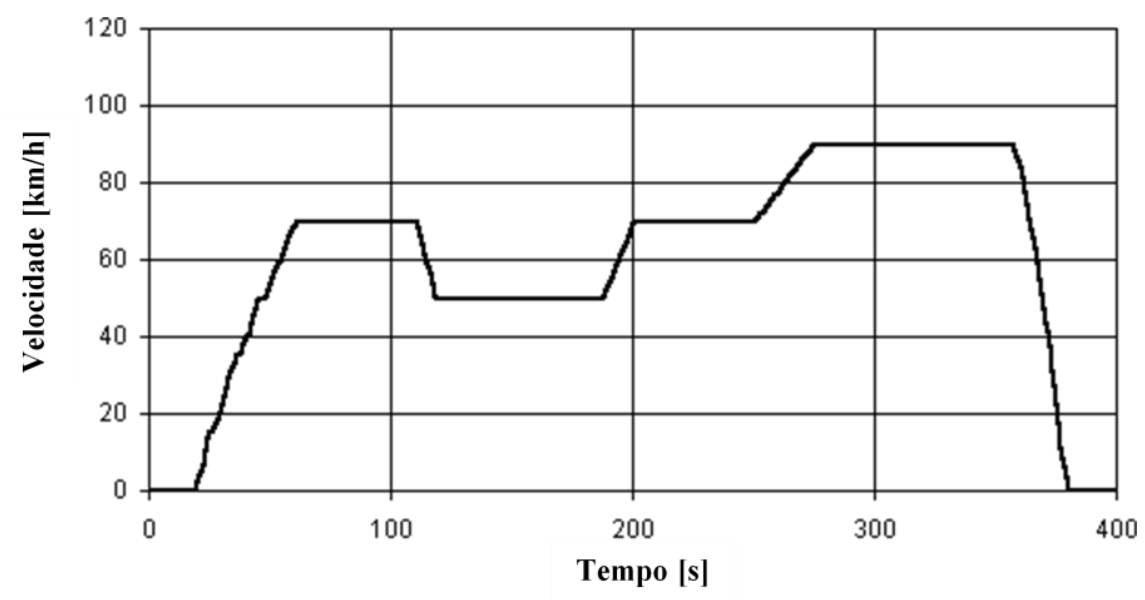

Figura 4.7 - Ciclo de condução EUDCL

O EUDCL é um ciclo suburbano para veículos de baixa potência. É semelhante ao EUDC, mas a velocidade máxima é de $90 \mathrm{~km} / \mathrm{h}$.

\section{d) NEDC}

Trata-se de um ciclo combinado que consiste em quatro ciclos ECE 15, seguido por um ciclo EUDC ou EUDCL. O NEDC é também chamado de ciclo ECE.

\section{e) HYZEM}

Os ciclos acima mencionados são ciclos estilísticos e não representam os padrões reais de condução. Os ciclos HYZEM são transientes. As partes em que a velocidade é constante são muito menores do que nos ciclos modais. Os ciclos HYZEM são derivados de padrões reais de condução em toda a Europa. Portanto, eles são uma melhor representação para as condições de condução do que os ciclos de padrão europeu. Os ciclos HYZEM são frequentemente utilizados, mas não são oficiais. Os ciclos HYZEM consistem em um ciclo urbano, um ciclo extraurbano e um ciclo de autoestrada. 


\subsubsection{Ciclos de condução norte-americanos}

a) FTP 72

Esse ciclo foi desenvolvido no inicio dos anos 70 para descrever uma rota urbana. $O$ FTP 72 também é frequentemente chamado FUDS, UDDS ou LA-4.

\section{b) SFUDS}

O SFUDS foi desenvolvido para simular descarga e carga de baterias durante uma viagem com um veículo elétrico. Foi derivado para um veículo específico com propulsão elétrica de eixo dual aperfeiçoado. O perfil de velocidade é adaptado para esse veículo para obter-se um perfil de descarga e carga que consistem em fases de potência constante.

\section{c) $\quad$ FTP 75}

O FTP 75 é o FTP 72 com uma terceira fase extra. Essa fase é idêntica à primeira fase, mas é realizada com o motor quente.

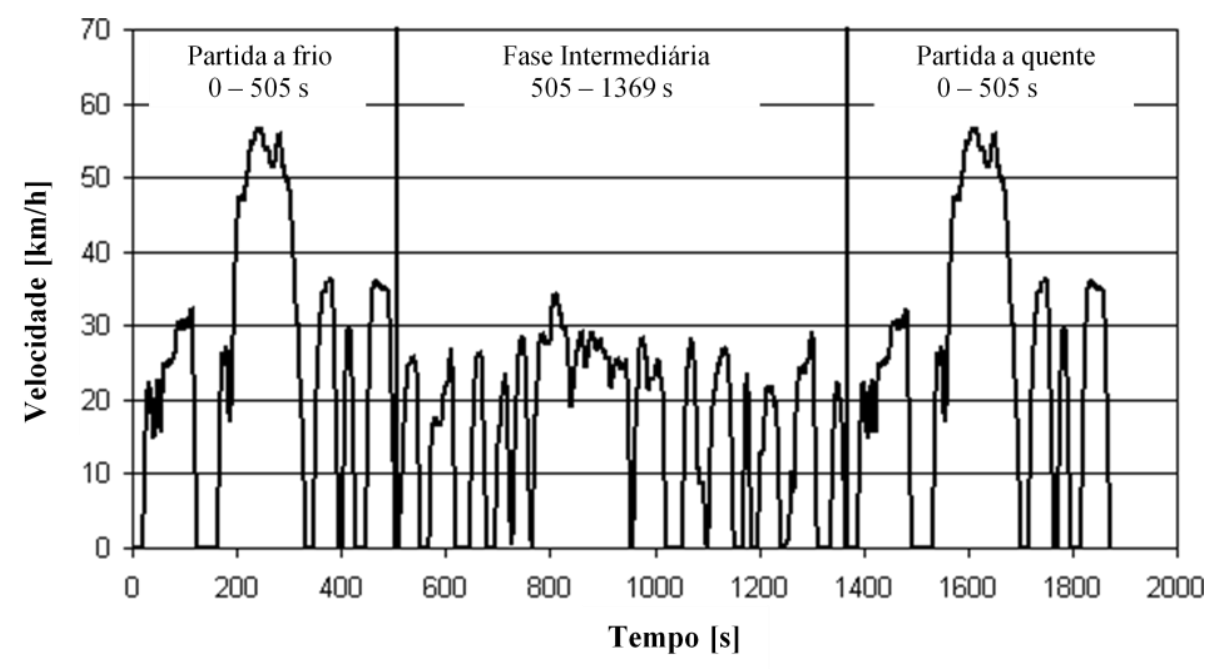

Figura 4.8 - Ciclo de condução FTP 75

d) HFEDS

Esse ciclo representa condução extraurbana e em autoestrada. 
e) IM 240

Esse é um ciclo usado com propósito de inspeção. Através desse ciclo, as emissões são determinadas durante o teste de manutenção periódica.

f) LA-92

O LA-92 representa uma rota urbana como o FTP 72. Foi desenvolvido em 1992 porque o existente FTP 72 deixou de ser uma representação realística dos padrões de condução urbana. Por exemplo, o LA-92 tem uma velocidade média maior.

g) NYCC

Esse ciclo representa uma rota urbana de Nova lorque. A característica desse ciclo é a baixa velocidade média.

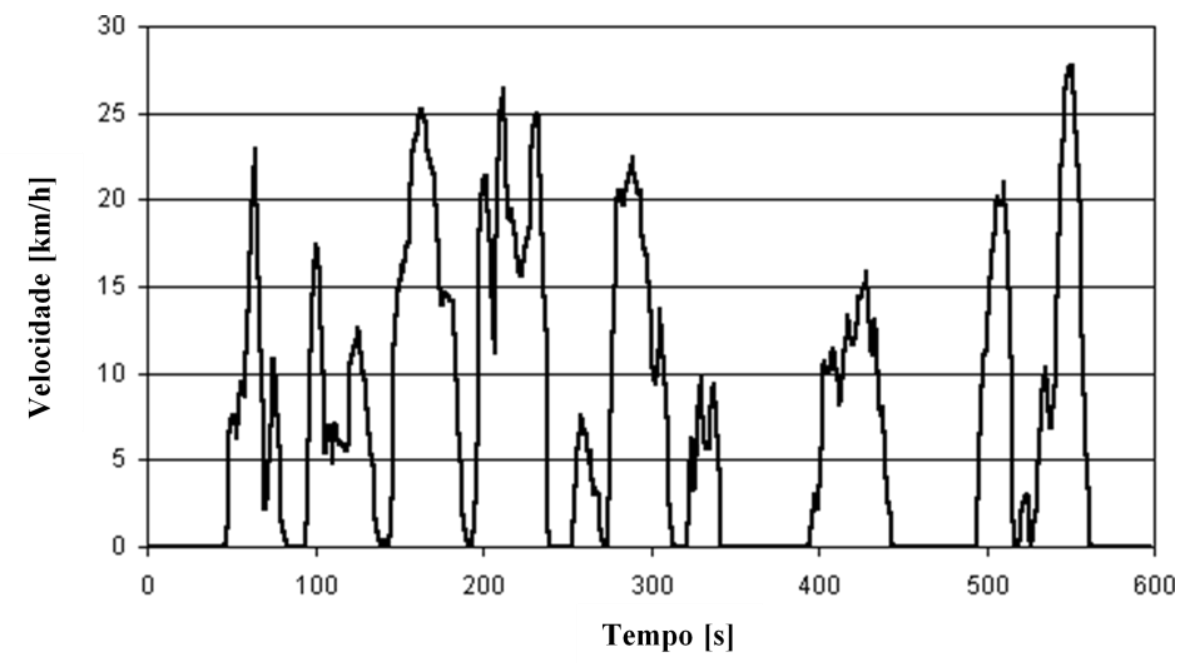

Figura 4.9 - Ciclo de condução NYCC

h) US 06

Esse é o chamado ciclo de condução agressiva. Foi desenvolvido para descrever um padrão de condução com grande carga no motor. 


\subsubsection{Ciclos de condução japoneses}

a) 10 MODE

Esse ciclo representa uma rota urbana.

b) $15 \mathrm{MODE}$

Esse ciclo é uma combinação de uma rota urbana e uma extraurbana. A velocidade máxima é $70 \mathrm{~km} / \mathrm{h}$.

c) $10-15 \mathrm{MODE}$

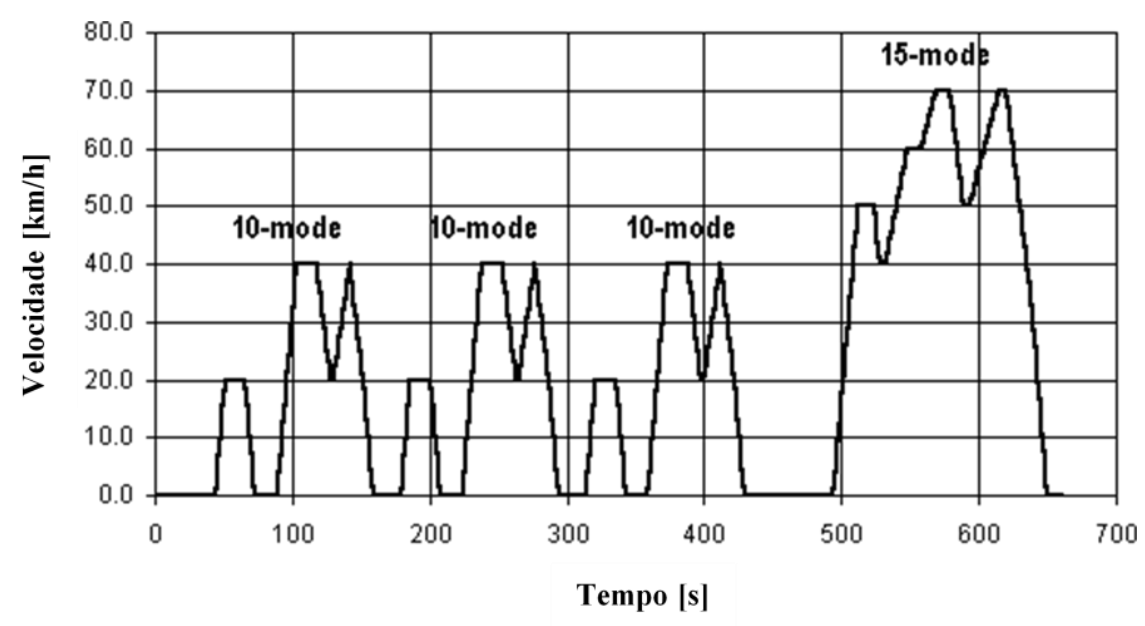

Figura 4.10 - Ciclo de condução 10-15 MODE

Esse ciclo é uma combinação de cinco ciclos. Primeiro o 15-MODE, então três vezes o 10-MODE, e por último, novamente o 15-MODE. O primeiro ciclo não é mostrado na figura.

Dentre os ciclos, o europeu designado NEDC (New European Drive Cycle), mostrado na Figura 4.11, tem sido muito utilizado em testes para veículos elétricos. É um ciclo combinado consistindo de quatro repetições do ciclo europeu ECE 15, que representa um ciclo de condução urbano, seguido de um ciclo europeu EUDC, que representa um ciclo suburbano onde o veículo acelera para uma velocidade de estrada ao final do ciclo. 


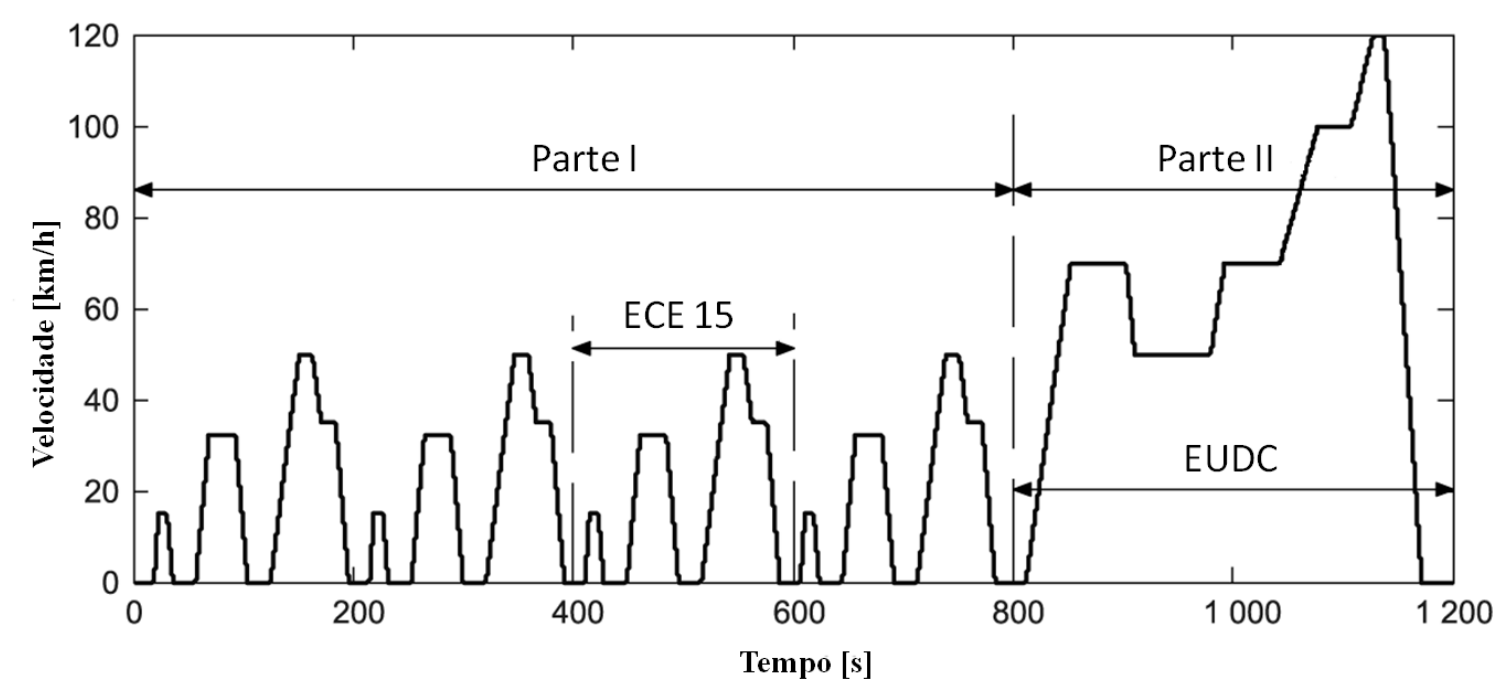

Figura 4.11 - Novo ciclo de condução europeu (NEDC)

Nota: As curvas de ciclos de condução apresentadas neste capítulo foram obtidas no site da DieselNet.

\subsection{METODOLOGIA DE DIMENSIONAMENTO}

Como mencionado no capítulo de introdução, uma das motivações para esse trabalho é que há anos os veículos elétricos puros já têm sido utilizados em diversas aplicações e com os recentes avanços tecnológicos, no atual estado da arte, essas aplicações aumentam a cada dia.

A aplicação do veículo é um fator chave para o seu projeto e em função dela, definem-se os parâmetros da especificação técnica para a determinação dos parâmetros de projeto, conforme mostrados a seguir:

\section{Parâmetros da especificação técnica:}

a) Velocidade nominal de cruzeiro

b) Aceleração para atingir a velocidade nominal de cruzeiro

c) Velocidade máxima

d) Aclive máximo

e) Autonomia 


\section{Parâmetros de projeto:}

a) Potência do motor (e conversor de potência)

b) Velocidade nominal do motor

c) Velocidade máxima do motor

d) Relação de transmissão

e) Capacidade da bateria

Idealmente, o objetivo é atender aos requisitos da especificação com a mínima potência. Entretanto, isso não significa que será utilizado um motor com essa potência mínima. Primeiro porque nem sempre encontraremos um motor com potência nominal igual à mínima determinada e que ao mesmo tempo suas curvas de torque-velocidade sejam compatíveis com a relação de transmissão. Depois porque um conjunto motor transmissão um pouco maiores podem ter rendimentos melhores na região de operação esperada e assim ser uma opção melhor.

Deve-se observar que a determinação dos parâmetros de projeto é um processo iterativo uma vez que existem duas variáveis desconhecidas e interdependentes que são: a potência do sistema de tração e a massa do veículo.

\subsubsection{Determinação da potência necessária (nas rodas):}

Como descrito em Erro! Fonte de referência não encontrada., obtém-se o valor da potência para tracionar o veículo, de acordo com as especificações técnicas de projeto, através da equação:

$$
P_{t}=\left[f_{r} M g \cos (\propto)+\frac{1}{2} \rho_{\mathrm{a}} \mathrm{A}_{\mathrm{f}} \mathrm{C}_{\mathrm{D}}\left(\mathrm{V}-\mathrm{V}_{\mathrm{w}}\right)^{2}+M g \operatorname{sen}(\propto)+\frac{M d V(t)}{d t}+\frac{\left(i_{g}^{2} I+I_{w}\right)}{r_{d}^{2}} \frac{d V(t)}{d t}\right] V(t)
$$

onde $f_{r}, \mathrm{~A}_{\mathrm{f}}, \mathrm{C}_{\mathrm{D}}, I, I_{w}, i_{g}, \eta_{t}$ e $r_{d}$ são parâmetros conhecidos do projeto mecânico do

veículo e $\propto, V$ e $\frac{d V(t)}{d t}$ são parâmetros da especificação técnica. $\rho_{a}$ e $g$, a densidade do ar e aceleração da gravidade, respectivamente.

O único parâmetro desconhecido é a massa $\mathrm{M}$ do veículo que pode ser estimada com boa aproximação através dos recursos oferecidos pelos programas de projeto 
mecânico e ficando pendente apenas a massa do próprio sistema de tração. Nesse ponto, é importante a experiência ou a assessoria de alguém com conhecimento em sistemas de tração para veículos elétricos para ajudar a fazer essa estimativa.

Devem ser calculados os valores de potência para cada uma das condições definidas na especificação técnica e, dependendo da aplicação do veículo, em um ou mais ciclos de condução, como por exemplo, o NEDC apresentado em 4.6.1.

É importante observar que a potência determinada acima é a potência de tração nas rodas.

Para o cálculo da potência requerida no eixo do motor deve-se considerar o rendimento da transmissão. Para o cálculo da potência requerida na saída do conversor de potência/alimentação do motor, deve-se considerar o rendimento do motor. E para o cálculo da potência nos terminais das baterias/alimentação do conversor de potência, deve-se considerar o rendimento do conversor de potência.

Como o objetivo deste trabalho é dimensionar os componentes do sistema de tração, os rendimentos do sistema de transmissão, do motor e do controlador/conversor de potência serão considerados valores constantes. Tal suposição não afetará qualquer dos resultados.

\subsubsection{Dimensionamento do motor elétrico}

$$
P_{m}=\frac{P_{t}}{\eta_{t}}
$$

Utilizam-se os valores obtidos para a potência de tração $\left(P_{t}\right)$ para as condições da especificação técnica e ciclos de condução, se aplicáveis.

\subsubsection{Determinação da rotação nominal e rotação máxima do motor:}

a) Calculo da rotação $\left(N_{t}\right)$ nas rodas/pneus em [RPM] a partir da velocidade do veículo $\left(V_{k}\right)$ em $[\mathrm{km} / \mathrm{h}]$ :

$$
V=\frac{V_{k}}{3,6}
$$




$$
\begin{gathered}
V=\omega r_{d} \\
V=\frac{2 \pi N_{t} r_{d}}{60} \\
N_{t}=\frac{30 V}{\pi r_{d}}
\end{gathered}
$$

b) Determinação da rotação do motor em [RPM], multiplicando a rotação na roda/pneu pela relação de transmissão total:

$$
N_{m}=i_{g} N_{t}
$$

Dessa forma obtêm-se as rotações do motor referentes à velocidade nominal de cruzeiro e à velocidade máxima do veículo, respectivamente.

\subsubsection{Verificação da curva de torque e da relação de transmissão}

Essa verificação é importante para a previsão do desempenho do veículo, especificamente a sua aceleração e o seu consumo de energia, em todo o ciclo de condução e, particularmente, nas condições extremas como a velocidade máxima, o aclive máximo com a capacidade máxima de carga e a aceleração máxima com capacidade máxima de carga.

Dependendo dos resultados obtidos, a alteração da relação de transmissão e/ou troca do motor pode ser vantajosa ou necessária, para a obtenção de um melhor desempenho do veículo.

A curva de demanda de torque no motor é construída a partir da equação:

$$
T_{m}=\frac{1}{\eta_{t} i_{g}}\left[\mathrm{r}_{\mathrm{d}} f_{r} M g \cos (\propto)+\mathrm{r}_{\mathrm{d}} \frac{1}{2} \rho_{\mathrm{a}} \mathrm{A}_{\mathrm{f}} \mathrm{C}_{\mathrm{D}}\left(\mathrm{V}-\mathrm{V}_{\mathrm{W}}\right)^{2}+\mathrm{r}_{\mathrm{d}} M g \operatorname{sen}(\propto)+\mathrm{r}_{\mathrm{d}} \frac{M d V(t)}{d t}+\frac{\left(i_{g}^{2} I+I_{\mathrm{w}}\right)}{r_{d}} \frac{d V(t)}{d t}\right](4.8)
$$

Também é importante lembrar a verificação da aderência solo/pneu e da máxima força de tração. A força de tração desenvolvida por um motor de tração nas rodas/pneus do veículo é expressa por:

$$
F_{t}=\frac{T_{m} i_{g} \eta_{t}}{r_{d}}
$$




\subsubsection{Verificação da capacidade térmica do motor}

O aquecimento e a capacidade de refrigeração do motor são características importantes a serem observadas na escolha do motor e no projeto do veículo. Como a vida útil do material isolante dos enrolamentos do motor é, aproximadamente, inversamente proporcional à sua temperatura de operação, é fundamental que o motor tenha a classe de isolação, que determina a sua temperatura máxima, escolhida adequadamente. Em geral, os motores de tração são de classe $\mathrm{H}\left(180^{\circ} \mathrm{C}\right)$ ou C (acima de $\left.180^{\circ} \mathrm{C}\right)$.

Uma peculiaridade da aplicação em tração é que, geralmente, o motor é mais solicitado em termos de torque e corrente quando o veículo está em baixas velocidades, e consequentemente, a refrigeração natural e com ventilador no próprio eixo do motor é deficiente. Assim, na maioria dos projetos, será necessário um sistema auxiliar de refrigeração forçada.

No mercado existem programas computacionais para efetuar a análise térmica de motores elétricos que podem ser adquiridos para auxiliar na execução da tarefa ou como alternativa, pode-se solicitar ao fabricante do motor que efetue esse levantamento a partir das condições de utilização do motor.

\subsubsection{Dimensionamento do controlador /conversor de potência}

Em princípio o controlador do motor e o conversor de potência são unidades distintas, mas cada vez mais têm sido construídos unificados para melhor aproveitamento de componentes, espaço e peso.

Como cada tipo de motor possui seu controlador específico e, apesar de serem de concepção complexa, seu uso tem sido simplificado através de recursos de programação e interfaces amigáveis desenvolvidas pelos fabricantes.

Além da função principal de controlar o motor para o fornecimento de um perfil torque-velocidade desejado, pode realizar funções como de proteção própria e do motor, verificação das conexões e monitoramento de parâmetros.

A potência do controlador/conversor de potência é calculada pela equação: 


$$
P_{c c}=\frac{P_{m}}{\eta_{m}}
$$

$\mathrm{Ou}$

$$
P_{c c}=\frac{P_{t}}{\eta_{m} \eta_{t}}
$$

\subsubsection{Dimensionamento da capacidade das baterias}

Para a determinação da capacidade de energia e capacidade de potência das baterias é necessário o conhecimento da aplicação do veículo com exatidão bem como a autonomia requerida.

Determina-se a curva de potência ao longo do ciclo de condução, pelo produto da força de tração e da velocidade instantânea e, através da integração no tempo, obtém-se a energia consumida no percurso, conforme descrito na revisão bibliográfica, através da equação:

$$
E_{\text {out }}=\int_{\text {tração }} P_{\text {tot }} d t+\int_{\text {frenagem }} P_{\text {reg }} d t
$$

A potência instantânea total consumida é dada por:

$$
P_{t o t}=\frac{V}{\eta_{t} \eta_{m} \eta_{c c}}\left[M g\left(f_{r} \cos (\propto)+\operatorname{sen}(\propto)\right)+\frac{1}{2} \rho_{\mathrm{a}} \mathrm{A}_{\mathrm{f}} \mathrm{C}_{\mathrm{D}}\left(\mathrm{V}-\mathrm{V}_{\mathrm{w}}\right)^{2}+\left(M+\frac{\left(i_{g}^{2} I+I_{w}\right)}{r_{d}^{2}}\right) \frac{d V(t)}{d t}\right] V(t)
$$

E a potência instantânea regenerada por:

$$
P_{t o t}=\frac{\xi V}{\eta_{t} \eta_{m} \eta_{c c}}\left[M g\left(f_{r} \cos (\propto)+\operatorname{sen}(\propto)\right)+\frac{1}{2} \rho_{\mathrm{a}} \mathrm{A}_{\mathrm{f}} \mathrm{C}_{\mathrm{D}}\left(\mathrm{V}-\mathrm{V}_{\mathrm{w}}\right)^{2}+\left(M+\frac{\left(i_{g}^{2} I+I_{w}\right)}{r_{d}^{2}}\right) \frac{d V(t)}{d t}\right] V(t)
$$

Conhecendo-se o numero de ciclos de condução que o veículo deve percorrer com uma carga das baterias, obtém-se a quantidade de energia necessária, ou seja, a capacidade de fornecimento de energia útil das baterias ${ }^{3}$ para autonomia total do veículo.

\footnotetext{
${ }^{3}$ Para alguns tipos de bateria, a capacidade nominal não é a capacidade de fornecimento de energia útil.
} 
Com relação à capacidade de potência, caso não se utilize outro dispositivo de armazenamento de energia, como os ultracapacitores, a capacidade de potência das baterias deverá ser igual ou superior à potência total consumida. Se forem utilizados ultracapacitores, a capacidade de potência das baterias deverá ser igual ou superior à diferença entre a potência total consumida e a potência dos ultracapacitores, conforme apresentado adiante.

\subsubsection{Dimensionamento do banco de ultracapacitores}

Embora alguns dos trabalhos, apresentados na revisão bibliográfica, mencionem que adicionar um banco de ultracapacitores em veículos elétricos a bateria faz pouco ou nenhum sentido do ponto de vista de custo e/ou desempenho do veículo, em aplicações onde o veículo é submetido a frequentes acelerações e desacelerações, um banco de ultracapacitores pode ajudar a melhorar o rendimento do sistema, o desempenho de aceleração e aumentar a vida útil das baterias (JINRUI et al., 2006; BURKE; MILLER; ZHAO, 2010).

Talvez ainda não compense a inclusão de um banco de ultracapacitores considerando-se a relação entre o custo e os benefícios ao preço atual. Todavia, a tendência é que os preços baixem com avanço da tecnologia e com a produção em maior escala.

De acordo com (FERREIRA et al., 2007), o limite de corrente do ultracapacitor é bastante elevado e a principal informação para o dimensionamento da capacitância é a quantidade de energia útil que ele deve ser capaz de transferir.

Ainda, segundo (FERREIRA et al., 2007), dimensionar o ultracapacitor para a condição de regeneração máxima de energia ou potência, pouco contribui para melhorar o desempenho dinâmico do veículo, sendo mais apropriado dimensionar o ultracapacitor para a situação de fornecimento máximo de energia, o que assegura obter melhor resposta dinâmica do veículo durante as acelerações sem aumentar muito o custo de aquisição dos ultracapacitores.

Assim, a capacitância do ultracapacitor $\left(C_{u c}\right)$ é determinada em termos da energia útil $\left(E_{u c}\right)$ e das tensões de operação mínima $\left(U_{u c m i n}\right)$ e máxima $\left(U_{u c m a x}\right)$. Como a tensão de operação do ultracapacitor deve corresponder à situação de energia 
média entre as tensões máxima e mínima, para que possa absorver ou fornecer energia, é possível escrever (FERREIRA et al., 2007):

$$
C_{u c}=2 \frac{2 E_{u c}}{U_{u c m a x}^{2}-U_{u c m i n}^{2}}
$$

Uma estratégia para dimensionamento da capacidade de potência das baterias e ultracapacitores é limitar a potência fornecida pelas baterias à potência média consumida pelo veículo em um ciclo de percurso e os capacitores fornecerem à diferença entre a potência total máxima consumida e a potência média consumida (BURKE; MILLER; ZHAO, 2010).

$$
P_{b a t}=\frac{1}{t} \int_{0}^{t} P_{t o t} d t
$$

e

$$
P_{u c}=P_{t o t}-P_{b a t}
$$

Para o dimensionamento da capacidade de energia dos ultracapacitores, toma-se o pulso de potência que resultar em maior energia, fornecido pelos ultracapacitores, e através da integração desse pulso de potência no intervalo de duração, obtém-se a quantidade de energia:

$$
E_{u c}=\int_{t_{1}}^{t_{2}} P_{u c}(t) d t
$$

Considera-se que o intervalo de tempo, entre picos de potência sucessivos, seja suficiente para a recarga dos ultracapacitores. 


\section{APLICAÇÃO E RESULTADOS}

Neste capítulo será mostrada uma aplicação prática da metodologia apresentada e os resultados obtidos. O objetivo era desenvolver uma linha de veículos elétricos e produzi-los em série para atender o mercado brasileiro, em 1994.

Robustez, simplicidade, baixo índice de falhas e custo eram questões fundamentais para a viabilidade do negócio. Outras empresas já haviam tentado produzir veículos elétricos, mas não obtiveram sucesso, deixando no mercado a imagem de que veículos elétricos a bateria não eram produtos com maturidade tecnológica suficiente para serem confiáveis.

Como visto na revisão bibliográfica, atualmente, os tipos de motores mais usados em tração elétrica são os de indução e os de imãs permanentes sem escovas, alimentados por baterias de lítio ou hidreto metálico de níquel.

$\mathrm{Na}$ época, em 1994, não havia disponibilidade no mercado de controladores/conversores de potência para o acionamento de motores de indução, motores de imãs permanentes sem escovas e motores de relutância chaveada. Principalmente, com custos e assistência pós-vendas que não inviabilizassem o produto final. Assim, a melhor opção ainda eram os motores de corrente contínua com escovas acionados por recortadores (choppers) com modulação de largura de pulso (PWM).

Nessa conjuntura e com limitados recursos computacionais, basicamente um computador pessoal com uma planilha de cálculos, comprovando a simplicidade da metodologia, foi levado adiante o projeto de desenvolvimento de veículos elétricos.

\subsection{CARACTERIZAÇÃO E APLICAÇÃO DO PRODUTO}

Veículo elétrico a bateria para transporte de matéria-prima, componentes e produtos acabados pelas áreas internas e externas de instalações fabris. 
5.2 ESPECIFICAÇÃO TÉCNICA

Tabela 5.1 - Especificação técnica

\begin{tabular}{|c|c|c|}
\hline PARÂMETRO & VALOR & UNIDADE \\
\hline Tara: & 600 & {$[\mathrm{~kg}]$} \\
\hline \multicolumn{3}{|l|}{ Autonomia: } \\
\hline - Percurso & 40 & {$[\mathrm{~km}]$} \\
\hline - Tempo & 2 & {$[\mathrm{~h}]$} \\
\hline Capacidade de carga: & 900 & {$[\mathrm{~kg}]$} \\
\hline \multicolumn{3}{|l|}{ Velocidade máxima: } \\
\hline - $0 \%$ carga em aclive de $0 \%$ & 19 & {$[\mathrm{~km} / \mathrm{h}]$} \\
\hline - $100 \%$ carga em aclive de $0 \%$ & 12 & {$[\mathrm{~km} / \mathrm{h}]$} \\
\hline \multicolumn{3}{|l|}{ Velocidade mínima: } \\
\hline - $0 \%$ carga em aclive de $20 \%$ & 12 & {$[\mathrm{~km} / \mathrm{h}]$} \\
\hline - $100 \%$ carga em aclive de $10 \%$ & 5 & {$[\mathrm{~km} / \mathrm{h}]$} \\
\hline \multicolumn{3}{|l|}{ Acelerações: } \\
\hline - 0 a 19 km/h (0\% carga/0\% aclive) & 10 & {$[\mathrm{~s}]$} \\
\hline - 0 a 12 km/h (100\%carga/0\%aclive) & 10 & {$[\mathrm{~s}]$} \\
\hline
\end{tabular}




\subsection{DADOS DEFINIDOS PELO PROJETO}

Tabela 5.2 - Dados definidos pelo projeto

\section{DADOS DE PROJETO}

SIMBOLO VALOR [UNID.]

\begin{tabular}{lccc}
\hline MASSA (TARA) & $\mathrm{M}$ & 600 & $\mathrm{~kg}$ \\
\hline COEFICIENTE DE RESIST. ROLAMENTO & $\mathrm{f}_{\mathrm{r}}$ & 0,013 & adimens. \\
\hline COEFICIENTE AERODINAMICO & $\mathrm{C}_{\mathrm{D}}$ & 0,80 & adimens. \\
\hline ÁREA FRONTAL DO VEÍCULO & $\mathrm{A}_{\mathrm{f}}$ & 2,31 & $\mathrm{~m} 2$ \\
\hline MOMENTO DE INÉRCIA DA & $\mathrm{I}$ & 0,06 & $\mathrm{~kg}-\mathrm{m} 2$ \\
\hline TRANSMISSÃO & $\mathrm{I}_{\mathrm{w}}$ & 1,33 & $\mathrm{~kg}-\mathrm{m} 2$ \\
\hline MOMENTO DE INÉRCIA DAS & $\mathrm{I}_{\mathrm{g}}$ & 12,55 & adimens. \\
RODAS/PNEUS & $\mathrm{r}_{\mathrm{d}}$ & 0,22 & $\mathrm{~m}$ \\
\hline RELAÇÃO DA TRANSMISSÃO & & & \\
\hline RAIO DINÂMICO DO PNEU & $\mathrm{g}$ & 9,81 & $\mathrm{~m} / \mathrm{s} 2$ \\
\hline & $\rho_{\mathrm{a}}$ & 1,25 & $\mathrm{~kg} / \mathrm{m} 3$ \\
\hline Aceleração da gravidade & & & \\
\hline Densidade do ar & & 18,5 & $\mathrm{pol}$ \\
\hline & & & \\
\hline Diâmetro nominal do pneu & & & \\
\hline & $\eta_{\mathrm{t}}$ & 0,93 & adimens. \\
\hline Rendimento da transmissão total & $\eta_{\mathrm{m}}$ & 0,85 & adimens. \\
\hline Rendimento do motor & $\eta_{\mathrm{cc}}$ & 0,93 & adimens. \\
\hline Rendimento do controlador/conversor de pot. & &
\end{tabular}




\subsection{CICLO DE CONDUÇÃO}

Este ciclo de condução, especifico, foi desenvolvido visando simular a operação do veículo dentro de uma fábrica.

O ciclo é composto por quatro partes que se repetem, sucessivamente, durante a autonomia de uma carga do banco de baterias, ao longo do período de trabalho do veículo estabelecido em oito horas, conforme sumarizado na Tabela 5.3 e mostrado graficamente na Figura 5.1.

O ciclo completo tem duração de 32 minutos (1920 segundos). Portanto, o período de trabalho é composto por 15 ciclos.

Posteriormente, o veículo é retirado de serviço para recarga das baterias por um período mínimo de seis horas ou o banco de baterias é substituído por um banco recarregado.

Tabela 5.3 - Ciclo de condução

\begin{tabular}{lccccc}
\hline PARÂMETRO & I & II & III & IV & UNIDADE \\
\hline Carga & $\mathbf{0}$ & $\mathbf{1 0 0}$ & $\mathbf{0}$ & $\mathbf{1 0 0}$ & {$[\%]$} \\
\hline Aclive & $\mathbf{0}$ & $\mathbf{0}$ & $\mathbf{2 0}$ & $\mathbf{1 0}$ & {$[\%]$} \\
\hline Velocidade máxima & $\mathbf{1 9}$ & $\mathbf{1 2}$ & $\mathbf{1 2}$ & $\mathbf{8}$ & {$[\mathrm{km} / \mathrm{h}]$} \\
\hline Tempo em movimento & 100 & 150 & 100 & 150 & {$[\mathrm{~s}]$} \\
\hline Tempo parado & 380 & 330 & 380 & 330 & {$[\mathrm{~s}]$} \\
\hline Tempo total & 480 & 480 & 480 & 480 & {$[\mathrm{~s}]$} \\
\hline
\end{tabular}




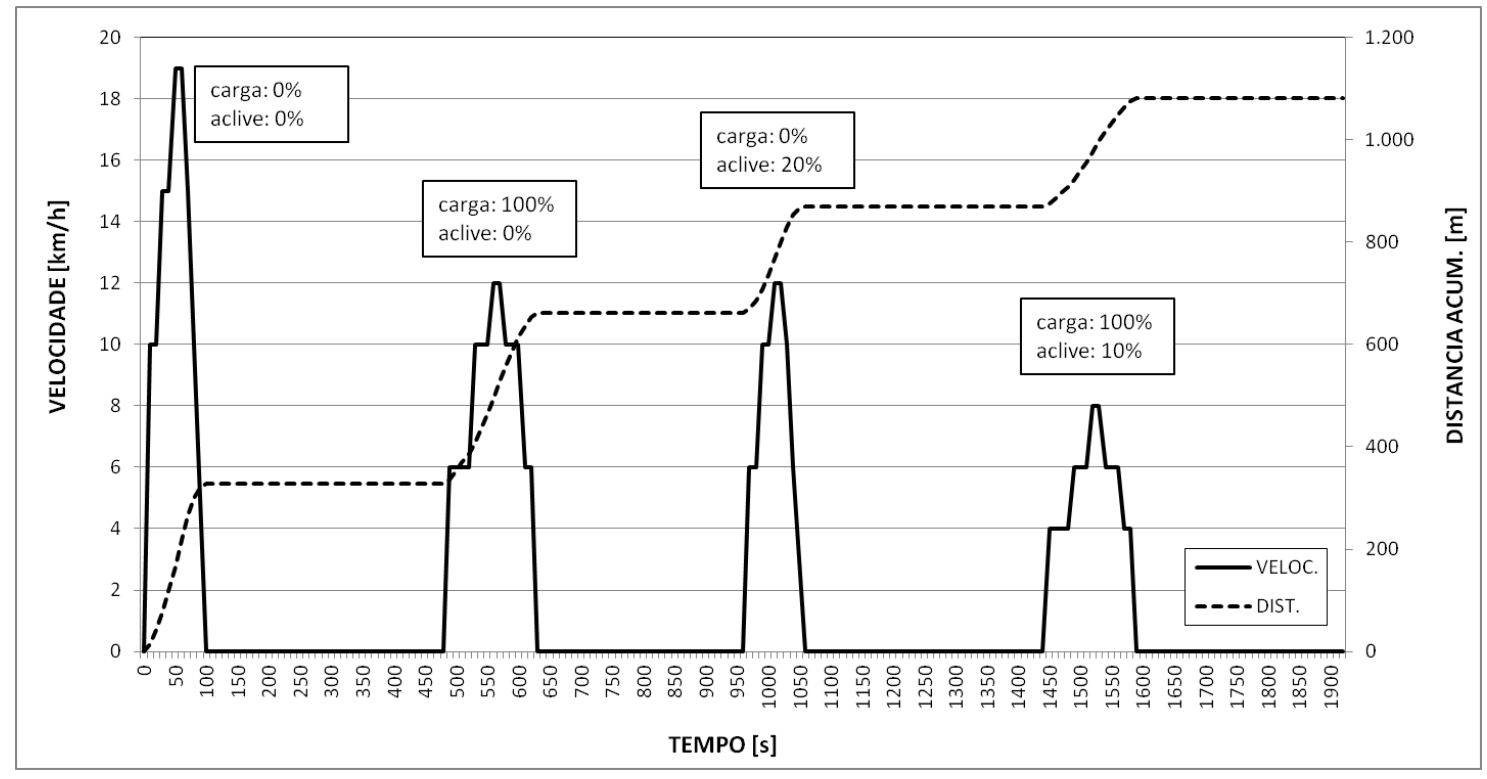

Figura 5.1 - Ciclo de condução

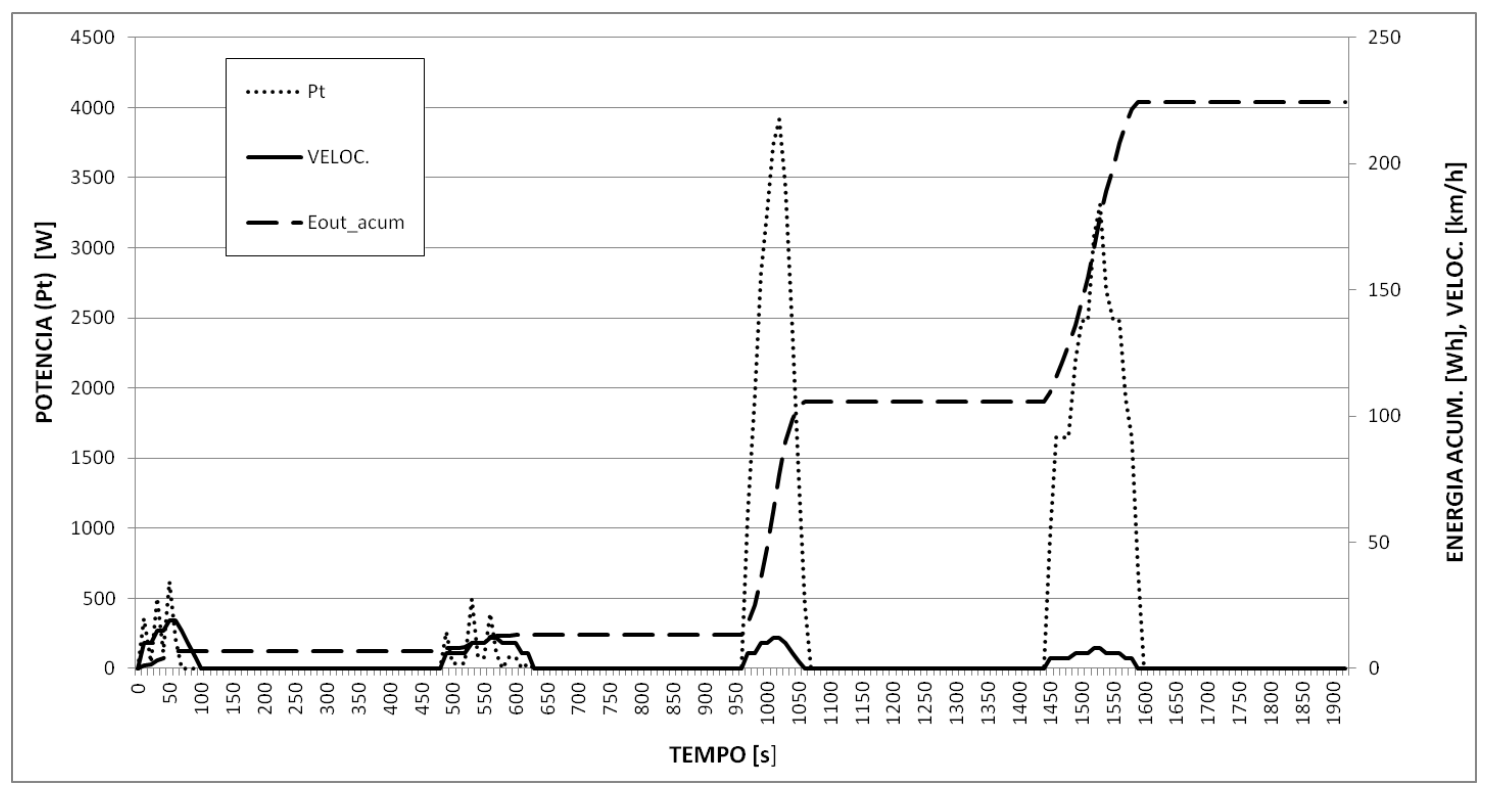

Figura 5.2 - Potência e energia consumida no ciclo de condução 


\subsection{PLANILHAS DE CÁLCULOS}

As planilhas, Figura 5.4, Figura 5.5, Figura 5.6 e Figura 5.7, mostram os resultados dos cálculos efetuados de acordo com a metodologia de dimensionamento apresentada em 4.7, no ciclo de condução discutido em 5.4. O algoritmo utilizado para os cálculos na planilha é dado na Figura 5.3. A potência para tração requerida nas rodas e a energia consumida em um ciclo são mostradas graficamente na Figura 5.2. 


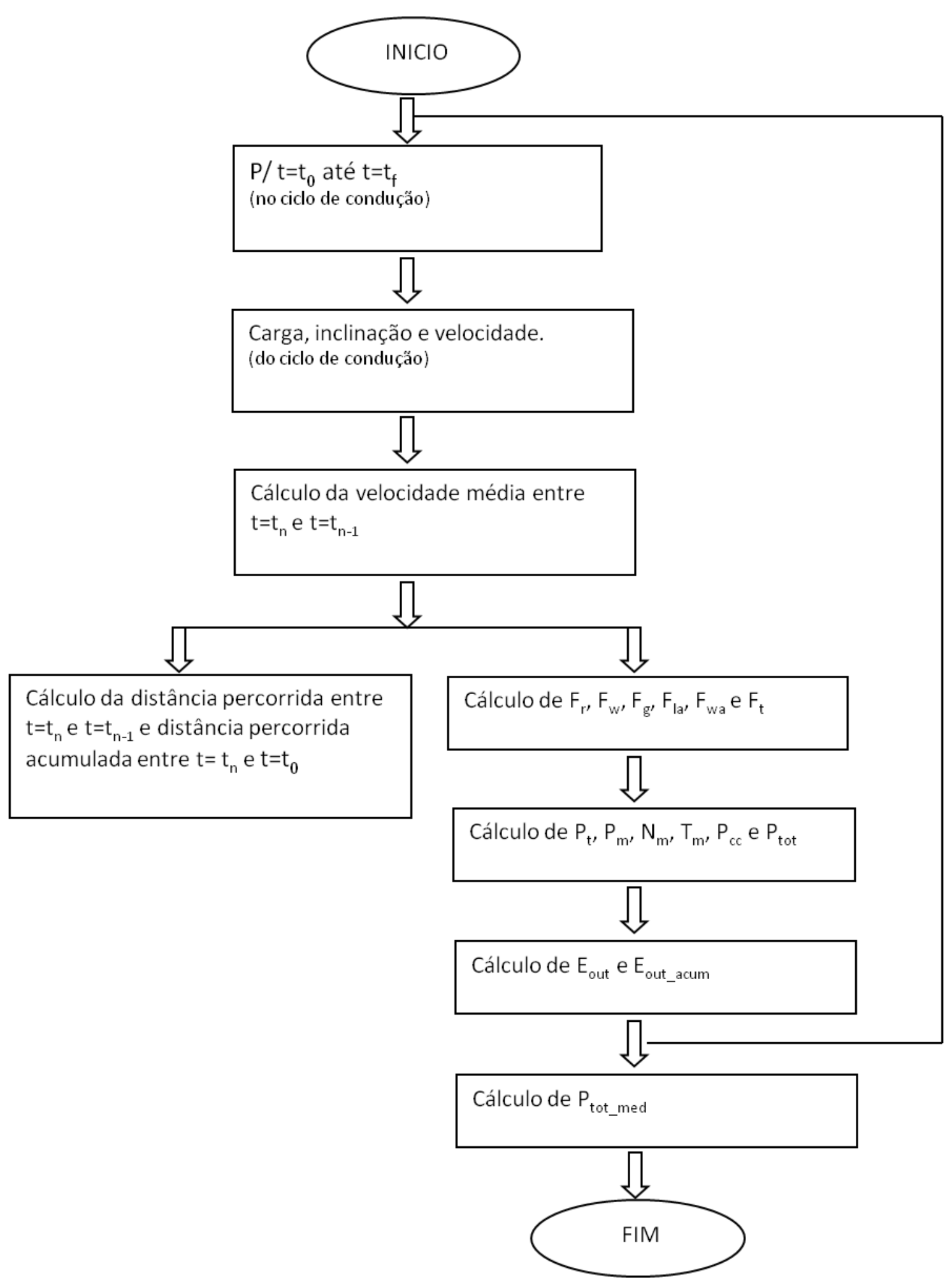

Figura 5.3 - Algoritmo para planilha de cálculos 
CICLO DE CONDUÇÃO - PARTE I

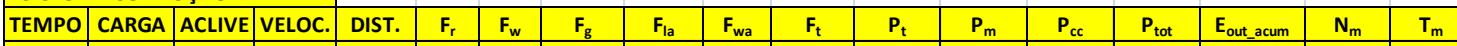

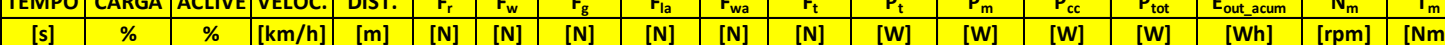
\begin{tabular}{|c|c|c|c|c|r|r|r|r|r|r|r|c|c|c|c|c|c|c|c|}
\hline 0 & $0 \%$ & $0 \%$ & 0 & 0 & 7,8 & 0,0 & 0,0 & 0 & 0 & $\mathbf{7 , 8}$ & $\mathbf{0}$ & $\mathbf{0}$ & $\mathbf{0}$ & $\mathbf{0}$ & $\mathbf{0}$ & 0 & 0,1 \\
\hline 10 & $0 \%$ & $0 \%$ & 10 & 14 & 7,8 & 2,2 & 0,0 & 166,7 & 79,0 & $\mathbf{2 5 5 , 7}$ & $\mathbf{3 5 5}$ & $\mathbf{3 8 2}$ & $\mathbf{4 4 9}$ & $\mathbf{4 8 3}$ & $\mathbf{1 , 3}$ & 1491 & 4,9 \\
\hline
\end{tabular} \begin{tabular}{|l|l|l|l|l|r|r|r|r|r|r|r|r|r|r|r|r|r|r|}
\hline 20 & $0 \%$ & $0 \%$ & 10 & 42 & 7,8 & 8,9 & 0,0 & 0,0 & 0,0 & $\mathbf{1 6 , 7}$ & $\mathbf{4 6}$ & $\mathbf{5 0}$ & $\mathbf{5 9}$ & $\mathbf{6 3}$ & $\mathbf{1 , 5}$ & 1491 & 0,3 \\
\hline 30 & $0 \%$ & $0 \%$ & 15 & 76 & 7,8 & 13,9 & 0,0 & 83,3 & 39,5 & $\mathbf{1 4 4 , 5}$ & $\mathbf{5 0 2}$ & $\mathbf{5 4 0}$ & $\mathbf{6 3 5}$ & $\mathbf{6 8 3}$ & $\mathbf{3 , 4}$ & $\mathbf{2 2 3 7}$ & 2,8 \\
\hline
\end{tabular} \begin{tabular}{|l|l|l|l|l|r|r|r|r|r|r|r|r|r|r|r|r|r|r|r|}
\hline 30 & $0 \%$ & $0 \%$ & 15 & 76 & 7,8 & 13,9 & 0,0 & 83,3 & 39,5 & $\mathbf{1 4 4 , 5}$ & $\mathbf{5 0 2}$ & $\mathbf{5 4 0}$ & $\mathbf{6 3 5}$ & $\mathbf{6 8 3}$ & $\mathbf{3 , 4}$ & 2237 & 2,8 \\
\hline 40 & $0 \%$ & $0 \%$ & 15 & 118 & 7,8 & 20,0 & 0,0 & 0,0 & 0,0 & $\mathbf{2 7 , 8}$ & $\mathbf{1 1 6}$ & $\mathbf{1 2 5}$ & $\mathbf{1 4 7}$ & $\mathbf{1 5 8}$ & $\mathbf{3 , 9}$ & 2237 & 0,5 \\
\hline
\end{tabular} \begin{tabular}{|l|l|l|l|l|l|l|r|r|r|r|r|r|r|r|r|r|r|}
\hline 50 & $0 \%$ & $0 \%$ & 19 & 165 & 7,8 & 25,7 & 0,0 & 66,7 & 31,6 & $\mathbf{1 3 1 , 8}$ & $\mathbf{6 2 2}$ & $\mathbf{6 6 9}$ & $\mathbf{7 8 7}$ & $\mathbf{8 4 7}$ & $\mathbf{6 , 2}$ & $\mathbf{2 8 3 4}$ & 2,5 \\
\hline 60 & $0 \%$ & $0 \%$ & 19 & 218 & 7,8 & 32,2 & 0,0 & 0,0 & 0,0 & $\mathbf{4 0 , 0}$ & $\mathbf{2 1 1}$ & $\mathbf{2 2 7}$ & $\mathbf{2 6 7}$ & $\mathbf{2 8 7}$ & $\mathbf{7 , 0}$ & $\mathbf{2 8 3 4}$ & 0,8 \\
\hline
\end{tabular} \begin{tabular}{|c|c|c|c|c|c|c|r|r|r|r|r|r|r|r|r|r|r|r|}
\hline 70 & $0 \%$ & $0 \%$ & 15 & 265 & 7,8 & 25,7 & 0,0 & $-66,7$ & $-31,6$ & $\mathbf{0 , 0}$ & $\mathbf{0}$ & $\mathbf{0}$ & $\mathbf{0}$ & $\mathbf{0}$ & $\mathbf{7 , 0}$ & 2237 & 0,0 \\
\hline 80
\end{tabular} \begin{tabular}{|c|c|c|c|c|r|r|r|r|r|r|r|r|r|r|r|r|r|}
\hline 80 & $0 \%$ & $0 \%$ & 10 & 300 & 7,8 & 13,9 & 0,0 & $-83,3$ & $-39,5$ & $\mathbf{0 , 0}$ & $\mathbf{0}$ & $\mathbf{0}$ & $\mathbf{0}$ & $\mathbf{0}$ & $\mathbf{7 , 0}$ & 1491 & 0,0 \\
\hline 90 & $0 \%$ & $0 \%$ & 5 & 321 & 7,8 & 5,0 & 0,0 & $-83,3$ & $-39,5$ & $\mathbf{0 , 0}$ & $\mathbf{0}$ & $\mathbf{0}$ & $\mathbf{0}$ & $\mathbf{0}$ & $\mathbf{7 , 0}$ & $\mathbf{7 4 6}$ & 0,0 \\
\hline
\end{tabular} \begin{tabular}{|c|c|c|c|c|c|c|c|c|c|c|c|c|c|c|c|c|c|c|}
\hline 100 & $0 \%$ & $0 \%$ & 0 & 328 & 7,8 & 0,6 & 0,0 & $-83,3$ & $-39,5$ & $\mathbf{0 , 0}$ & $\mathbf{0}$ & $\mathbf{0}$ & $\mathbf{0}$ & $\mathbf{0}$ & $\mathbf{7 , 0}$ & 0 & 0,0 \\
\hline
\end{tabular} \begin{tabular}{|l|l|l|l|l|l|l|l|l|l|l|l|l|l|l|l|l|l|}
\hline 110 & $0 \%$ & $0 \%$ & 0 & 328 & 7,8 & 0,0 & 0,0 & 0,0 & 0,0 & $\mathbf{7 , 8}$ & $\mathbf{0}$ & $\mathbf{0}$ & $\mathbf{0}$ & $\mathbf{0}$ & $\mathbf{7 , 0}$ & 0 & 0,1 \\
\hline 120 & $0 \%$ & $0 \%$ & 0 & 328 & 7,8 & 0,0 & 0,0 & 0,0 & 0,0 & $\mathbf{7 , 8}$ & $\mathbf{0}$ & $\mathbf{0}$ & $\mathbf{0}$ & $\mathbf{0}$ & $\mathbf{7 , 0}$ & 0 & 0,1 \\
\hline
\end{tabular} \begin{tabular}{|l|l|l|l|l|l|l|l|l|l|l|l|l|l|l|l|l|l|l|}
\hline 130 & $0 \%$ & $0 \%$ & 0 & 328 & 7,8 & 0,0 & 0,0 & 0,0 & 0,0 & $\mathbf{7 , 8}$ & $\mathbf{0}$ & $\mathbf{0}$ & $\mathbf{0}$ & $\mathbf{0}$ & $\mathbf{7 , 0}$ & 0 & 0,1 \\
\hline
\end{tabular} \begin{tabular}{|l|l|l|l|l|l|l|l|l|l|l|l|l|l|l|l|l|l|l|l|}
\hline 140 & $0 \%$ & $0 \%$ & 0 & 328 & 7,8 & 0,0 & 0,0 & 0,0 & 0,0 & $\mathbf{7 , 8}$ & $\mathbf{0}$ & $\mathbf{0}$ & $\mathbf{0}$ & $\mathbf{0}$ & $\mathbf{7 , 0}$ & 0 & 0,1 \\
\hline
\end{tabular} \begin{tabular}{|l|l|l|l|l|l|l|l|l|l|l|l|l|l|l|l|l|l|l|}
\hline 150 & $0 \%$ & $0 \%$ & 0 & 328 & 7,8 & 0,0 & 0,0 & 0,0 & 0,0 & $\mathbf{7 , 8}$ & $\mathbf{0}$ & $\mathbf{0}$ & $\mathbf{0}$ & $\mathbf{0}$ & $\mathbf{7 , 0}$ & 0 & 0,1 \\
\hline
\end{tabular} \begin{tabular}{|l|l|l|l|l|l|l|l|l|l|l|l|l|l|l|l|l|l|}
\hline 160 & $0 \%$ & $0 \%$ & 0 & 328 & 7,8 & 0,0 & 0,0 & 0,0 & 0,0 & $\mathbf{7 , 8}$ & $\mathbf{0}$ & $\mathbf{0}$ & $\mathbf{0}$ & $\mathbf{0}$ & $\mathbf{7 , 0}$ & 0 & 0,1 \\
\hline
\end{tabular} \begin{tabular}{|l|l|l|l|l|l|l|l|l|l|l|l|l|l|l|l|l|l|}
\hline 170 & $0 \%$ & $0 \%$ & 0 & 328 & 7,8 & 0,0 & 0,0 & 0,0 & 0,0 & $\mathbf{7 , 8}$ & $\mathbf{0}$ & $\mathbf{0}$ & $\mathbf{0}$ & $\mathbf{0}$ & $\mathbf{7 , 0}$ & 0 & 0,1 \\
\hline 180 & $0 \%$ & $0 \%$ & 0 & 328 & 7,8 & 0,0 & 0,0 & 0,0 & 0,0 & $\mathbf{7 , 8}$ & $\mathbf{0}$ & $\mathbf{0}$ & $\mathbf{0}$ & $\mathbf{0}$ & $\mathbf{7 , 0}$ & 0 & 0,1 \\
\hline
\end{tabular} \begin{tabular}{|l|l|l|l|l|l|l|l|l|l|l|l|l|l|l|l|l|}
\hline 190 & $0 \%$ & $0 \%$ & 0 & 328 & 7,8 & 0,0 & 0,0 & 0,0 & 0,0 & $\mathbf{7 , 8}$ & $\mathbf{0}$ & $\mathbf{0}$ & $\mathbf{0}$ & $\mathbf{0}$ & $\mathbf{7 , 0}$ & 0 \\
\hline
\end{tabular} \begin{tabular}{|l|l|l|l|l|l|l|l|l|l|l|l|l|l|l|l|l|l|l|}
200 & $0 \%$ & $0 \%$ & 0 & 328 & 7,8 & 0,0 & 0,0 & 0,0 & 0,0 & $\mathbf{7 , 8}$ & $\mathbf{0}$ & $\mathbf{0}$ & $\mathbf{0}$ & $\mathbf{0}$ & $\mathbf{7 , 0}$ & 0 & 0,1 \\
\hline 210 & $0 \%$ & $0 \%$ & 0 & 328 & 7,8 & 0,0 & 0,0 & 0,0 & 0,0 & $\mathbf{7 , 8}$ & $\mathbf{0}$ & $\mathbf{0}$ & $\mathbf{0}$ & $\mathbf{0}$ & $\mathbf{7 , 0}$ & 0 & 0,1 \\
\hline
\end{tabular} \begin{tabular}{|l|l|l|l|l|l|l|l|l|l|l|l|l|}
\hline 210 & $0 \%$ & $0 \%$ & 0 & 328 & 7,8 & 0,0 & 0,0 & 0,0 & 0,0 & 7,8 & 0 \\
\hline 220 & $0 \%$ & $0 \%$ & 0 & 328 & 7,8 & 0,0 & 0,0 & 0,0 & 0,0 & 7,8 & 0 \\
\hline
\end{tabular} \begin{tabular}{|l|l|l|l|l|l|l|l|l|l|l|l|l|l|l|l|l|l|l|l|l|l|}
\hline 220 & $0 \%$ & $0 \%$ & 0 & 328 & 7,8 & 0,0 & 0,0 & 0,0 & 0,0 & $\mathbf{7 , 8}$ & $\mathbf{0}$ & $\mathbf{0}$ & $\mathbf{0}$ & $\mathbf{0}$ & $\mathbf{7 , 0}$ & 0 & 0,1 \\
\hline 230 & $0 \%$ & $0 \%$ & 0 & 328 & 7,8 & 0,0 & 0,0 & 0,0 & 0,0 & $\mathbf{7 , 8}$ & $\mathbf{0}$ & $\mathbf{0}$ & $\mathbf{0}$ & $\mathbf{0}$ & $\mathbf{7 , 0}$ & 0 & 0,1 \\
\hline
\end{tabular} \begin{tabular}{|l|l|l|l|l|l|l|l|l|l|l|l|l|l|l|l|l|l|}
\hline 240 & $0 \%$ & $0 \%$ & 0 & 328 & 7,8 & 0,0 & 0,0 & 0,0 & 0,0 & $\mathbf{7 , 8}$ & $\mathbf{0}$ & $\mathbf{0}$ & $\mathbf{0}$ & $\mathbf{0}$ & $\mathbf{7 , 0}$ & 0 & 0,1 \\
\hline
\end{tabular}

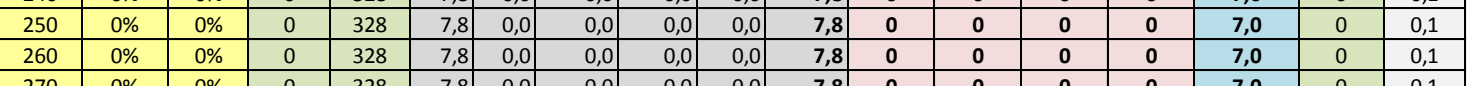
\begin{tabular}{|l|l|l|l|l|l|l|l|l|l|l|l|l|l|l|l|l|}
270 & $0 \%$ & $0 \%$ & 0 & 328 & 7,8 & 0,0 & 0,0 & 0,0 & 0,0 & $\mathbf{7 , 8}$ & $\mathbf{0}$ & $\mathbf{0}$ & $\mathbf{0}$ & $\mathbf{0}$ & $\mathbf{7 , 0}$ & 0 \\
\hline
\end{tabular}

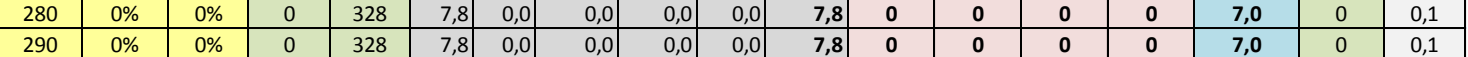
\begin{tabular}{|l|l|l|l|l|l|l|l|l|l|l|l|l|l|l|l|l|l|}
\hline 300 & $0 \%$ & $0 \%$ & 0 & 328 & 7,8 & 0,0 & 0,0 & 0,0 & 0,0 & $\mathbf{7 , 8}$ & $\mathbf{0}$ & $\mathbf{0}$ & $\mathbf{0}$ & $\mathbf{0}$ & $\mathbf{7 , 0}$ & 0 & 0,1 \\
\hline
\end{tabular} \begin{tabular}{|l|l|l|l|l|l|l|l|l|l|l|l|l|l|l|l|l|l|l|}
\hline 310 & $0 \%$ & $0 \%$ & 0 & 328 & 7,8 & 0,0 & 0,0 & 0,0 & 0,0 & $\mathbf{7 , 8}$ & $\mathbf{0}$ & $\mathbf{0}$ & $\mathbf{0}$ & $\mathbf{0}$ & $\mathbf{7 , 0}$ & 0 & 0,1 \\
\hline 320 & $0 \%$ & $0 \%$ & 0 & 328 & 7,8 & 0,0 & 0,0 & 0,0 & 0,0 & $\mathbf{7 , 8}$ & $\mathbf{0}$ & $\mathbf{0}$ & $\mathbf{0}$ & $\mathbf{0}$ & $\mathbf{7 , 0}$ \\
\hline
\end{tabular} \begin{tabular}{|l|l|l|l|l|l|l|l|l|l|l|l|l|l|l|l|l|}
\hline 320 & $0 \%$ & $0 \%$ & 0 & 328 & 7,8 & 0,0 & 0,0 & 0,0 & 0,0 & $\mathbf{7 , 8}$ & $\mathbf{0}$ & $\mathbf{0}$ & $\mathbf{0}$ & $\mathbf{0}$ & $\mathbf{7 , 0}$ & 0 \\
\hline 330 & $0 \%$ & $0 \%$ & 0 & 328 & 7,8 & 0,0 & 0,0 & 0,0 & 0,0 & $\mathbf{7 , 8}$ & $\mathbf{0}$ & $\mathbf{0}$ & $\mathbf{0}$ & $\mathbf{0}$ & $\mathbf{7 , 0}$ & 0 \\
\hline
\end{tabular}

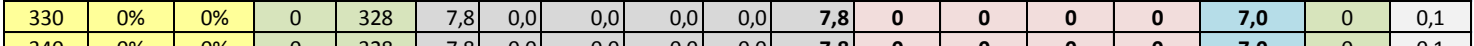

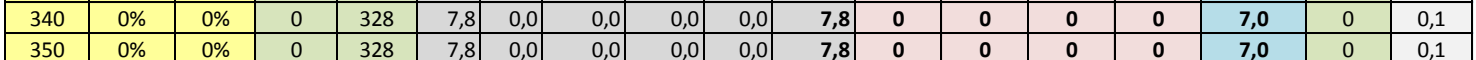
\begin{tabular}{|l|l|l|l|l|l|l|l|l|l|l|l|l|l|l|l|l|l|}
\hline 360 & $0 \%$ & $0 \%$ & 0 & 328 & 7,8 & 0,0 & 0,0 & 0,0 & 0,0 & $\mathbf{7 , 8}$ & $\mathbf{0}$ & $\mathbf{0}$ & $\mathbf{0}$ & $\mathbf{0}$ & $\mathbf{7 , 0}$ & 0 & 0,1 \\
\hline
\end{tabular} \begin{tabular}{|l|l|l|l|l|l|l|l|l|l|l|l|l|l|l|l|l|l|}
\hline 360 & $0 \%$ & $0 \%$ & 0 & 328 & 7,8 & 0,0 & 0,0 & 0,0 & 0,0 & $\mathbf{7 , 8}$ & $\mathbf{0}$ & $\mathbf{0}$ & $\mathbf{0}$ & $\mathbf{0}$ & $\mathbf{7 , 0}$ & 0 & 0,1 \\
\hline 370 & $0 \%$ & $0 \%$ & 0 & 328 & 7,8 & 0,0 & 0,0 & 0,0 & 0,0 & $\mathbf{7 , 8}$ & $\mathbf{0}$ & $\mathbf{0}$ & $\mathbf{0}$ & $\mathbf{0}$ & $\mathbf{7 , 0}$ & 0 & 0,1 \\
\hline
\end{tabular}

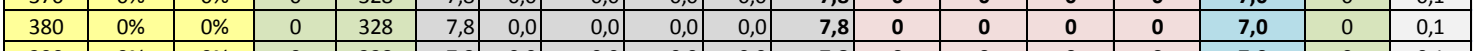

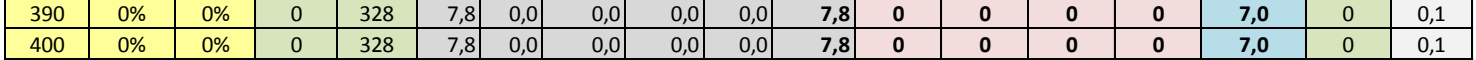
\begin{tabular}{|l|l|l|l|l|l|l|l|l|l|l|l|l|l|l|l|l|}
\hline 410 & $0 \%$ & $0 \%$ & 0 & 328 & 7,8 & 0,0 & 0,0 & 0,0 & 0,0 & $\mathbf{7 , 8}$ & $\mathbf{0}$ & $\mathbf{0}$ & $\mathbf{0}$ & $\mathbf{0}$ & $\mathbf{7 , 0}$ & 0 \\
\hline
\end{tabular}

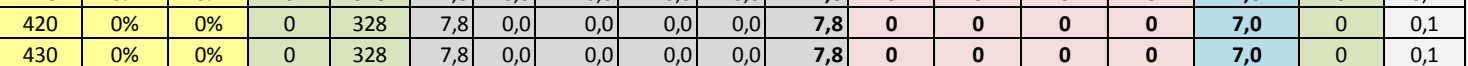
\begin{tabular}{|l|l|l|l|l|l|l|l|l|l|l|l|l|l|l|l|l|l|}
\hline 440 & $0 \%$ & $0 \%$ & 0 & 328 & 7,8 & 0,0 & 0,0 & 0,0 & 0,0 & $\mathbf{7 , 8}$ & $\mathbf{0}$ & $\mathbf{0}$ & $\mathbf{0}$ & $\mathbf{0}$ & $\mathbf{7 , 0}$ & 0 & 0,1 \\
\hline
\end{tabular} \begin{tabular}{|l|l|l|l|l|l|l|l|l|l|l|l|l|l|l|l|l|l|}
\hline 450 & $0 \%$ & $0 \%$ & 0 & 328 & 7,8 & 0,0 & 0,0 & 0,0 & 0,0 & $\mathbf{7 , 8}$ & $\mathbf{0}$ & $\mathbf{0}$ & $\mathbf{0}$ & $\mathbf{0}$ & $\mathbf{7 , 0}$ & 0 & 0,1 \\
\hline 460 & $0 \%$ & $0 \%$ & 0 & 328 & 7,8 & 0,0 & 0,0 & 0,0 & 0,0 & $\mathbf{7 , 8}$ & $\mathbf{0}$ & $\mathbf{0}$ & $\mathbf{0}$ & $\mathbf{0}$ & $\mathbf{7 , 0}$ & 0 & 0,1 \\
\hline
\end{tabular} \begin{tabular}{|l|l|l|l|l|l|l|l|l|l|l|l|l|l|l|l|l|}
\hline 470 & $0 \%$ & $0 \%$ & 0 & 328 & 7,8 & 0,0 & 0,0 & 0,0 & 0,0 & $\mathbf{7 , 8}$ & $\mathbf{0}$ & $\mathbf{0}$ & $\mathbf{0}$ & $\mathbf{0}$ & $\mathbf{7 , 0}$ & 0 \\
\hline
\end{tabular}

Figura 5.4 - Planilha de cálculos (parte I) 


\begin{tabular}{|c|c|c|c|c|c|c|c|c|c|c|c|c|c|c|c|c|c|}
\hline \multicolumn{4}{|c|}{ CICLO DE CONDUÇÃO - PARTE II } & \multirow[b]{2}{*}{ DIST. } & \multirow[b]{2}{*}{$F_{r}$} & \multirow[b]{2}{*}{$F_{w}$} & \multirow[b]{2}{*}{$F_{g}$} & \multirow[b]{2}{*}{$F_{\mathrm{la}}$} & \multirow[b]{2}{*}{$F_{\text {wa }}$} & \multirow[b]{2}{*}{$F_{t}$} & \multirow[b]{2}{*}{$\mathbf{P}_{\mathrm{t}}$} & \multirow[b]{2}{*}{$\mathbf{P}_{\mathrm{m}}$} & \multirow[b]{2}{*}{$\mathbf{P}_{\mathrm{cc}}$} & \multirow[b]{2}{*}{$P_{\text {tot }}$} & \multirow[b]{2}{*}{$E_{\text {out_acum }}$} & \multirow[b]{2}{*}{$\mathbf{N}_{\mathrm{m}}$} & \multirow[b]{2}{*}{$T_{m}$} \\
\hline TEMPO & CARGA & ACLIVE & VELOC. & & & & & & & & & & & & & & \\
\hline$[\mathrm{s}]$ & $\%$ & $\%$ & {$[\mathrm{~km} / \mathrm{h}]$} & {$[\mathrm{m}]$} & {$[\mathrm{N}]$} & {$[\mathrm{N}]$} & {$[\mathrm{N}]$} & {$[\mathrm{N}]$} & {$[\mathrm{N}]$} & {$[\mathrm{N}]$} & {$[\mathrm{W}]$} & {$[W]$} & [W] & [W] & [Wh] & [rpm] & {$[\mathrm{Nm}]$} \\
\hline 480 & $100 \%$ & $0 \%$ & 0 & 328 & 19,5 & 0,0 & 0,0 & 0,0 & 0,0 & 19,5 & 0 & 0 & 0 & 0 & 7,0 & 0 & 0,4 \\
\hline 490 & $100 \%$ & $0 \%$ & 6 & 336 & 19,5 & 0,8 & 0,0 & 250,0 & 47,4 & 317,7 & 265 & 285 & 335 & 360 & 8,0 & 895 & 6,1 \\
\hline 500 & $100 \%$ & $0 \%$ & 6 & 353 & 19,5 & 3,2 & 0,0 & 0,0 & 0,0 & 22,7 & 38 & 41 & 48 & 51 & 8,1 & 895 & 0,4 \\
\hline 510 & $100 \%$ & $0 \%$ & 6 & 369 & 19,5 & 3,2 & 0,0 & 0,0 & 0,0 & 22,7 & 38 & 41 & 48 & 51 & 8,3 & 895 & 0,4 \\
\hline 520 & $100 \%$ & $0 \%$ & 6 & 386 & 19,5 & 3,2 & 0,0 & 0,0 & 0,0 & 22,7 & 38 & 41 & 48 & 51 & 8,4 & 895 & 0,4 \\
\hline 530 & $100 \%$ & $0 \%$ & 10 & 408 & 19,5 & 5,7 & 0,0 & 166,7 & 31,6 & 223,5 & 497 & 534 & 628 & 675 & 10,3 & 1491 & 4,3 \\
\hline 540 & $100 \%$ & $0 \%$ & 10 & 436 & 19,5 & 8,9 & 0,0 & 0,0 & 0,0 & 28,4 & 79 & 85 & 100 & 107 & 10,6 & 1491 & 0,5 \\
\hline 550 & $100 \%$ & $0 \%$ & 10 & 464 & 19,5 & 8,9 & 0,0 & 0,0 & 0,0 & 28,4 & 79 & 85 & 100 & 107 & 10,9 & 1491 & 0,5 \\
\hline 560 & $100 \%$ & $0 \%$ & 12 & 494 & 19,5 & 10,8 & 0,0 & 83,3 & 15,8 & 129,4 & 395 & 425 & 500 & 538 & 12,4 & 1790 & 2,5 \\
\hline 570 & $100 \%$ & $0 \%$ & 12 & 528 & 19,5 & 12,8 & 0,0 & 0,0 & 0,0 & 32,3 & 108 & 116 & 136 & 147 & 12,8 & 1790 & 0,6 \\
\hline 580 & $100 \%$ & $0 \%$ & 10 & 558 & 19,5 & 10,8 & 0,0 & $-83,3$ & $-15,8$ & 0,0 & 0 & 0 & 0 & 0 & 12,8 & 1491 & 0,0 \\
\hline 590 & $100 \%$ & $0 \%$ & 10 & 586 & 19,5 & 8,9 & 0,0 & 0,0 & 0,0 & 28,4 & 79 & 85 & 100 & 107 & 13,1 & 1491 & 0,5 \\
\hline 600 & $100 \%$ & $0 \%$ & 10 & 614 & 19,5 & 8,9 & 0,0 & 0,0 & 0,0 & 28,4 & 79 & 85 & 100 & 107 & 13,4 & 1491 & 0,5 \\
\hline 610 & $100 \%$ & $0 \%$ & 6 & 636 & 19,5 & 5,7 & 0,0 & $-166,7$ & $-31,6$ & 0,0 & 0 & 0 & 0 & 0 & 13,4 & 895 & 0,0 \\
\hline 620 & $100 \%$ & $0 \%$ & 6 & 653 & 19,5 & 3,2 & 0,0 & 0,0 & 0,0 & 22,7 & 38 & 41 & 48 & 51 & 13,5 & 895 & 0,4 \\
\hline 630 & $100 \%$ & $0 \%$ & 0 & 661 & 19,5 & 0,8 & 0,0 & $-250,0$ & $-47,4$ & 0,0 & 0 & 0 & 0 & 0 & 13,5 & 0 & 0,0 \\
\hline 640 & $0 \%$ & $0 \%$ & 0 & 661 & 7,8 & 0,0 & 0,0 & 0,0 & 0,0 & 7,8 & 0 & 0 & 0 & 0 & 13,5 & 0 & 0,1 \\
\hline 650 & $0 \%$ & $0 \%$ & 0 & 661 & 7,8 & 0,0 & 0,0 & 0,0 & 0,0 & 7,8 & 0 & 0 & 0 & 0 & 13,5 & 0 & 0,1 \\
\hline 660 & $0 \%$ & $0 \%$ & 0 & 661 & 7,8 & 0,0 & 0,0 & 0,0 & 0,0 & 7,8 & 0 & 0 & 0 & 0 & 13,5 & 0 & 0,1 \\
\hline 670 & $0 \%$ & $0 \%$ & 0 & 661 & 7,8 & 0,0 & 0,0 & 0,0 & 0,0 & 7,8 & 0 & 0 & 0 & 0 & 13,5 & 0 & 0,1 \\
\hline 680 & $0 \%$ & $0 \%$ & 0 & 661 & 7,8 & 0,0 & 0,0 & 0,0 & 0,0 & 7,8 & 0 & 0 & 0 & 0 & 13,5 & 0 & 0,1 \\
\hline 690 & $0 \%$ & $0 \%$ & 0 & 661 & 7,8 & 0,0 & 0,0 & 0,0 & 0,0 & 7,8 & 0 & 0 & 0 & 0 & 13,5 & 0 & 0,1 \\
\hline 700 & $0 \%$ & $0 \%$ & 0 & 661 & 7,8 & 0,0 & 0,0 & 0,0 & 0,0 & 7,8 & 0 & 0 & 0 & 0 & 13,5 & 0 & 0,1 \\
\hline 710 & $0 \%$ & $0 \%$ & 0 & 661 & 7,8 & 0,0 & 0,0 & 0,0 & 0,0 & 7,8 & 0 & 0 & 0 & 0 & 13,5 & 0 & 0,1 \\
\hline 720 & $0 \%$ & $0 \%$ & 0 & 661 & 7,8 & 0,0 & 0,0 & 0,0 & 0,0 & 7,8 & 0 & 0 & 0 & 0 & 13,5 & 0 & 0,1 \\
\hline 730 & $0 \%$ & $0 \%$ & 0 & 661 & 7,8 & 0,0 & 0,0 & 0,0 & 0,0 & 7,8 & 0 & 0 & 0 & 0 & 13,5 & 0 & 0,1 \\
\hline 740 & $0 \%$ & $0 \%$ & 0 & 661 & 7,8 & 0,0 & 0,0 & 0,0 & 0,0 & 7,8 & 0 & 0 & 0 & 0 & 13,5 & 0 & 0,1 \\
\hline 750 & $0 \%$ & $0 \%$ & 0 & 661 & 7,8 & 0,0 & 0,0 & 0,0 & 0,0 & 7,8 & 0 & 0 & 0 & 0 & 13,5 & 0 & 0,1 \\
\hline 760 & $0 \%$ & $0 \%$ & 0 & 661 & 7,8 & 0,0 & 0,0 & 0,0 & 0,0 & 7,8 & 0 & 0 & 0 & 0 & 13,5 & 0 & 0,1 \\
\hline 770 & $0 \%$ & $0 \%$ & 0 & 661 & 7,8 & 0,0 & 0,0 & 0,0 & 0,0 & 7,8 & 0 & 0 & 0 & 0 & 13,5 & 0 & 0,1 \\
\hline 780 & $0 \%$ & $0 \%$ & 0 & 661 & 7,8 & 0,0 & 0,0 & 0,0 & 0,0 & 7,8 & 0 & 0 & 0 & 0 & 13,5 & 0 & 0,1 \\
\hline 790 & $0 \%$ & $0 \%$ & 0 & 661 & 7,8 & 0,0 & 0,0 & 0,0 & 0,0 & 7,8 & 0 & 0 & 0 & 0 & 13,5 & 0 & 0,1 \\
\hline 800 & $0 \%$ & $0 \%$ & 0 & 661 & 7,8 & 0,0 & 0,0 & 0,0 & 0,0 & 7,8 & 0 & 0 & 0 & 0 & 13,5 & 0 & 0,1 \\
\hline 810 & $0 \%$ & $0 \%$ & 0 & 661 & 7,8 & 0,0 & 0,0 & 0,0 & 0,0 & 7,8 & 0 & 0 & 0 & 0 & 13,5 & 0 & 0,1 \\
\hline 820 & $0 \%$ & $0 \%$ & 0 & 661 & 7,8 & 0,0 & 0,0 & 0,0 & 0,0 & 7,8 & 0 & 0 & 0 & 0 & 13,5 & 0 & 0,1 \\
\hline 830 & $0 \%$ & $0 \%$ & 0 & 661 & 7,8 & 0,0 & 0,0 & 0,0 & 0,0 & 7,8 & 0 & 0 & 0 & 0 & 13,5 & 0 & 0,1 \\
\hline 840 & $0 \%$ & $0 \%$ & 0 & 661 & 7,8 & 0,0 & 0,0 & 0,0 & 0,0 & 7,8 & 0 & 0 & 0 & 0 & 13,5 & 0 & 0,1 \\
\hline 850 & $0 \%$ & $0 \%$ & 0 & 661 & 7,8 & 0,0 & 0,0 & 0,0 & 0,0 & 7,8 & 0 & 0 & 0 & 0 & 13,5 & 0 & 0,1 \\
\hline 860 & $0 \%$ & $0 \%$ & 0 & 661 & 7,8 & 0,0 & 0,0 & 0,0 & 0,0 & 7,8 & 0 & 0 & 0 & 0 & 13,5 & 0 & 0,1 \\
\hline 870 & $0 \%$ & $0 \%$ & 0 & 661 & 7,8 & 0,0 & 0,0 & 0,0 & 0,0 & 7,8 & 0 & 0 & 0 & 0 & 13,5 & 0 & 0,1 \\
\hline 880 & $0 \%$ & $0 \%$ & 0 & 661 & 7,8 & 0,0 & 0,0 & 0,0 & 0,0 & 7,8 & 0 & 0 & 0 & 0 & 13,5 & 0 & 0,1 \\
\hline 890 & $0 \%$ & $0 \%$ & 0 & 661 & 7,8 & 0,0 & 0,0 & 0,0 & 0,0 & 7,8 & 0 & 0 & 0 & 0 & 13,5 & 0 & 0,1 \\
\hline 900 & $0 \%$ & $0 \%$ & 0 & 661 & 7,8 & 0,0 & 0,0 & 0,0 & 0,0 & 7,8 & 0 & 0 & 0 & 0 & 13,5 & 0 & 0,1 \\
\hline 910 & $0 \%$ & $0 \%$ & 0 & 661 & 7,8 & 0,0 & 0,0 & 0,0 & 0,0 & 7,8 & 0 & 0 & 0 & 0 & 13,5 & 0 & 0,1 \\
\hline 920 & $0 \%$ & $0 \%$ & 0 & 661 & 7,8 & 0,0 & 0,0 & 0,0 & 0,0 & 7,8 & 0 & 0 & 0 & 0 & 13,5 & 0 & 0,1 \\
\hline 930 & $0 \%$ & $0 \%$ & 0 & 661 & 7,8 & 0,0 & 0,0 & 0,0 & 0,0 & 7,8 & 0 & 0 & 0 & 0 & 13,5 & 0 & 0,1 \\
\hline 940 & $0 \%$ & $0 \%$ & 0 & 661 & 7,8 & 0,0 & 0,0 & 0,0 & 0,0 & 7,8 & 0 & 0 & 0 & 0 & 13,5 & 0 & 0,1 \\
\hline 950 & $0 \%$ & $0 \%$ & 0 & 661 & 7,8 & 0,0 & 0,0 & 0,0 & 0,0 & 7,8 & 0 & 0 & 0 & 0 & 13,5 & 0 & 0,1 \\
\hline
\end{tabular}

Figura 5.5 - Planilha de cálculos (parte II) 


\begin{tabular}{|c|c|c|c|c|c|c|c|c|c|c|c|c|c|c|c|c|c|}
\hline \multicolumn{4}{|c|}{ CICLO DE CONDUÇÃO - PARTE III } & \multirow[b]{2}{*}{ DIST. } & \multirow[b]{2}{*}{$\mathbf{F}_{\mathrm{r}}$} & \multirow[b]{2}{*}{$F_{w}$} & \multirow[b]{2}{*}{$F_{g}$} & \multirow[b]{2}{*}{$F_{\mathrm{la}}$} & \multirow[b]{2}{*}{$F_{\text {wa }}$} & \multirow[b]{2}{*}{$F_{t}$} & \multirow[b]{2}{*}{$\mathbf{P}_{\mathrm{t}}$} & \multirow[b]{2}{*}{$\mathbf{P}_{\mathrm{m}}$} & \multirow[b]{2}{*}{$\mathbf{P}_{\mathrm{cc}}$} & \multirow[b]{2}{*}{$P_{\text {tot }}$} & \multirow[b]{2}{*}{$E_{\text {out_acum }}$} & \multirow[b]{2}{*}{$\mathbf{N}_{\mathrm{m}}$} & \multirow[b]{2}{*}{$T_{m}$} \\
\hline TEMPO & CARGA & ACLIVE & VELOC. & & & & & & & & & & & & & & \\
\hline$[\mathrm{s}]$ & $\%$ & $\%$ & {$[\mathrm{~km} / \mathrm{h}]$} & {$[\mathrm{m}]$} & {$[N]$} & {$[\mathrm{N}]$} & {$[\mathrm{N}]$} & {$[\mathrm{N}]$} & {$[\mathrm{N}]$} & {$[\mathrm{N}]$} & {$[\mathrm{W}]$} & [W] & [W] & {$[W]$} & [Wh] & [rpm] & {$[\mathrm{Nm}]$} \\
\hline 960 & $0 \%$ & $0 \%$ & 0 & 661 & 7,8 & 0,0 & 0,0 & 0,0 & 0,0 & 7,8 & 0 & 0 & 0 & 0 & 13,5 & 0 & 0,1 \\
\hline 970 & $0 \%$ & $20 \%$ & 6 & 669 & 7,6 & 0,8 & 1154,3 & 100,0 & 47,4 & 1310,2 & 1092 & 1174 & 1381 & 1485 & 17,7 & 895 & 25,1 \\
\hline 980 & $0 \%$ & $20 \%$ & 6 & 686 & 7,6 & 3,2 & 1154,3 & 0,0 & 0,0 & 1165,2 & 1942 & 2088 & 2457 & 2642 & 25,0 & 895 & 22,3 \\
\hline 990 & $0 \%$ & $20 \%$ & 10 & 708 & 7,6 & 5,7 & 1154,3 & 66,7 & 31,6 & 1265,9 & 2813 & 3025 & 3559 & 3827 & 35,6 & 1491 & 24,2 \\
\hline 1000 & $0 \%$ & $20 \%$ & 10 & 736 & 7,6 & 8,9 & 1154,3 & 0,0 & 0,0 & 1170,9 & 3252 & 3497 & 4114 & 4424 & 47,9 & 1491 & 22,4 \\
\hline 1010 & $0 \%$ & $20 \%$ & 12 & 767 & 7,6 & 10,8 & 1154,3 & 33,3 & 15,8 & 1221,9 & 3734 & 4015 & 4723 & 5079 & 62,0 & 1790 & 23,4 \\
\hline 1020 & $0 \%$ & $20 \%$ & 12 & 800 & 7,6 & 12,8 & 1154,3 & 0,0 & 0,0 & 1174,8 & 3916 & 4211 & 4954 & 5327 & 76,8 & 1790 & 22,5 \\
\hline 1030 & $0 \%$ & $20 \%$ & 10 & 831 & 7,6 & 10,8 & 1154,3 & $-33,3$ & $-15,8$ & 1123,6 & 3433 & 3692 & 4343 & 4670 & 89,8 & 1491 & 21,5 \\
\hline 1040 & $0 \%$ & $20 \%$ & 6 & 853 & 7,6 & 5,7 & 1154,3 & $-66,7$ & $-31,6$ & 1069,4 & 2377 & 2555 & 3006 & 3233 & 98,8 & 895 & 20,5 \\
\hline 1050 & $0 \%$ & $20 \%$ & 3 & 865 & 7,6 & 1,8 & 1154,3 & $-50,0$ & $-23,7$ & 1090,1 & 1363 & 1465 & 1724 & 1853 & 103,9 & 447 & 20,8 \\
\hline 1060 & $0 \%$ & $20 \%$ & 0 & 869 & 7,6 & 0,2 & 1154,3 & $-50,0$ & $-23,7$ & 1088,5 & 454 & 488 & 574 & 617 & 105,6 & 0 & 20,8 \\
\hline 1070 & $0 \%$ & $0 \%$ & 0 & 869 & 7,8 & 0,0 & 0,0 & 0,0 & 0,0 & 7,8 & 0 & 0 & 0 & 0 & 105,6 & 0 & 0,1 \\
\hline 1080 & $0 \%$ & $0 \%$ & 0 & 869 & 7,8 & 0,0 & 0,0 & 0,0 & 0,0 & 7,8 & 0 & 0 & 0 & 0 & 105,6 & 0 & 0,1 \\
\hline 1090 & $0 \%$ & $0 \%$ & 0 & 869 & 7,8 & 0,0 & 0,0 & 0,0 & 0,0 & 7,8 & 0 & 0 & 0 & 0 & 105,6 & 0 & 0,1 \\
\hline 1100 & $0 \%$ & $0 \%$ & 0 & 869 & 7,8 & 0,0 & 0,0 & 0,0 & 0,0 & 7,8 & 0 & 0 & 0 & 0 & 105,6 & 0 & 0,1 \\
\hline 1110 & $0 \%$ & $0 \%$ & 0 & 869 & 7,8 & 0,0 & 0,0 & 0,0 & 0,0 & 7,8 & 0 & 0 & 0 & 0 & 105,6 & 0 & 0,1 \\
\hline 1120 & $0 \%$ & $0 \%$ & 0 & 869 & 7,8 & 0,0 & 0,0 & 0,0 & 0,0 & 7,8 & 0 & 0 & 0 & 0 & 105,6 & 0 & 0,1 \\
\hline 1130 & $0 \%$ & $0 \%$ & 0 & 869 & 7,8 & 0,0 & 0,0 & 0,0 & 0,0 & 7,8 & 0 & 0 & 0 & 0 & 105,6 & 0 & 0,1 \\
\hline 1140 & $0 \%$ & $0 \%$ & 0 & 869 & 7,8 & 0,0 & 0,0 & 0,0 & 0,0 & 7,8 & 0 & 0 & 0 & 0 & 105,6 & 0 & 0,1 \\
\hline 1150 & $0 \%$ & $0 \%$ & 0 & 869 & 7,8 & 0,0 & 0,0 & 0,0 & 0,0 & 7,8 & 0 & 0 & 0 & 0 & 105,6 & 0 & 0,1 \\
\hline 1160 & $0 \%$ & $0 \%$ & 0 & 869 & 7,8 & 0,0 & 0,0 & 0,0 & 0,0 & 7,8 & 0 & 0 & 0 & 0 & 105,6 & 0 & 0,1 \\
\hline 1170 & $0 \%$ & $0 \%$ & 0 & 869 & 7,8 & 0,0 & 0,0 & 0,0 & 0,0 & 7,8 & 0 & 0 & 0 & 0 & 105,6 & 0 & 0,1 \\
\hline 1180 & $0 \%$ & $0 \%$ & 0 & 869 & 7,8 & 0,0 & 0,0 & 0,0 & 0,0 & 7,8 & 0 & 0 & 0 & 0 & 105,6 & 0 & 0,1 \\
\hline 1190 & $0 \%$ & $0 \%$ & 0 & 869 & 7,8 & 0,0 & 0,0 & 0,0 & 0,0 & 7,8 & 0 & 0 & 0 & 0 & 105,6 & 0 & 0,1 \\
\hline 1200 & $0 \%$ & $0 \%$ & 0 & 869 & 7,8 & 0,0 & 0,0 & 0,0 & 0,0 & 7,8 & 0 & 0 & 0 & 0 & 105,6 & 0 & 0,1 \\
\hline 1210 & $0 \%$ & $0 \%$ & 0 & 869 & 7,8 & 0,0 & 0,0 & 0,0 & 0,0 & 7,8 & 0 & 0 & 0 & 0 & 105,6 & 0 & 0,1 \\
\hline 1220 & $0 \%$ & $0 \%$ & 0 & 869 & 7,8 & 0,0 & 0,0 & 0,0 & 0,0 & 7,8 & 0 & 0 & 0 & 0 & 105,6 & 0 & 0,1 \\
\hline 1230 & $0 \%$ & $0 \%$ & 0 & 869 & 7,8 & 0,0 & 0,0 & 0,0 & 0,0 & 7,8 & 0 & 0 & 0 & 0 & 105,6 & 0 & 0,1 \\
\hline 1240 & $0 \%$ & $0 \%$ & 0 & 869 & 7,8 & 0,0 & 0,0 & 0,0 & 0,0 & 7,8 & 0 & 0 & 0 & 0 & 105,6 & 0 & 0,1 \\
\hline 1250 & $0 \%$ & $0 \%$ & 0 & 869 & 7,8 & 0,0 & 0,0 & 0,0 & 0,0 & 7,8 & 0 & 0 & 0 & 0 & 105,6 & 0 & 0,1 \\
\hline 1260 & $0 \%$ & $0 \%$ & 0 & 869 & 7,8 & 0,0 & 0,0 & 0,0 & 0,0 & 7,8 & 0 & 0 & 0 & 0 & 105,6 & 0 & 0,1 \\
\hline 1270 & $0 \%$ & $0 \%$ & 0 & 869 & 7,8 & 0,0 & 0,0 & 0,0 & 0,0 & 7,8 & 0 & 0 & 0 & 0 & 105,6 & 0 & 0,1 \\
\hline 1280 & $0 \%$ & $0 \%$ & 0 & 869 & 7,8 & 0,0 & 0,0 & 0,0 & 0,0 & 7,8 & 0 & 0 & 0 & 0 & 105,6 & 0 & 0,1 \\
\hline 1290 & $0 \%$ & $0 \%$ & 0 & 869 & 7,8 & 0,0 & 0,0 & 0,0 & 0,0 & 7,8 & 0 & 0 & 0 & 0 & 105,6 & 0 & 0,1 \\
\hline 1300 & $0 \%$ & $0 \%$ & 0 & 869 & 7,8 & 0,0 & 0,0 & 0,0 & 0,0 & 7,8 & 0 & 0 & 0 & 0 & 105,6 & 0 & 0,1 \\
\hline 1310 & $0 \%$ & $0 \%$ & 0 & 869 & 7,8 & 0,0 & 0,0 & 0,0 & 0,0 & 7,8 & 0 & 0 & 0 & 0 & 105,6 & 0 & 0,1 \\
\hline 1320 & $0 \%$ & $0 \%$ & 0 & 869 & 7,8 & 0,0 & 0,0 & 0,0 & 0,0 & 7,8 & 0 & 0 & 0 & 0 & 105,6 & 0 & 0,1 \\
\hline 1330 & $0 \%$ & $0 \%$ & 0 & 869 & 7,8 & 0,0 & 0,0 & 0,0 & 0,0 & 7,8 & 0 & 0 & 0 & 0 & 105,6 & 0 & 0,1 \\
\hline 1340 & $0 \%$ & $0 \%$ & 0 & 869 & 7,8 & 0,0 & 0,0 & 0,0 & 0,0 & 7,8 & 0 & 0 & 0 & 0 & 105,6 & 0 & 0,1 \\
\hline 1350 & $0 \%$ & $0 \%$ & 0 & 869 & 7,8 & 0,0 & 0,0 & 0,0 & 0,0 & 7,8 & 0 & 0 & 0 & 0 & 105,6 & 0 & 0,1 \\
\hline 1360 & $0 \%$ & $0 \%$ & 0 & 869 & 7,8 & 0,0 & 0,0 & 0,0 & 0,0 & 7,8 & 0 & 0 & 0 & 0 & 105,6 & 0 & 0,1 \\
\hline 1370 & $0 \%$ & $0 \%$ & 0 & 869 & 7,8 & 0,0 & 0,0 & 0,0 & 0,0 & 7,8 & 0 & 0 & 0 & 0 & 105,6 & 0 & 0,1 \\
\hline 1380 & $0 \%$ & $0 \%$ & 0 & 869 & 7,8 & 0,0 & 0,0 & 0,0 & 0,0 & 7,8 & 0 & 0 & 0 & 0 & 105,6 & 0 & 0,1 \\
\hline 1390 & $0 \%$ & $0 \%$ & 0 & 869 & 7,8 & 0,0 & 0,0 & 0,0 & 0,0 & 7,8 & 0 & 0 & 0 & 0 & 105,6 & 0 & 0,1 \\
\hline 1400 & $0 \%$ & $0 \%$ & 0 & 869 & 7,8 & 0,0 & 0,0 & 0,0 & 0,0 & 7,8 & 0 & 0 & 0 & 0 & 105,6 & 0 & 0,1 \\
\hline 1410 & $0 \%$ & $0 \%$ & 0 & 869 & 7,8 & 0,0 & 0,0 & 0,0 & 0,0 & 7,8 & 0 & 0 & 0 & 0 & 105,6 & 0 & 0,1 \\
\hline 1420 & $0 \%$ & $0 \%$ & 0 & 869 & 7,8 & 0,0 & 0,0 & 0,0 & 0,0 & 7,8 & 0 & 0 & 0 & 0 & 105,6 & 0 & 0,1 \\
\hline 1430 & $0 \%$ & $0 \%$ & 0 & 869 & 7,8 & 0,0 & 0,0 & 0,0 & 0,0 & 7,8 & 0 & 0 & 0 & 0 & 105,6 & 0 & 0,1 \\
\hline
\end{tabular}

Figura 5.6 - Planilha de cálculos (parte III) 


\begin{tabular}{|c|c|c|c|c|c|c|c|c|c|c|c|c|c|c|c|c|c|}
\hline \multicolumn{18}{|c|}{ CICLO DE CONDUÇÃO - PARTE IV } \\
\hline TEMPO & CARGA & ACLIVE & VELOC. & DIST. & $F_{r}$ & $F_{w}$ & $F_{g}$ & $F_{\mathrm{la}}$ & $F_{\text {wa }}$ & $F_{t}$ & $\mathbf{P}_{\mathbf{t}}$ & $\mathbf{P}_{\mathrm{m}}$ & $\mathbf{P}_{\mathrm{cc}}$ & $\mathbf{P}_{\text {tot }}$ & $E_{\text {out_acum }}$ & $\mathbf{N}_{\mathrm{m}}$ & $T_{m}$ \\
\hline [s] & $\%$ & $\%$ & {$[\mathrm{~km} / \mathrm{h}]$} & [m] & {$[\mathrm{N}]$} & {$[\mathrm{N}]$} & {$[\mathrm{N}]$} & {$[\mathrm{N}]$} & {$[\mathrm{N}]$} & {$[\mathrm{N}]$} & [W] & [W] & [W] & [W] & [Wh] & [rpm] & {$[\mathrm{Nm}]$} \\
\hline 1440 & $100 \%$ & $10 \%$ & 0 & 869 & 19,4 & 0,0 & 1464,2 & 0,0 & 0,0 & 1483,6 & 0 & 0 & 0 & 0 & 105,6 & 0 & 28,4 \\
\hline 1450 & $100 \%$ & $10 \%$ & 4 & 875 & 19,4 & 0,4 & 1464,2 & 166,7 & 31,6 & 1682,2 & 935 & 1005 & 1182 & 1271 & 109,2 & 597 & 32,2 \\
\hline 1460 & $100 \%$ & $10 \%$ & 4 & 886 & 19,4 & 1,4 & 1464,2 & 0,0 & 0,0 & 1485,0 & 1650 & 1774 & 2087 & 2244 & 115,4 & 597 & 28,4 \\
\hline 1470 & $100 \%$ & $10 \%$ & 4 & 897 & 19,4 & 1,4 & 1464,2 & 0,0 & 0,0 & 1485,0 & 1650 & 1774 & 2087 & 2244 & 121,6 & 597 & 28,4 \\
\hline 1480 & $100 \%$ & $10 \%$ & 4 & 908 & 19,4 & 1,4 & 1464,2 & 0,0 & 0,0 & 1485,0 & 1650 & 1774 & 2087 & 2244 & 127,9 & 597 & 28,4 \\
\hline 1490 & $100 \%$ & $10 \%$ & 6 & 922 & 19,4 & 2,2 & 1464,2 & 83,3 & 15,8 & 1585,0 & 2201 & 2367 & 2785 & 2994 & 136,2 & 895 & 30,3 \\
\hline 1500 & $100 \%$ & $10 \%$ & 6 & 939 & 19,4 & 3,2 & 1464,2 & 0,0 & 0,0 & 1486,8 & 2478 & 2665 & 3135 & 3371 & 145,6 & 895 & 28,4 \\
\hline 1510 & $100 \%$ & $10 \%$ & 6 & 956 & 19,4 & 3,2 & 1464,2 & 0,0 & 0,0 & 1486,8 & 2478 & 2665 & 3135 & 3371 & 154,9 & 895 & 28,4 \\
\hline 1520 & $100 \%$ & $10 \%$ & 8 & 975 & 19,4 & 4,4 & 1464,2 & 83,3 & 15,8 & 1587,1 & 3086 & 3318 & 3904 & 4198 & 166,6 & 1193 & 30,4 \\
\hline 1530 & $100 \%$ & $10 \%$ & 8 & 997 & 19,4 & 5,7 & 1464,2 & 0,0 & 0,0 & 1489,3 & 3310 & 3559 & 4187 & 4502 & 179,1 & 1193 & 28,5 \\
\hline 1540 & $100 \%$ & $10 \%$ & 6 & 1.017 & 19,4 & 4,4 & 1464,2 & $-83,3$ & $-15,8$ & 1388,8 & 2701 & 2904 & 3416 & 3673 & 189,3 & 895 & 26,6 \\
\hline 1550 & $100 \%$ & $10 \%$ & 6 & 1.033 & 19,4 & 3,2 & 1464,2 & 0,0 & 0,0 & 1486,8 & 2478 & 2665 & 3135 & 3371 & 198,7 & 895 & 28,4 \\
\hline 1560 & $100 \%$ & $10 \%$ & 6 & 1.050 & 19,4 & 3,2 & 1464,2 & 0,0 & 0,0 & 1486,8 & 2478 & 2665 & 3135 & 3371 & 208,0 & 895 & 28,4 \\
\hline 1570 & $100 \%$ & $10 \%$ & 4 & 1.064 & 19,4 & 2,2 & 1464,2 & $-83,3$ & $-15,8$ & 1386,7 & 1926 & 2071 & 2436 & 2620 & 215,3 & 597 & 26,5 \\
\hline 1580 & $100 \%$ & $10 \%$ & 4 & 1.075 & 19,4 & 1,4 & 1464,2 & 0,0 & 0,0 & 1485,0 & 1650 & 1774 & 2087 & 2244 & 221,5 & 597 & 28,4 \\
\hline 1590 & $100 \%$ & $10 \%$ & 0 & 1.081 & 19,4 & 0,4 & 1464,2 & $-166,7$ & $-31,6$ & 1285,7 & 714 & 768 & 904 & 972 & 224,2 & 0 & 24,6 \\
\hline 1600 & $0 \%$ & $0 \%$ & 0 & 1.081 & 7,8 & 0,0 & 0,0 & 0,0 & 0,0 & 7,8 & 0 & 0 & 0 & 0 & 224,2 & 0 & 0,1 \\
\hline 1610 & $0 \%$ & $0 \%$ & 0 & 1.081 & 7,8 & 0,0 & 0,0 & 0,0 & 0,0 & 7,8 & 0 & 0 & 0 & 0 & 224,2 & 0 & 0,1 \\
\hline 1620 & $0 \%$ & $0 \%$ & 0 & 1.081 & 7,8 & 0,0 & 0,0 & 0,0 & 0,0 & 7,8 & 0 & 0 & 0 & 0 & 224,2 & 0 & 0,1 \\
\hline 1630 & $0 \%$ & $0 \%$ & 0 & 1.081 & 7,8 & 0,0 & 0,0 & 0,0 & 0,0 & 7,8 & 0 & 0 & 0 & 0 & 224,2 & 0 & 0,1 \\
\hline 1640 & $0 \%$ & $0 \%$ & 0 & 1.081 & 7,8 & 0,0 & 0,0 & 0,0 & 0,0 & 7,8 & 0 & 0 & 0 & 0 & 224,2 & 0 & 0,1 \\
\hline 1650 & $0 \%$ & $0 \%$ & 0 & 1.081 & 7,8 & 0,0 & 0,0 & 0,0 & 0,0 & 7,8 & 0 & 0 & 0 & 0 & 224,2 & 0 & 0,1 \\
\hline 1660 & $0 \%$ & $0 \%$ & 0 & 1.081 & 7,8 & 0,0 & 0,0 & 0,0 & 0,0 & 7,8 & 0 & 0 & 0 & 0 & 224,2 & 0 & 0,1 \\
\hline 1670 & $0 \%$ & $0 \%$ & 0 & 1.081 & 7,8 & 0,0 & 0,0 & 0,0 & 0,0 & 7,8 & 0 & 0 & 0 & 0 & 224,2 & 0 & 0,1 \\
\hline 1680 & $0 \%$ & $0 \%$ & 0 & 1.081 & 7,8 & 0,0 & 0,0 & 0,0 & 0,0 & 7,8 & 0 & 0 & 0 & 0 & 224,2 & 0 & 0,1 \\
\hline 1690 & $0 \%$ & $0 \%$ & 0 & 1.081 & 7,8 & 0,0 & 0,0 & 0,0 & 0,0 & 7,8 & 0 & 0 & 0 & 0 & 224,2 & 0 & 0,1 \\
\hline 1700 & $0 \%$ & $0 \%$ & 0 & 1.081 & 7,8 & 0,0 & 0,0 & 0,0 & 0,0 & 7,8 & 0 & 0 & 0 & 0 & 224,2 & 0 & 0,1 \\
\hline 1710 & $0 \%$ & $0 \%$ & 0 & 1.081 & 7,8 & 0,0 & 0,0 & 0,0 & 0,0 & 7,8 & 0 & 0 & 0 & 0 & 224,2 & 0 & 0,1 \\
\hline 1720 & $0 \%$ & $0 \%$ & 0 & 1.081 & 7,8 & 0,0 & 0,0 & 0,0 & 0,0 & 7,8 & 0 & 0 & 0 & 0 & 224,2 & 0 & 0,1 \\
\hline 1730 & $0 \%$ & $0 \%$ & 0 & 1.081 & 7,8 & 0,0 & 0,0 & 0,0 & 0,0 & 7,8 & 0 & 0 & 0 & 0 & 224,2 & 0 & 0,1 \\
\hline 1740 & $0 \%$ & $0 \%$ & 0 & 1.081 & 7,8 & 0,0 & 0,0 & 0,0 & 0,0 & 7,8 & 0 & 0 & 0 & 0 & 224,2 & 0 & 0,1 \\
\hline 1750 & $0 \%$ & $0 \%$ & 0 & 1.081 & 7,8 & 0,0 & 0,0 & 0,0 & 0,0 & 7,8 & 0 & 0 & 0 & 0 & 224,2 & 0 & 0,1 \\
\hline 1760 & $0 \%$ & $0 \%$ & 0 & 1.081 & 7,8 & 0,0 & 0,0 & 0,0 & 0,0 & 7,8 & 0 & 0 & 0 & 0 & 224,2 & 0 & 0,1 \\
\hline 1770 & $0 \%$ & $0 \%$ & 0 & 1.081 & 7,8 & 0,0 & 0,0 & 0,0 & 0,0 & 7,8 & 0 & 0 & 0 & 0 & 224,2 & 0 & 0,1 \\
\hline 1780 & $0 \%$ & $0 \%$ & 0 & 1.081 & 7,8 & 0,0 & 0,0 & 0,0 & 0,0 & 7,8 & 0 & 0 & 0 & 0 & 224,2 & 0 & 0,1 \\
\hline 1790 & $0 \%$ & $0 \%$ & 0 & 1.081 & 7,8 & 0,0 & 0,0 & 0,0 & 0,0 & 7,8 & 0 & 0 & 0 & 0 & 224,2 & 0 & 0,1 \\
\hline 1800 & $0 \%$ & $0 \%$ & 0 & 1.081 & 7,8 & 0,0 & 0,0 & 0,0 & 0,0 & 7,8 & 0 & 0 & 0 & 0 & 224,2 & 0 & 0,1 \\
\hline 1810 & $0 \%$ & $0 \%$ & 0 & 1.081 & 7,8 & 0,0 & 0,0 & 0,0 & 0,0 & 7,8 & 0 & 0 & 0 & 0 & 224,2 & 0 & 0,1 \\
\hline 1820 & $0 \%$ & $0 \%$ & 0 & 1.081 & 7,8 & 0,0 & 0,0 & 0,0 & 0,0 & 7,8 & 0 & 0 & 0 & 0 & 224,2 & 0 & 0,1 \\
\hline 1830 & $0 \%$ & $0 \%$ & 0 & 1.081 & 7,8 & 0,0 & 0,0 & 0,0 & 0,0 & 7,8 & 0 & 0 & 0 & 0 & 224,2 & 0 & 0,1 \\
\hline 1840 & $0 \%$ & $0 \%$ & 0 & 1.081 & 7,8 & 0,0 & 0,0 & 0,0 & 0,0 & 7,8 & 0 & 0 & 0 & 0 & 224,2 & 0 & 0,1 \\
\hline 1850 & $0 \%$ & $0 \%$ & 0 & 1.081 & 7,8 & 0,0 & 0,0 & 0,0 & 0,0 & 7,8 & 0 & 0 & 0 & 0 & 224,2 & 0 & 0,1 \\
\hline 1860 & $0 \%$ & $0 \%$ & 0 & 1.081 & 7,8 & 0,0 & 0,0 & 0,0 & 0,0 & 7,8 & 0 & 0 & 0 & 0 & 224,2 & 0 & 0,1 \\
\hline 1870 & $0 \%$ & $0 \%$ & 0 & 1.081 & 7,8 & 0,0 & 0,0 & 0,0 & 0,0 & 7,8 & 0 & 0 & 0 & 0 & 224,2 & 0 & 0,1 \\
\hline 1880 & $0 \%$ & $0 \%$ & 0 & 1.081 & 7,8 & 0,0 & 0,0 & 0,0 & 0,0 & 7,8 & 0 & 0 & 0 & 0 & 224,2 & 0 & 0,1 \\
\hline 1890 & $0 \%$ & $0 \%$ & 0 & 1.081 & 7,8 & 0,0 & 0,0 & 0,0 & 0,0 & 7,8 & 0 & 0 & 0 & 0 & 224,2 & 0 & 0,1 \\
\hline 1900 & $0 \%$ & $0 \%$ & 0 & 1.081 & 7,8 & 0,0 & 0,0 & 0,0 & 0,0 & 7,8 & 0 & 0 & 0 & 0 & 224,2 & 0 & 0,1 \\
\hline 1910 & $0 \%$ & $0 \%$ & 0 & 1.081 & 7,8 & 0,0 & 0,0 & 0,0 & 0,0 & 7,8 & 0 & 0 & 0 & 0 & 224,2 & 0 & 0,1 \\
\hline 1920 & $0 \%$ & $0 \%$ & 0 & 1.081 & 7,8 & 0,0 & 0,0 & 0,0 & 0,0 & 7,8 & 0 & 0 & 0 & 0 & 224,2 & 0 & 0,1 \\
\hline
\end{tabular}

Figura 5.7 - Planilha de cálculos (parte IV) 


\subsection{DETERMINAÇÃO DO MOTOR ELÉTRICO}

A partir dos resultados obtidos na planilha de cálculos, mostrados graficamente na Figura 5.8, os requisitos a serem atendidos pelo motor de tração foram definidos e são apresentados na Tabela 5.4.

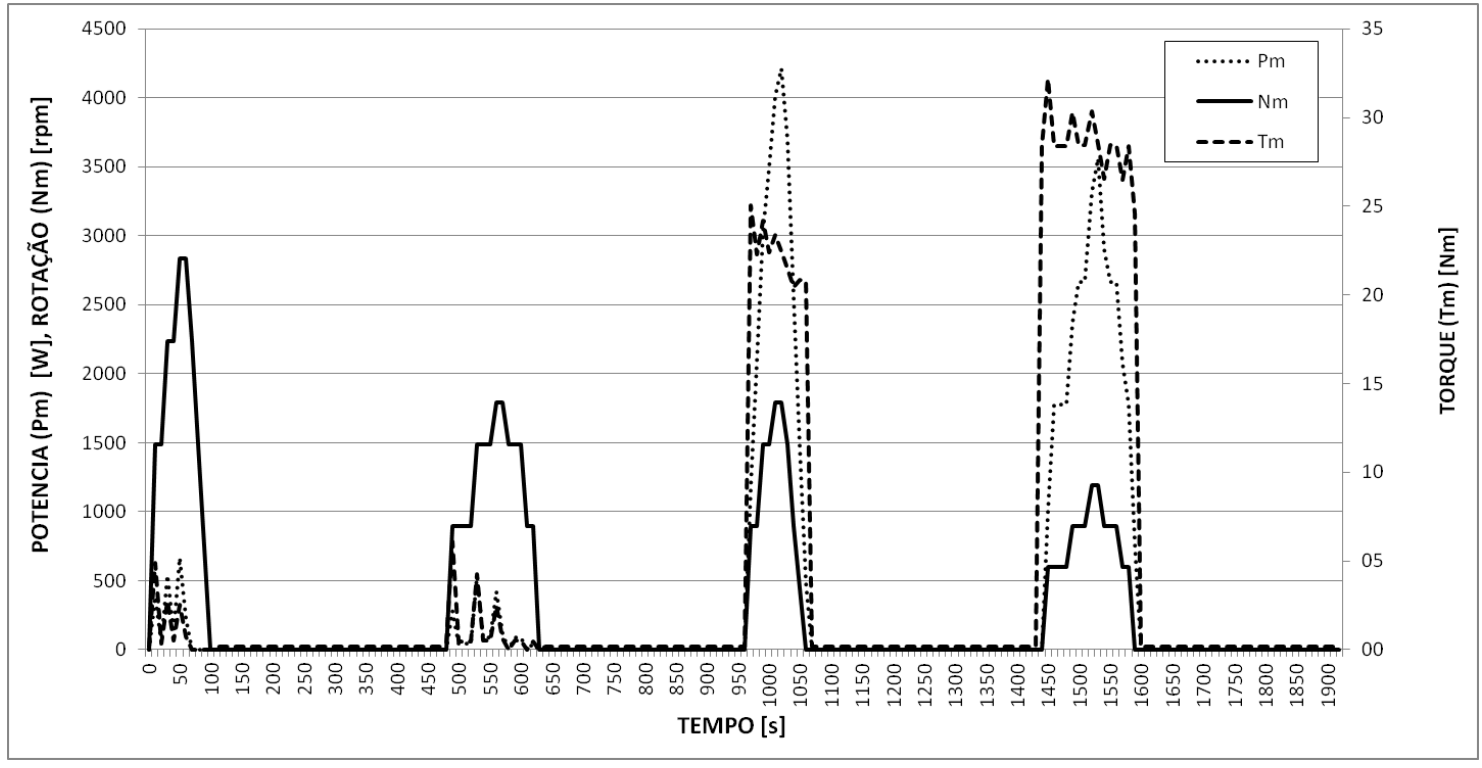

Figura 5.8 - Potência, torque e rotação no motor

Tabela 5.4 - Requisitos para o motor de tração

\begin{tabular}{lccl}
\hline REQUISITOS PARA & VALOR & UNIDADE & OBSERVAÇŌES \\
O MOTOR & & & \\
\hline Potência máxima & 4211 & {$[\mathrm{~W}]$} & $1790-1490 \mathrm{rpm}(60 \mathrm{~s} /$ ciclo $)$ \\
& 3559 & & $1193-895 \mathrm{rpm}(80 \mathrm{~s} /$ ciclo $)$ \\
\hline Torque máximo & 32,2 & {$[\mathrm{Nm}]$} & $597-1193 \mathrm{rpm}(150 \mathrm{~s} /$ ciclo $)$ \\
& 25,1 & & $895-1790 \mathrm{rpm}(100 \mathrm{~s} /$ ciclo $)$ \\
\hline Rotação máxima & 2834 & {$[\mathrm{rpm}]$} & $19 \mathrm{~km} / \mathrm{h}(\mathrm{Tm}=2,5 \mathrm{Nm})$ \\
\hline Eficiência mínima & 85 & $\%$ & \\
\hline
\end{tabular}


As principais características do motor adotado são apresentadas na Tabela 5.5 e na Figura 5.9.

Tabela 5.5 - Principais características do motor CC c/ escovas ADCM AC1-4001

\begin{tabular}{ccccccc}
\hline $\begin{array}{c}\text { ROTAÇÃO } \\
\text { [rpm] }\end{array}$ & \multicolumn{2}{c}{ TORQUE } & \multicolumn{2}{c}{ POTÊNCIA } & EFICIENCIA & CORRENTE \\
& {$[\mathrm{Lb}-\mathrm{Ft}]$} & {$[\mathrm{Nm}]$} & {$[\mathrm{HP}]$} & {$[\mathbf{W}]$} & {$[\%]$} & {$[$ [A] } \\
\hline 1300 & 40 & 54,2 & 9,5 & 7087 & 76 & 248,7 \\
\hline 1550 & 30 & 40,7 & 8,6 & 6416 & 81 & 211,2 \\
\hline 1850 & 20 & 27,1 & 7 & 5222 & 87 & 160,1 \\
\hline 2350 & 10 & 13,6 & 4,5 & 3357 & 89 & 100,6 \\
\hline 2900 & 5,4 & 7,3 & 3 & 2238 & 85 & 70,2 \\
\hline
\end{tabular}

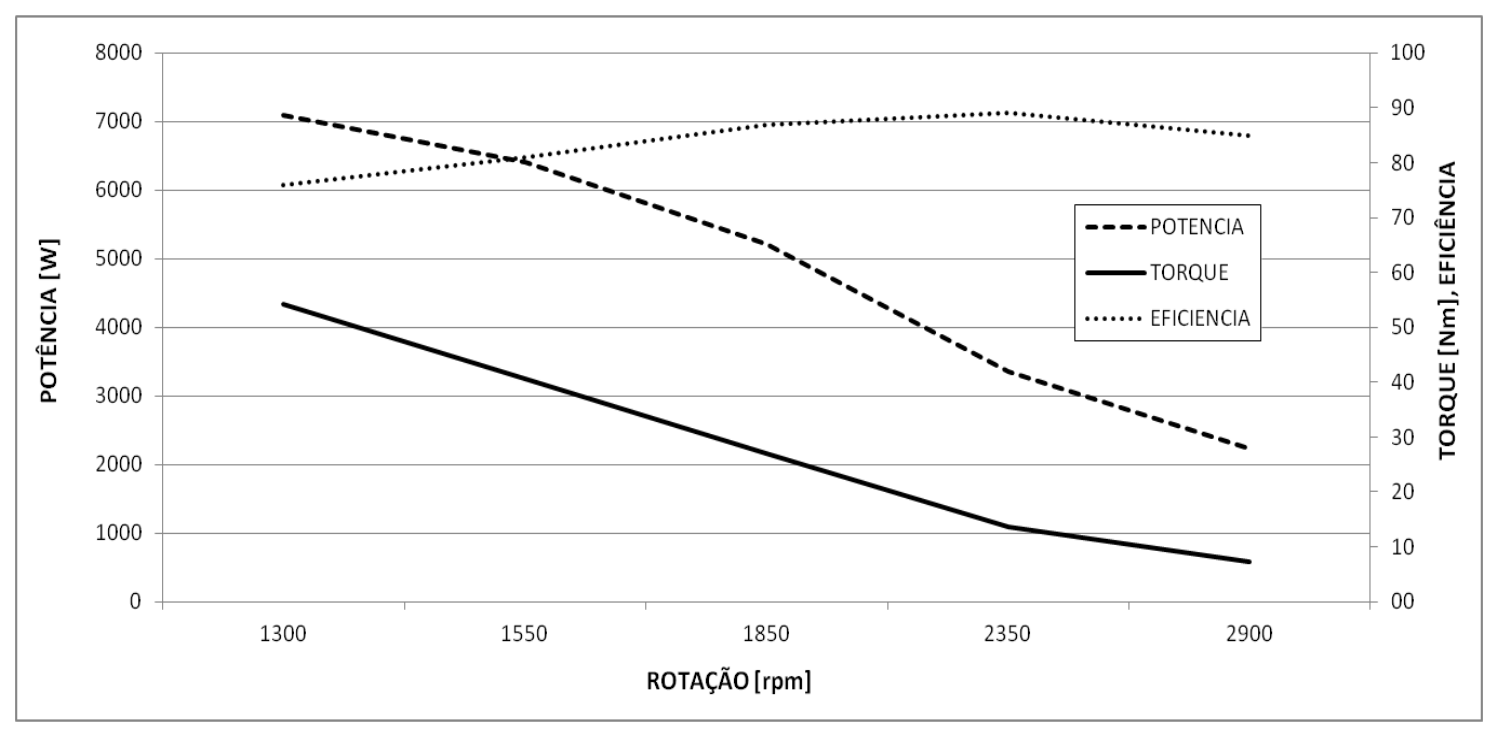

Figura 5.9 - Curvas características do motor ADCM AC1-4001 


\subsection{DETERMINAÇÃO DO CONTROLADOR/CONVERSOR DE POTÊNCIA}

Novamente, através dos resultados obtidos na planilha de cálculos do item 5.5, na Figura 5.10 e definições de projeto, os requisitos para o controlador/conversor de potência foram estabelecidos e são apresentados na Tabela 5.6.

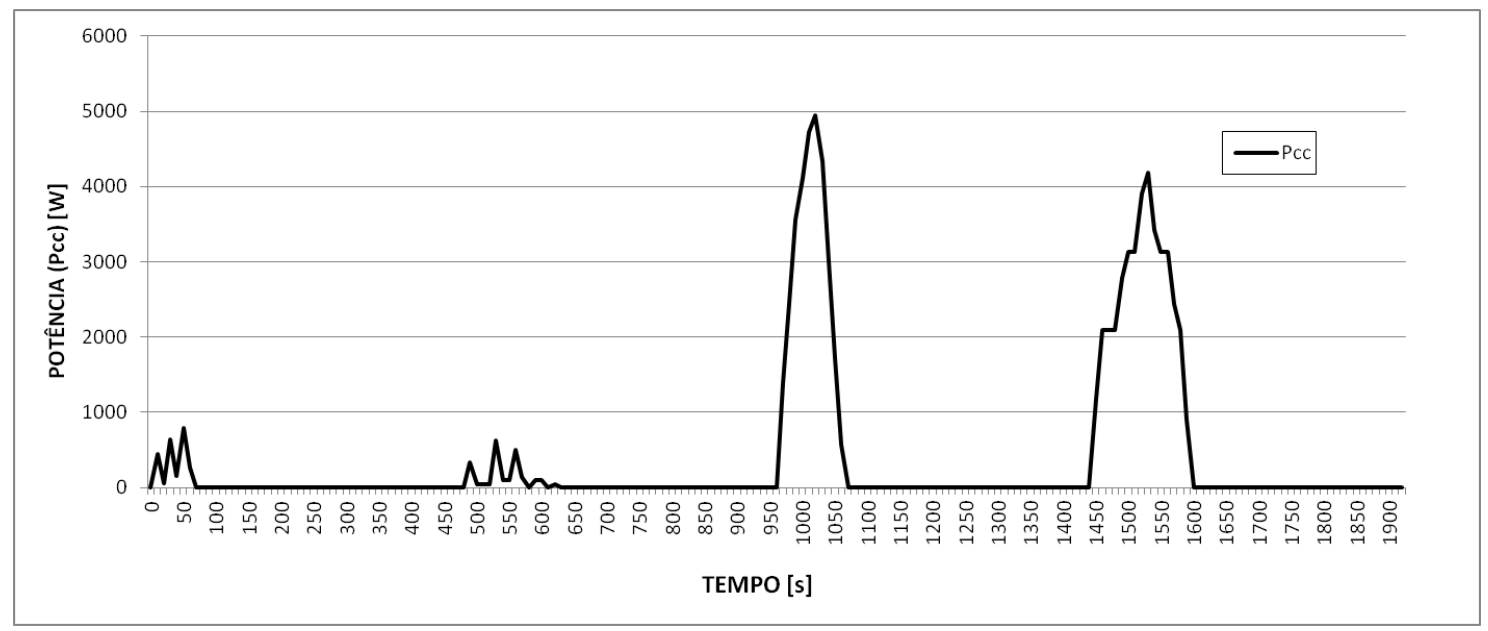

Figura 5.10 - Potência no controlador/conversor de potência

Tabela 5.6 - Requisitos para o controlador/conversor de potência

\begin{tabular}{|c|c|c|c|}
\hline $\begin{array}{l}\text { REQUISITOS PARA O } \\
\text { CONTROL./CONVERSOR }\end{array}$ & VALOR & UNIDADE & OBSERVAÇŌES \\
\hline \multirow[t]{2}{*}{ Potência máxima } & 4954 & {$[\mathrm{~W}]$} & 138 A (60s/ciclo) \\
\hline & 4187 & {$[\mathrm{~W}]$} & 117 A (80s/ciclo) \\
\hline Tensão nominal & 36 & {$[\mathrm{~V}]$} & Operar em faixa de 30V a 44V \\
\hline Recortador & & & $\begin{array}{l}\text { Modulação de largura de pulso } \\
\text { (PWM) }\end{array}$ \\
\hline Eficiência mínima & 90 & $\%$ & \\
\hline
\end{tabular}


As principais características do controlador/conversor de potência adotado são apresentadas na Tabela 5.7 e na Figura 5.11.

Tabela 5.7 - Características do controlador/conversor de potência Curtis 1204-0XX

\begin{tabular}{lcc}
\hline PARÂMETRO & VALOR & UNIDADE \\
\hline Tensão nominal das baterias & $24-36$ & {$[\mathrm{~V}]$} \\
\hline Limite de corrente & 275 & {$[\mathrm{~A}]$} \\
\hline Capacidade de corrente (2 min.) & $\mathbf{2 7 5}$ & {$[\mathrm{A}]$} \\
\hline Capacidade de corrente (5 min.) & $\mathbf{2 0 0}$ & {$[\mathrm{A}]$} \\
\hline Capacidade de corrente (1 h) & $\mathbf{1 2 5}$ & {$[\mathrm{A}]$} \\
\hline Queda de tensão (@ 100 A) & 0,35 & {$[\mathrm{~V}]$} \\
\hline Desligamento por subtensão & 16 & {$[\mathrm{~V}]$} \\
\hline Frequência PWM & 15 & {$[\mathrm{kHz}]$} \\
\hline
\end{tabular}

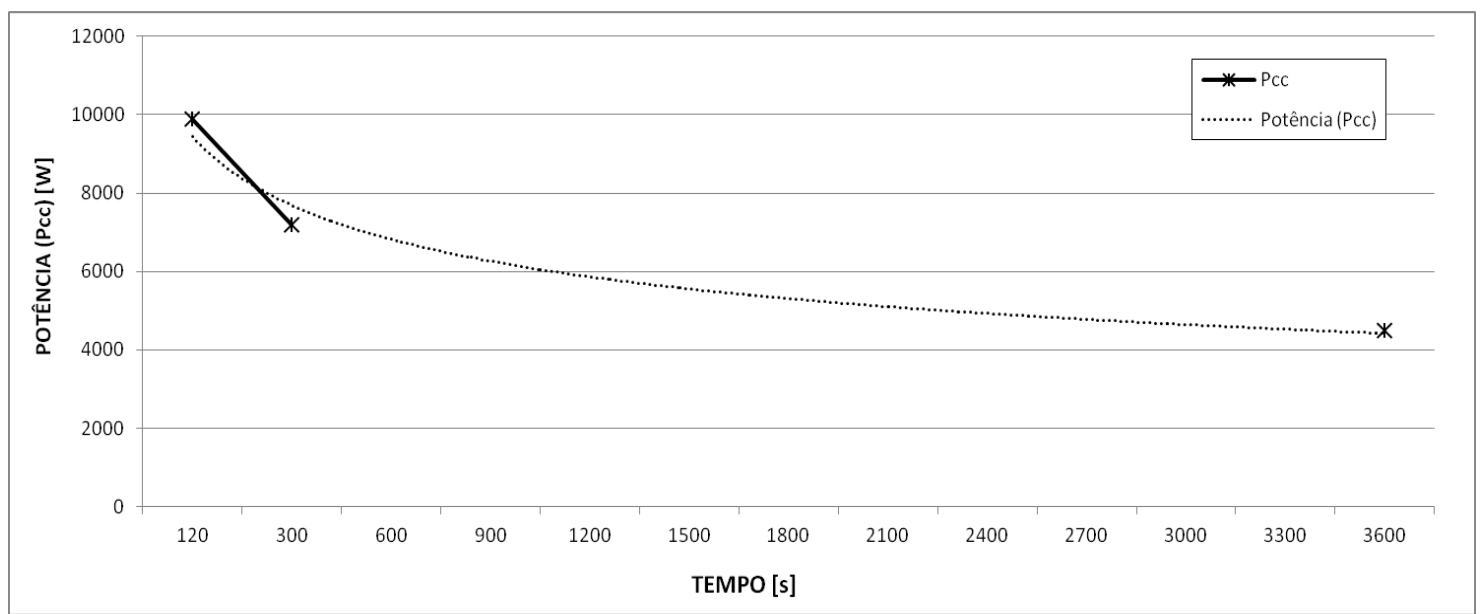

Figura 5.11 - Capac. potência do controlador/conversor de potência Curtis 1204-0XX 


\subsection{DETERMINAÇÃO DAS BATERIAS}

Em 1994, ano em que o veículo elétrico objeto deste trabalho foi desenvolvido, as principais tecnologias de baterias viáveis ao projeto eram as baterias de chumboácido e as de níquel-cádmio.

Baterias com maiores densidades de energia como as de lítio e hidreto metálico de níquel já existiam, mas eram economicamente inviáveis ou ainda não possuíam suficiente maturidade tecnológica.

A escolha, ainda na fase de anteprojeto do veículo, foi pelas baterias de chumboácido principalmente em função do custo e facilidade de manutenção.

A partir dos resultados obtidos para a demanda de potência e consumo de energia em um ciclo de condução na planilha de cálculos no item 5.5 e mostrados na Figura 5.12, foram definidos os requisitos para as baterias como apresentados na Tabela 5.8 .

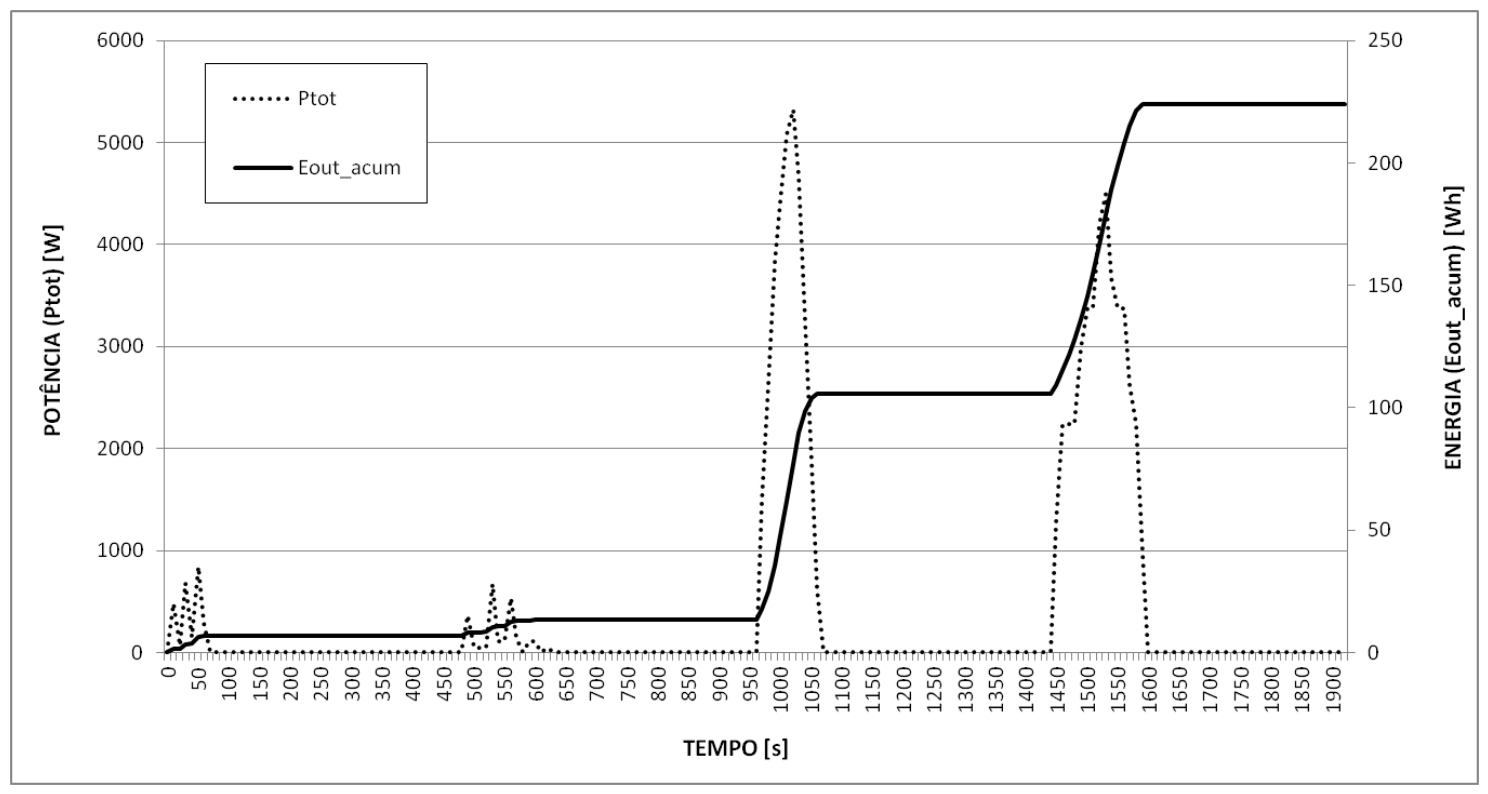

Figura 5.12 - Potência e energia consumida das baterias em um ciclo de condução 
Tabela 5.8 - Requisitos para o banco de baterias

\begin{tabular}{lcc}
\hline REQUISITOS PARA O BANCO DE & VALOR & UNIDADE \\
BATERIAS & & \\
\hline Capacidade de energia útil & 3363 & {$[\mathrm{Wh}]$} \\
\hline Capacidade de potência & 5327 & {$[\mathrm{~W}]$} \\
\hline Tensão nominal & 36 & {$[\mathrm{~V}]$} \\
\hline
\end{tabular}

Como o consumo de energia em um ciclo é de $224,2 \mathrm{Wh}$, e a autonomia do banco de baterias deve ser suficiente para 15 ciclos, a necessidade total de energia útil é de 3363 Wh.

A Tabela 5.9 mostra as principais características do banco de baterias adotado.

Tabela 5.9 - características do banco de baterias (Trojan T-105)

\begin{tabular}{lcc}
\hline PARÂMETRO & VALOR & UNIDADE \\
\hline Capacidade de energia útil do banco de baterias & $\mathbf{4 5 2 8}^{(1)}$ & {$[\mathrm{Wh}]$} \\
\hline Capacidade de potência do banco de baterias & $\mathbf{1 2 6 0 0}^{(2)}$ & {$[\mathrm{W}]$} \\
\hline Número de baterias (em série) no banco & 6 & [unidade] \\
\hline Capacidade de energia útil de uma bateria & $\mathbf{7 5 5}$ & {$[\mathrm{Wh}]$} \\
\hline Capacidade de potência de uma bateria & 2100 & {$[\mathrm{~W}]$} \\
\hline Tensão nominal do banco de baterias & 36 & {$[\mathrm{~V}]$} \\
\hline Vida & 630 & [ciclos] \\
\hline
\end{tabular}

Notas:

1. Embora possa parecer superdimensionada a capacidade do banco de baterias ser aproximadamente $35 \%$ superior a necessária, diversos fatores como temperatura, idade e manutenção podem reduzir esta capacidade. 
2. Como mencionado na revisão bibliográfica, a capacidade de potência do banco de baterias para veículos elétricos puros raramente é fator limitante.

\subsection{DETERMINAÇÃO DO BANCO DE ULTRACAPACITORES}

Como mencionado anteriormente, raramente, é necessário ou traz vantagens significativas, adicionar um banco de ultracapacitores em veículos elétricos puros a bateria porque o banco de baterias teria capacidade de potência suficiente.

O veículo deste exemplo de aplicação prática não tem ultracapacitores e a capacidade de potência do banco de baterias adotado é mais de duas vezes superior a necessidade. Todos os resultados de desempenho apresentados neste trabalho foram obtidos sem os ultracapacitores.

Entretanto, apenas com finalidade didática para consolidar a metodologia apresentada no item 4.7.5, será mostrado como seria o dimensionamento de um banco de ultracapacitores (hipotético) para este exemplo.

A estratégia de dimensionamento será suprir a potência média através das baterias e o que exceder esse valor será suprido através dos ultracapacitores. Para a determinação da potência média, bastaria dividir a energia total consumida em um ciclo de condução pelo período de tempo do ciclo. Entretanto, nesta aplicação especifica, nota-se que o veículo permanece parado, aproximadamente, $75 \%$ do tempo do ciclo. Assim, o cálculo da potência média, neste caso, será feito pela razão da energia total consumida no ciclo pelo tempo total do veículo em movimento, que é quando ocorre a demanda de potência e consumo de energia. $O$ valor da potência média obtido é $1794 \mathrm{~W}$.

Novamente, a partir dos resultados obtidos para a demanda de potência e consumo de energia em um ciclo de condução na planilha de cálculos no item 5.5 e mostrados na Figura 5.13, foram definidos os requisitos para os ultracapacitores como apresentados na Tabela 5.10. 


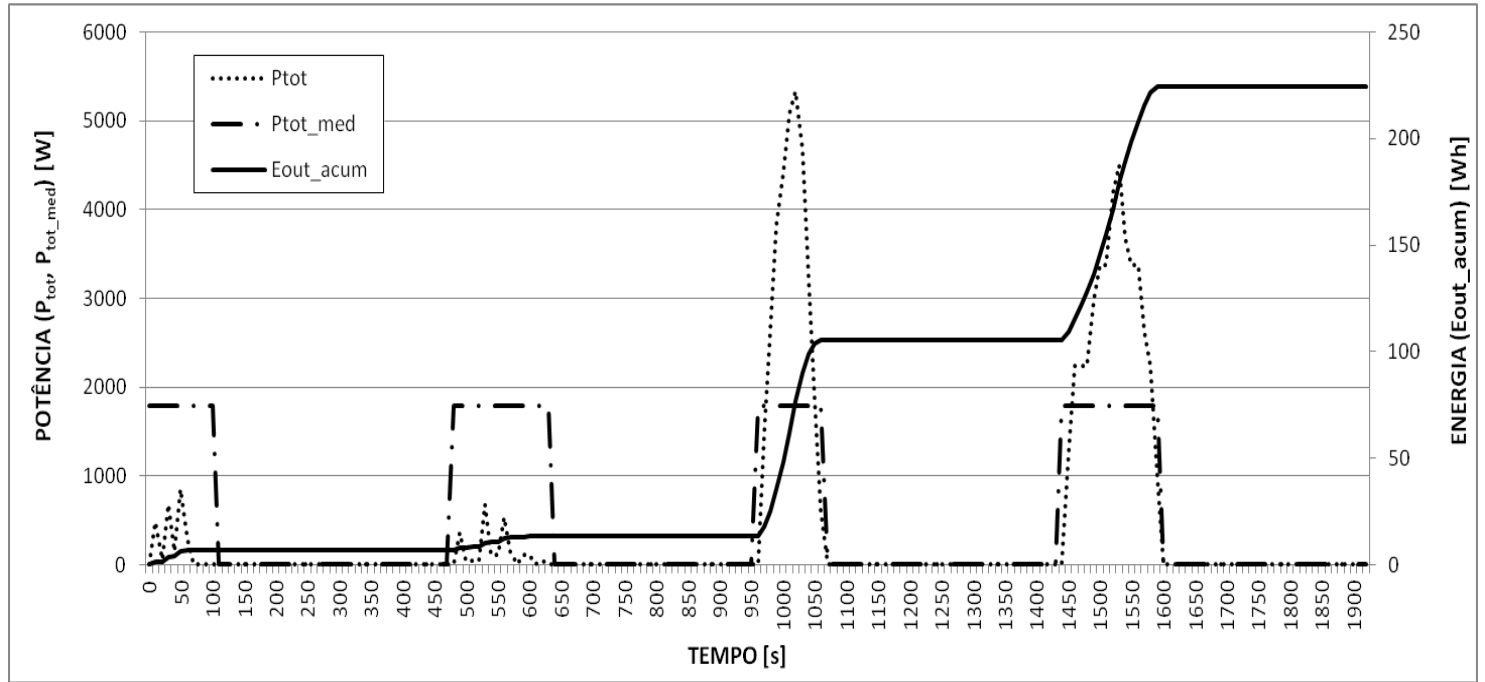

Figura 5.13 - Potências instantânea e média

Tabela 5.10 - Requisitos para o banco de ultracapacitores

\begin{tabular}{lcc}
\hline $\begin{array}{l}\text { REQUISITOS PARA O BANCO DE } \\
\text { ULTRACAPACITORES }\end{array}$ & VALOR & UNIDADE \\
\hline Capacitância & 781 & {$[\mathrm{~F}]$} \\
\hline Capacidade de potência & 3533 & {$[\mathrm{~W}]$} \\
\hline Capacidade de energia & 118,6 & {$[\mathrm{Wh}]$} \\
\hline Tensão mínima de operação & 27 & {$[\mathrm{~V}]$} \\
\hline Tensão máxima de operação & 54 & 24 \\
\hline
\end{tabular}

Notas:

1. Determinação da capacitância pela expressão:

$$
C_{u c}=2 \frac{2 E_{u c}}{U_{u c m a x}^{2}-U_{u c m i n}^{2}} \quad C_{u c}=2 \frac{2(224,2-105,6) 3600}{54^{2}-27^{2}}=781
$$

2. Determinação da capacidade de potência pela expressão:

$$
\begin{gathered}
P_{u c}=P_{t o t}-P_{b a t} \\
P_{u c}=5327-1794=3533
\end{gathered}
$$


onde se utiliza, neste exemplo, como $P_{\text {tot }} 0$ valor máximo que ocorre com o veículo em vazio e na rampa máxima e como $P_{b a t}$ o valor médio da potência.

3. As tensões mínima e máxima de operação são definições de projeto, principalmente, em função dos requisitos do conversor de potência a ser utilizado.

A Tabela 5.11 mostra as principais características do ultracapacitor escolhido e suas conexões para atendimento aos requisitos do banco conforme a Tabela 5.10.

Tabela 5.11 - Principais características dos ultracapacitores escolhidos

\begin{tabular}{lccc}
\hline PARÂMETRO & VALOR & UNIDADE \\
\hline Capacitância de um ultracapacitor (Yunasko) & 5200 & {$[\mathrm{~F}]$} \\
\hline $\begin{array}{l}\text { Capacitância do banco de ultracapacitores } \\
\text { Tensão nominal de um ultracapacitor }\end{array}$ & 780 & {$[\mathrm{~F}]$} \\
\hline Número de ultracapacitores em série no banco & 20 & [Unidade] \\
\hline $\begin{array}{l}\text { Número de ultracapacitores em paralelo no } \\
\text { banco }\end{array}$ & 3 & [unidade] \\
\hline $\begin{array}{l}\text { Massa de um ultracapacitor } \\
\text { Massa do banco de ultracapacitores }\end{array}$ & 0,068 & {$[\mathrm{~kg}]$} \\
\hline $\begin{array}{l}\text { Capacidade de potência do banco de ultracap. } \\
\text { (95\%) }\end{array}$ & 13920 & {$[\mathrm{~kg}]$} \\
\hline
\end{tabular}

Nota:

1. Para o banco de ultracapacitores também se observa que a capacidade de potência é muito superior à necessidade do veículo. 


\subsection{RESULTADOS DE DESEMPENHO OBTIDOS}

A seguir são apresentados alguns resultados reais obtidos com a utilização dos componentes dimensionados e determinados através da metodologia apresentada neste trabalho.

Devido às limitações na infraestrutura e de recursos, alguns dados podem conter erros de precisão e exatidão. As principais dificuldades para a realização das medições foram com relação à uniformidade da inclinação da pista no local de realização dos testes, o comprimento dos trechos de pista com as inclinações uniformes e as próprias inclinações que não eram nos valores requeridos.

O principal objetivo, na época, era criar um banco de dados para comparação em desenvolvimentos de novos produtos e todos os testes foram realizados na própria fábrica.

A Tabela 5.12, com medições efetuadas na fábrica, apresenta a demanda de potência nos terminais das baterias em diversas condições de velocidade, carga e aclive. Foi acrescentada a penúltima coluna nesta tabela, com dados obtidos por simulação na planilha de cálculos, para comparação de valores e avaliação dos resultados. A última coluna mostra o erro percentual entre os valores medidos e calculados para a potência.

Tabela 5.12 - Medições efetuadas na fábrica com o veículo

\begin{tabular}{|c|c|c|c|c|c|c|c|}
\hline $\begin{array}{c}\text { CARGA } \\
\text { [\%] }\end{array}$ & $\begin{array}{c}\text { ACLIVE } \\
\text { [\%] }\end{array}$ & $\begin{array}{l}\text { VELOC. } \\
{[\mathrm{km} / \mathrm{h}]}\end{array}$ & $\begin{array}{c}\mathbf{V}_{\text {bat(med) }} \\
{[\mathrm{V}]}\end{array}$ & $\begin{array}{c}I_{\text {bat(med) }} \\
{[A]}\end{array}$ & $\begin{array}{l}P_{\text {out(med) }} \\
{[W]}\end{array}$ & $\begin{array}{c}P_{\text {out(calc) }} \\
{[W]}\end{array}$ & $\begin{array}{c}\Delta \mathrm{P}_{\text {out }} / \mathrm{P}_{\text {out(med) }} \\
{[\%]}\end{array}$ \\
\hline $0 \%$ & $0 \%$ & 12 & 36,2 & 3,2 & 116 & 94 & $-19 \%$ \\
\hline $0 \%$ & $0 \%$ & 19 & 35,9 & 9,2 & 330 & 287 & $-13 \%$ \\
\hline $0 \%$ & $20 \%$ & 12 & 34,2 & 152,0 & 5198 & 5327 & $2 \%$ \\
\hline $100 \%$ & $0 \%$ & 12 & 36 & 4,7 & 169 & 147 & $-13 \%$ \\
\hline $100 \%$ & $10 \%$ & 6 & 35,3 & 94,9 & 3350 & 3371 & $1 \%$ \\
\hline $100 \%$ & $10 \%$ & 8 & 34,9 & 126,1 & 4401 & 4502 & $2 \%$ \\
\hline
\end{tabular}


Notas:

1. Foram utilizados dois multímetros digitais marca Fluke modelo CAT III, com amperímetro alicate, para as medições de corrente e tensão nas baterias.

2. As medições de velocidade foram realizadas com um radar de efeito Doppler marca Stalker modelo ATR.

A Tabela 5.13 apresenta as características reais de desempenho dos veículos produzidos e a especificação técnica de projeto para comparação e avaliação.

Os dados foram obtidos a partir de três veículos distintos e em épocas distintas. $\mathrm{O}$ primeiro, um protótipo na fase de desenvolvimento do produto. O segundo, um veículo novo produzido na linha de montagem após a construção da fábrica. $\mathrm{O}$ terceiro, um veículo também produzido na fábrica, mas após três anos de uso. 
Tabela 5.13 - Características reais de desempenho e especificações de projeto

\begin{tabular}{|c|c|c|c|c|c|}
\hline PARĀMETRO & Protót. & $\begin{array}{c}\text { Veículo } \\
0 \text { km }\end{array}$ & $\begin{array}{l}\text { Veículo } \\
3 \text { anos }\end{array}$ & $\begin{array}{l}\text { Espec. } \\
\text { projeto }\end{array}$ & UNID. \\
\hline Tara & 590 & 595 & 595 & 600 & {$[\mathrm{~kg}]$} \\
\hline \multicolumn{6}{|l|}{ Autonomia: } \\
\hline - Percurso & $>50$ & $>50$ & 43 & 40 & {$[\mathrm{~km}]$} \\
\hline - Tempo & $>2,2$ & $>2,2$ & 2,1 & 2 & {$[\mathrm{~h}]$} \\
\hline Capacidade de carga & 900 & 900 & 900 & 900 & [kg] \\
\hline \multicolumn{6}{|l|}{ Velocidades máximas: } \\
\hline - $0 \%$ carga em aclive de $0 \%$ & 22 & 19 & 19 & 19 & {$[\mathrm{~km} / \mathrm{h}]$} \\
\hline - $100 \%$ carga em aclive de $0 \%$ & 22 & 19 & 19 & 12 & {$[\mathrm{~km} / \mathrm{h}]$} \\
\hline \multicolumn{6}{|l|}{ Velocidades mínimas: } \\
\hline - $0 \%$ carga em aclive de $20 \%$ & 19 & 19 & 19 & 12 & {$[\mathrm{~km} / \mathrm{h}]$} \\
\hline - $100 \%$ carga em aclive de $10 \%$ & 12 & 12 & 10 & 5 & {$[\mathrm{~km} / \mathrm{h}]$} \\
\hline \multicolumn{6}{|l|}{ Acelerações: } \\
\hline - 0 a $19 \mathrm{~km} / \mathrm{h}$ (0\% carga/0\% aclive) & 5 & 6 & 7 & 10 & {$[\mathrm{~s}]$} \\
\hline - 0 a 12 km/h (100\% carga/0\% aclive) & 5 & 5 & 7 & 10 & {$[\mathrm{~s}]$} \\
\hline
\end{tabular}

Na primeira fase do projeto, e cujos resultados são mostrados neste trabalho, os veículos não possuíam frenagem regenerativa que foi introduzida apenas numa segunda fase. 


\subsection{AVALIAÇÃO DOS RESULTADOS PRÁTICOS}

Analisando os valores na Tabela 5.12, obtidos para a potência, nos terminais das baterias e aqueles calculados durante o dimensionamento, notam-se diferenças de até $19 \%$ para valores inferiores a $300 \mathrm{~W}$ e diferenças da ordem de $2 \%$ para valores superiores a $3300 \mathrm{~W}$. Provavelmente, devido às dificuldades para a realização das medições, como comentado anteriormente, que provocaram erros em valores absolutos e que afetaram relativamente mais os valores menores.

$\mathrm{Na}$ Tabela 5.13, observa-se que alguns resultados reais de desempenho superaram, significativamente, às especificações de projeto.

A velocidade máxima em terreno plano com o veículo carregado foi um caso de erro de especificação. No plano, o veículo carregado em relação ao vazio, teria apenas um acréscimo na força de resistência ao rolamento e por essa razão as velocidades máximas são praticamente iguais. A diferença está no tempo de aceleração para atingir essa velocidade.

As diferenças nas velocidades mínimas em aclive com o veículo vazio e carregado, na velocidade máxima em aclive com o veículo vazio e nos tempos de aceleração, foram devido às características de torque e capacidade de sobrecarga do motor escolhido que favoreceram o desempenho esperado para o veículo. É importante ressaltar que essas diferenças no desempenho foram proporcionais às diferenças nas características do motor.

Por último e talvez a mais importante avaliação dos resultados práticos seja a constatação de que o produto, dimensionado com a metodologia apresentada neste trabalho, atendeu a 100\% dos requisitos da especificação de projeto.

\subsection{O PRODUTO}

Os resultados práticos obtidos através do dimensionamento do sistema de tração de um veículo elétrico utilizando a metodologia apresentada neste trabalho são mostrados nas imagens da Figura 5.14 a Figura 5.21. 


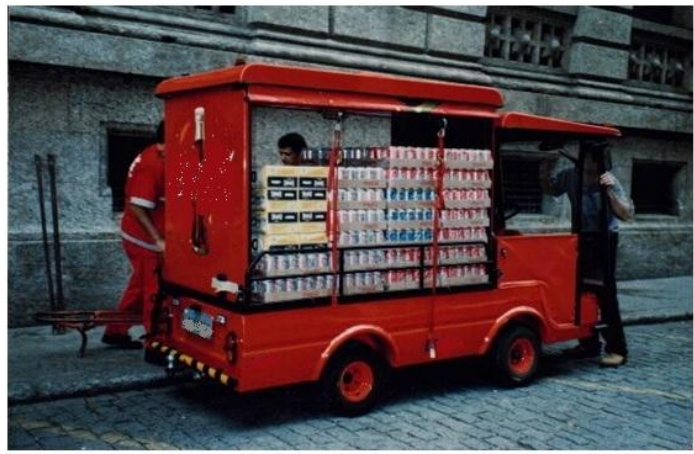

Figura 5.14 - Veículo elétrico (distribuição de bebidas)

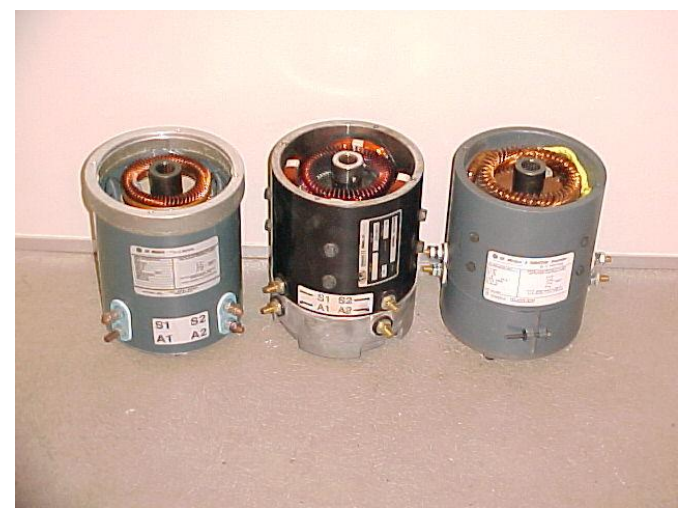

Figura 5.16 - Motores elétricos de tração

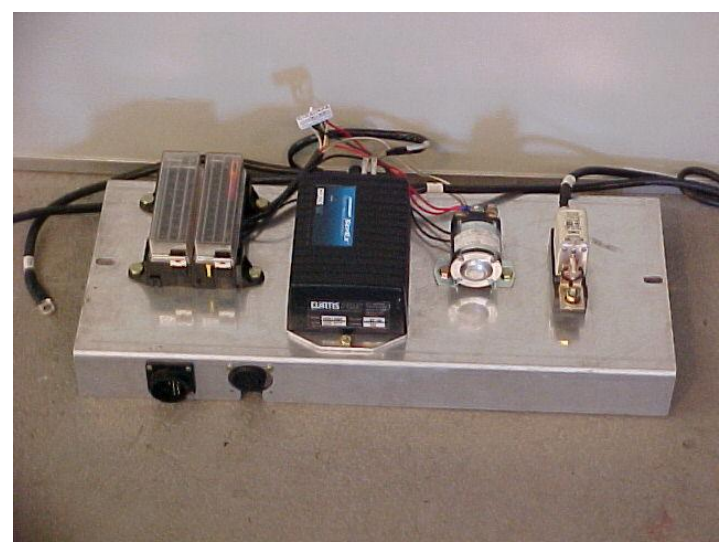

Figura 5.18 - Controlador/conversor de potência montado com contator e fusíveis

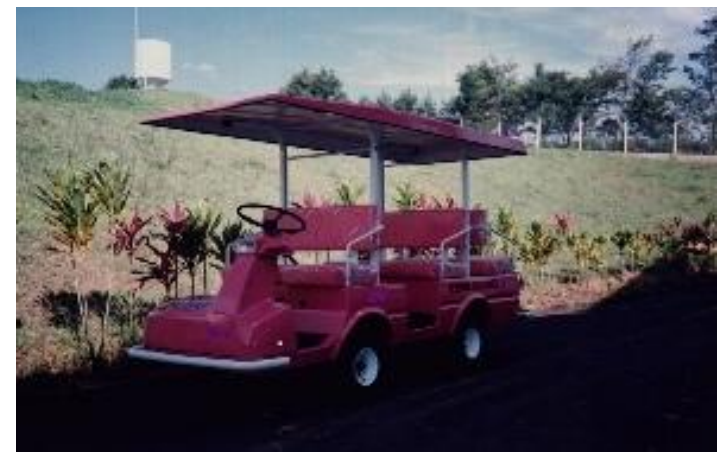

Figura 5.15 - Veículo elétrico (transporte de pessoas)

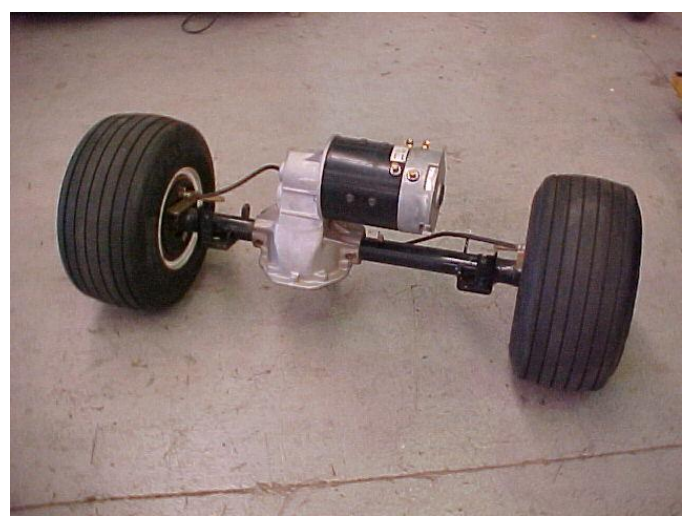

Figura 5.17 - Motor acoplado à transmissão e diferencial no eixo de tração

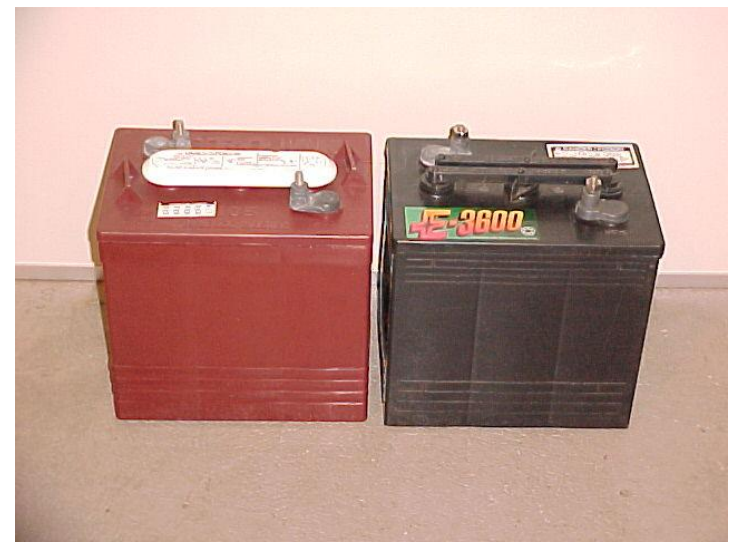

Figura 5.19 - Baterias 


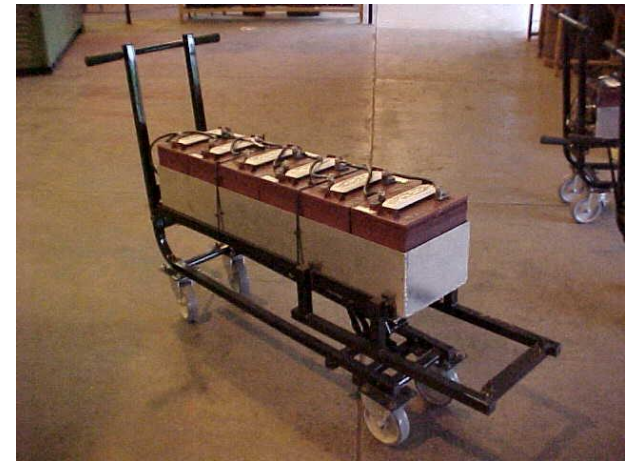

Figura 5.20 - Banco de baterias

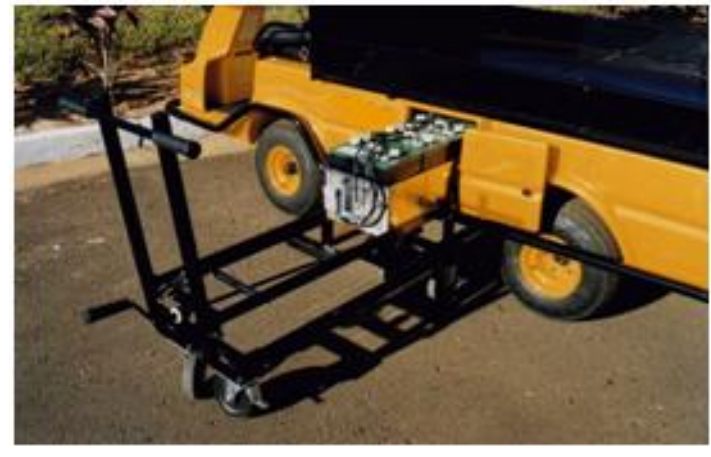

Figura 5.21 - Sistema de troca rápida de baterias 


\section{CONCLUSÕES}

O dimensionamento de sistemas de tração para veículos automotores tem sido realizado há mais de um século e, conceitualmente, não mudou significativamente. Entretanto, a metodologia tem evoluído à medida que novos recursos são desenvolvidos e informações disponibilizadas.

Com o retorno do interesse por veículos de tração elétrica e os avanços tecnológicos, que viabilizam um número crescente de aplicações de veículos elétricos a bateria, existe a necessidade de uma metodologia com foco no desenvolvimento desses novos produtos.

O presente trabalho contribui para atender essa necessidade, apresentando uma metodologia simples e direta de dimensionamento do sistema de tração para veículos elétricos a bateria.

$\mathrm{Na}$ revisão bibliográfica são apresentados alguns trabalhos similares para comparação de metodologias, os tipos de máquinas elétricas mais frequentemente usados, e o estado da arte em baterias e ultracapacitores para atender as necessidades de suprimento de energia e potência.

Os conceitos teóricos são apresentados de forma atualizada na revisão bibliográfica e reformulados ou complementados ao longo do desenvolvimento da metodologia, visando facilitar a compreensão, proporcionar maior exatidão e simplificar a execução, que são os principais diferenciais deste trabalho.

Ênfase especial é dada à exatidão utilizando-se uma equação completa para os cálculos, que permite a sua utilização em qualquer aplicação, e, deixando como opcional a utilização do fator de massa em situações onde não seja possível a obtenção dos momentos de inércia das partes girantes do sistema de transmissão.

A metodologia é fundamentada na sequência lógica para o desenvolvimento de produtos, a partir das necessidades dos clientes, traduzidas em especificação técnica de produto, até a escolha dos componentes que integrarão o produto final. Para consolidar o trabalho, um exemplo real é apresentado passo a passo, utilizando uma única planilha de cálculos, ratificando a simplicidade da metodologia. 
Os resultados práticos apresentados na Tabela 5.13, com as características de desempenho dos veículos fabricados, inclusive um veículo após três anos de uso, mostram que o desempenho satisfatório conseguido através do dimensionamento do sistema de tração não foi mera casualidade ou sorte.

Existem, atualmente em operação, produtos com mais de 15 anos de uso e mais de três mil veículos já foram produzidos e comercializados. 


\section{DESENVOLVIMENTOS FUTUROS}

Este trabalho pode ser complementado com um programa computacional contendo bancos de dados dos principais componentes, como baterias, ultracapacitores, motores elétricos e conversores de potência com a finalidade de facilitar ainda mais o dimensionamento através desta metodologia, que é um processo iterativo.

Um recurso importante neste programa seria a simulação com diferentes parâmetros para a frenagem regenerativa, incluindo-se um conversor de potência com múltiplas entradas e saídas para melhor aproveitamento e transferência de energia entre fonte(s), baterias, ultracapacitores e motor(es).

Esses cálculos, embora simples, devem ser repetidos várias vezes, razão pela qual um programa computacional com os bancos de dados e as características dos componentes a serem utilizados seria de grande ajuda. 


\section{REFERÊNCIAS}

AFFANNI, A. et al. Battery choice and management for new-generation electric vehicles. IEEE Transactions On Industrial Electronics, [S.I.], v. 52, n. 5, oct. 2005.

ALCALÁ, I.; CLAUDIO, A.; GUERRERO, G. V. Analysis of propulsion systems in electric vehicles. In: International Conference on Electrical and Electronics Engineering, 2., 2005, Mexico City. Proceedings... [S.I.:s.n.], 2005, p. 309-313.

ANDERSON, J.; ANDERSON, C. D. Electric and hybrid cars: a history. North Carolina: McFarland, 2005.

BARNITT, R.; EUDY, L. Overview of advanced technology transportation: 2005 update. [S.I.]: NREL, 2005, 20 p. (Technical Report).

BOTTURA, C. P.; BARRETO, G. Veículos elétricos. Campinas: Unicamp, 1989.

BRANT, B. Build your own electric vehicle. Pennsylvania: Tab Books, 1993.

BURKE, A. F. Batteries and ultracapacitors for electric, hybrid, and fuel cell vehicles. Proceedings of The IEEE, [S.I.], v. 95, n. 4, p. 806-820, apr. 2007.

BURKE, A. F. Ultracapacitor technologies and applications in hybrid and electric vehicles: UDC-ITS-RR-09-23. International Journal of Energy Research, Davis, CA, p.1-29, aug. 2009.

BURKE, A. F.; HARDIN, J. E.; DOWGIALLO, E. J. Application of ultracapacitors in electric vehicle propulsion systems. In: International Power Sources Symposium, 34., 1990, Ottawa. Proceedings... [S.I.:s.n.], 1990, p. 328-333.

BURKE, A. F.; MILLER, M. Update of ultracapacitor technology and hybrid vehicle applications: passenger cars and transit buses. In: EVS-18 - International Electric Vehicle Symposium and Exhibition, 18, 2001, Berlin. Proceedings of EVS-18 International electric vehicle symposium and exhibition. [S.I.: s.n.], 2001, 12 p.

BURKE, A. F.; MILLER, M.; ZHAO, H. Lithium batteries and ultracapacitors alone and in combination in hybrid vehicles: Fuel Economy and battery stress reduction advantages. In: EVS-25 - The 25 th World Battery, Hybrid and Fuel Cell Electric Vehicle Symposium \& Exhibition, 25, 2010, Shenzhen. Proceedings of EVS-25 The $25^{\text {th }}$ world battery, hybrid and fuel cell electric vehicle symposium \& exhibition. [S.I.: s.n.], 2010, 11 p.

BURKE, A. F.; MILLER, M.; ZHAO, H. Ultracapacitors in hybrid vehicle applications: Testing of new high power devices and prospects for increased energy density. In: EVS-26 - International Battery, Hybrid and Fuel Cell Electric Vehicle Symposium, 26, 2012, Los Angeles. Proceedings of EVS-26 - International battery, hybrid and fuel cell electric vehicle symposium. [S.I.: s.n.], 2012, 9 p. 
BURKE, A. F.; ZHAO, H. Energy saving and cost projections for advanced hybrid, battery electric, and fuel cell vehicles in 2015-2030. In: EVS-26 - International Battery, Hybrid and Fuel Cell Electric Vehicle Symposium, 26, 2012, Los Angeles. Proceedings of EVS-26 - International battery, hybrid and fuel cell electric vehicle symposium. [S.I.: s.n.], 2012, 13 p.

BURKE, A. F.; ZHAO, H. Simulations of plug-in hybrid vehicles using advanced lithium batteries and ultracapacitors on various driving cycles: UDC-ITS-RR-1002. Davis, CA: ITS, 2010, 14 p. (Research Report).

BUTLER, K. L.; EHSANI, M.; KAMATH, P. A matlab-based modeling and simulation package for electric and hybrid electric vehicle design. IEEE Transactions on Vehicular Technology, [S.I.], v. 48, n. 6, nov. 1999.

CALASANZ, T. et al. Hybrid-electric vehicle designed for slow, start/stop, low-gear driving in heavy traffic conditions in manila. In: IEEE Vehicle Power and Propulsion Conference, 2005, Chicago. Proceedings... [S.I.: IEEE], p. 510-516.

CHAN, C.C. An overview of electric vehicle technology. Proceedings of The IEEE, [S.I.], v. 81, n. 9, sep. 1993.

CHAN, C.C. Present status and future trends of electric vehicles. In: APSCOM-93 IEE International Conference on Advances in Power System Control, Operation and Management, 2., 1993, Hong Kong. Proceedings... [S.I.: IEE], 1993, v. 1, p. 456469.

CHAN, C.C.; CHAU, K. T. Power electronics challenges in electric vehicles. In:

IECON '93 - IEEE Industrial Electronics Annual Conference, 19., 1993, Maui.

Proceedings of the IECON '93 International Conference on Industrial

Electronics. [S.I.: IEEE], 1993, v. 2, p. 701-706.

CHAN, C.C. et al. Novel permanent magnet motor drives for electric vehicles. IEEE Transactions on Industrial Electronics, [S.I.], v. 43, n. 2, apr. 1996.

CHANG, L. Recent developments of electric vehicles and their propulsion systems. IEEE Aerospace and Electronic Systems Magazine, [S.I.], v. 8, issue 12, p. 3-6, dec. 1993.

DIESELNET. Ciclos de teste. Disponível em <http://www.dieselnet.com/standards/cycles/>. Acesso em: 21 ago 2012.

DOLL, C. Innovation in vehicle technology: the case of hybrid electric vehicles. In: Dime International Conference Innovation, Sustainability and Policy, 2008, Gretha. Proceedings... [S.I.: s.n.], 2008, p. 1-17.

EHSANI, M.; GAO, Y.; EMADI, A. Modern Electric, Hybrid Electric, and Fuel Cell Vehicles. Boca Raton: CRC Press, 2010. 
EHSANI, M.; RAHMAN, K. M.; TOLIYAT, H. A. Propulsion system design of electric and hybrid vehicles. IEEE Transactions on Industrial Electronics, [S.I.], v. 44, n. 1, feb. 1997.

ELECTRIC TRANSPORTATION APPLICATIONS. Electric vehicle constant speed range tests: Procedure ETA-NTP004, Revision 3, [S.I.], 2008.

ELECTRIC TRANSPORTATION APPLICATIONS. Electric vehicle constant speed range tests: Procedure ETA-TP004, Revision 3, [S.I.], 1997.

ELECTRIC TRANSPORTATION APPLICATIONS. Electric vehicle constant speed range tests: Procedure ETA-UTP004, Revision 0, [S.I.], 2001.

ELECTRIC TRANSPORTATION APPLICATIONS. Hybrid electric vehicle constant speed range tests: Procedure ETA-HTP04, Revision 1, [S.I.], 2005.

ELECTRIC TRANSPORTATION APPLICATIONS. Hybrid electric vehicle constant speed range tests: Procedure ETA-TP004, Revision 1, [S.I.], 2005.

ELECTRIC TRANSPORTATION APPLICATIONS. Implementation of SAE standard J1634 May93 - electric vehicle energy consumption and range test procedure: Procedure ETA-UTP003, Revision 0, [S.I.], 2001.

ELECTRIC TRANSPORTATION APPLICATIONS. Implementation of SAE standard J1666 May93 - hybrid electric vehicle acceleration, gradeability, and deceleration test procedure: Procedure ETA-HTP02, Revision 0, [S.I.], 2004.

ELECTRIC TRANSPORTATION APPLICATIONS. Implementation of SAE standard J2263 - road load measurement using onboard anenometry and coastdown techniques: Procedure ETA-HTP01, Revision 2, [S.I.], 2008.

EMADI, A. Handbook Of Automotive Power Electronics And Motor Drives. Boca Raton: CRC Press, 2005.

FERREIRA, A. A.; POMILIO, J. A.; SILVA, E. P.; CAMBRA, D. V. P. Metodologia para dimensionar múltiplas fontes de suprimento de energia de veículos elétricos. In: VE 2007 - Seminário e Exposição de Veículos Elétricos, 5., 2007, Rio de Janeiro. CD-ROM... [S.I.:ABVE], 2007.

FRANCFORT, J. E. Hybrid electric vehicle and lithium polymer NEV testing. In: Power Sources Conference, 42., 2006, Philadelphia. Information Bridge, DOE, OSTI. [Idaho: INL], 2006, 4 p.

FRANCFORT, J. E. Advanced technology vehicle testing. In: EVS-20 - International Electric Vehicle Symposium and Exhibition, 20., 2003, Long Beach. Proceedings of EVS-20 - international electric vehicle symposium and exhibition. [S.I.: s.n.], 2003, $13 \mathrm{p}$. 
FRANCFORT, J. E. Hybrid electric and pure electric vehicle testing (advanced vehicle testing activity). In: U.S. Department of Energy FreedomCAR \& Vehicle Technologies Program workshop, 2005, Idaho. Presentation... [S.I.: s.n.], 2005, 34 p.

FRANCFORT, J. E. Hybrid electric vehicle end-of-life testing on Honda Insights, Honda Gen I Civics and Toyota Gen I Priuses. [S.I.]: U.S. Department of Energy FreedomCAR \& Vehicle Technologies Program, 2006, 16 p. Technical Report.

FRANCFORT, J. E.; KARNER, D. Hybrid electric and plugin hybrid electric vehicle testing activities. In: EVS-23 - International Battery, Hybrid and Fuel Cell Electric Vehicle Symposium \& Exhibition, 23., 2007, Anaheim. Proceedings of EVS-23 international battery, hybrid and fuel cell electric vehicles symposium \& exhibition. [S.I.: s.n.], 2007, 20 p.

FRANCFORT, J. E.; KARNER, D. KATECH (lithium polymer) 4-passenger NEV range and battery testing report. [Idaho: INL], 2005, 33 p. Information Bridge, DOE, OSTI - Technical Report.

FRANCFORT, J. E.; KARNER, D. PHEV field test plans and testing results. In: DOE PHEV Annual Review Meeting, 2007, Washington DC. Presentation... [S.I.: s.n.], 2007, 27 p.

GAGE, T. B. Lead-acid Batteries: Key to electric vehicle commercialization: experience with design, manufacture, and use of EV'S. In: Annual Battery Conference on Applications and Advances, 15., 2000, Long Beach. Proceedings of the $15^{\text {th }}$ annual battery conference on applications and advances. Piscataway: IEEE, 1999, p. 217-222.

GAIR, S. et al. Electronic differential with sliding mode controller for a direct wheel drive electric vehicle. In: ICM '04 - IEEE International Conference on Mechatronics, 2004, Istanbul. Proceedings of the IEEE international conference on mechatronics. [S.I.: IEEE], 2004, p. 98-103.

GILLESPIE, T. D. Fundamentals of Vehicle Dynamics. Warrendale: SAE, 1992.

GULHANE, V.; TARAMBALE, M. R.; NERKAR, Y. P. A scope for the research and development activities on electric vehicle technology in Pune city. In: ICEHV '06 IEEE Conference on Electric and Hybrid Vehicles, 2006, Pune, India.

Proceedings... [S.I.: IEEE], 2006, p. 1-8.

GUZZELLA, L.; SCIARRETTA, A. Vehicle Propulsion Systems: Introduction to Modeling and Optimization. Berlin: Springer, 2005.

HAYES, J. G. Battery charging systems for electric vehicles. In: IEE Colloquium on Electric Vehicles - A Technology Roadmap for the Future, 1998, London. Digest... London: IEE, 1998, n. 1998/262, p. 4/1-4/8. 
HOWELL, D. Plug-In hybrid electric vehicle battery research and development activities. In: DOE/EERE PHEV Stakeholder Workshop, 2007, Washington DC. Presentation... [S.I.: s.n.], 2007, 17 p.

INTERNATIONAL ENERGY AGENCY. Electric vehicles: technology, performance and potential. Paris: OECD, 1993.

JINRUI, N.; ZHIFU, W.; QINGLIAN, R. Simulation and analysis of performance of a pure electric vehicle with a super-capacitor. In: VPPC'06 - IEEE Vehicle Power and Propulsion Conference, 2006, Windsor. Proceedings... [S.I.: s.n.], 2006, p. 1-6.

KEOUN, B. C. Designing an electric vehicle conversion. In: SOUTHCON/95, 1995, Fort Lauderdale. Conference Record. Piscataway: IEEE, 1995, p. 303-308.

LARMINIE, J.; LOWRY, J. Electric Vehicle Technology Explained. Chichester: John Wiley \& Sons, 2003.

LIPMAN, T.; DELUCCHI, M. A. Hybrid-electric vehicle design: retail and lifecycle cost analysis. University of California, CA: [s.n.], 2003. 71 p. (Final Report UCD-ITSRR-03-01).

LONDON, Mayor of. An electric vehicle delivery plan for London. Disponível em $<$ https://www.london.gov.uk/sites/default/files/uploads/electric-vehicles-plan.pdf>. Acesso em: 29 ago 2012.

LU, S.; CORZINE, K. A.; FERDOWSI, M. A new battery/ultracapacitor energy storage system design and its motor drive integration for hybrid electric vehicles. IEEE Transactions on Vehicular Technology, [S.I.], v. 56, n. 4, jul. 2007.

MAGGETTO, G. Electric vehicle technology: a worldwide perspective. In: IEE Colloquium on Electric Vehicles - A Technology Roadmap for the Future, 1998, London. Digest... London.: IEE, 1998, n. 1998/262, p. 1/1-1/10.

MARCEL, M. J.; HASKEW, T. A.; Williams, K. A. Test facility for a hybrid fuel cell electric vehicle. In: IEEE SOUTHEASTCON, 2007, Richmond. Proceedings... [S.I.: IEEE], 2007, p. 734-739.

MICELI, R. et al. A test cycle for the standardization and characterization of electric drives for electric vehicles. In: PEDES'98 - IEEE International Conference on Power Electronics, Drives and Energy Systems for Industrial Growth, 1996, New Delhi. Proceedings of the international conference on power electronics, drives and energy systems for industrial growth. [S.I.: IEEE], v. 1, p. 313-317.

MILLER, J. M. Power electronics in hybrid electric vehicle applications. In: APEC '03 - IEEE Applied Power Electronics Conference and Exposition, 18., 2003, Miami. Proceedings of IEEE applied power electronics conference and exposition. [S.I.: IEEE], 2003, v. 1, p. 23-29.

MURPHY, G. J. Considerations in the design of drive systems for on-the-road electric vehicles. Proceedings of the IEEE, [S.I.], v. 60, n. 12, p. 1519-1533, dec. 1972. 
MURPHY, M. E. A neighborhood electric vehicle (NEV) developed for the $21^{\text {st }}$ century. In: NORTHCON/96 - IEEE Technical Applications Conference, 1996. Conference record. [S.I.: IEEE], 1996, p. 369-372.

NANDA, G.; KAR, N. C. A survey and comparison of characteristics of motor drives used in electric vehicles. In: CCECE 2006 - Canadian Conference on Electrical and Computer Engineering, 2006, Ottawa. Proceedings... [S.I.:s.n.], 2006, p. 811-814.

NAUNIN, D. Electric vehicles. In: ISIE '96 - IEEE International Symposium on Industrial Electronics, 1996, Warsaw, Poland. Proceedings of the IEEE international symposium on industrial electronics. [S.I.: IEEE], 1996, v.1, p. 1124.

ONODA, S. et al. A PSIM-based modeling tool for conventional, electric, and hybrid electric vehicles studies. In: VTC 2002-FALL - IEEE Vehicular Technology Conference, 56., 2002. Proceedings of the IEEE vehicular technology conference. [S.I.: IEEE], 2002, v. 3, p. 1676-1680.

PARTEN, M.; MAXWELL, T. Development of a hybrid electric sport utility vehicle. In: IEEE VTS/VTC 2001 FALL - Vehicular Technology Conference, 54., 2001, Atlantic City. Proceedings... [S.I.: IEEE], 2001, v. 4, p. 2221-2224.

PESARAN, A. et al. FY2007 NREL energy storage R\&D progress report. Golden, CO: NREL, 2007. 27 p. (Annual Report NREL/TP-540-42716)

PINAL, F. J. P. et al. Step by step design procedure of an independent-wheeled small EV applying EVLS. In: IECON'06 - Annual Conference on IEEE Industrial Electronics, 32., 2006, Paris. Proceedings... [S.I.:s.n.], 2006, p. 1176-1181.

PRATT, R. et al. Potential impacts of high penetration of plug-in hybrid vehicles on the U.S. power grid. In: DOE/EERE PHEV Stakeholder Workshop, 2007, Washington DC. Presentation... [S.I.: s.n.], 2007, 14 p.

RAHIM, N. A.; PING, H. W.; TADJUDDIN, M. Design of an in-wheel axial flux brushless DC motor for electric vehicle. In: IFOST2006 - International Forum on Strategic Technology, 1., 2006, Ulsan, Korea. Proceedings... [S.I.: s.n.], p. 16-19.

RAHIM, N. A.; PING, H. W.; TADJUDDIN, M. Design of axial flux permanent magnet brushless DC motor for direct drive of electric vehicle. In: IEEE Power Engineering Society General Meeting, 2007, Tampa, Florida. Proceedings... [S.I.: s.n.], 2007, p. $1-6$.

RIEZENMAN, M. J. The EV future: continuing environmental concerns are moving electric vehicles into high gear at development facilities everywhere. IEEE Expectrum, [S.I], p. 19-20, nov. 1998.

SADEGHI, S.; MILIMONFARED, J.; MIRSALIM, M. Dynamic modeling and simulation of a series hybrid electric vehicle using a switched reluctance motor. In: ICEMS - International Conference on Electrical Machines and Systems, 2007, Seoul. 
Proceedings of international conference on electrical machines and systems 2007. [S.I.: s.n.], 2007, p. 2017-2022.

SARGENT, N. B. A laboratory facility for electric vehicle propulsion system testing. In: IEEE Vehicular Technology Conference, $30^{\text {th }}, 1980$, Dearborn, MI.

Proceedings... [S.I.:s.n.], 1980, v. 30, p. 261-264.

SCHOFIELD, N.; YAP, H. T.; BINGHAM, C. M. Hybrid energy sources for electric and fuel cell vehicle propulsion. In: IEEE Vehicle Power and Propulsion Conference, 2005, Chicago. Proceedings... [S.I.: IEEE], p. 522-529.

SHACKET, S. R. The complete book of electric vehicles. Chicago: Domus Books, 1979.

SHIMIZU, H. et al. Advanced concepts in electric vehicle design. IEEE Transactions On Industrial Electronics, [S.I.], v. 44, n. 1, feb. 1997.

SIMPSON, A. G.; WALKER, G. R. Lifecycle costs of ultracapacitors in electric vehicle applications. In: PESC 02 - IEEE Annual Power Electronics Specialists Conference, 33, 2002, Cairns, QLD. Proceedings of the 2002 power electronics specialists conference. Piscataway, NJ: IEEE, 2002, v. 2, p. 1015-1020.

SPEEDACE. Electric cars: history \& links. Disponível em: <http://www.speedace.info/electric_cars.htm>. Acesso em: 15 ago. 2009.

SULLIVAN, R. Plug-In hybrid electric vehicle R\&D plan. In: DOE/EERE PHEV Stakeholder Workshop, 2007, Washington DC. Presentation... [S.I.: s.n.], 2007, 9 p.

TANAKA, C. N.; GOLDEMBERG, C. Experiência de construção de veículos elétricos. In: VE 2007 - Seminário e Exposição de Veículos Elétricos, 5., 2007, Rio de Janeiro. CD-ROM... [S.I.:ABVE], 2007.

TZIRAKIS, E. et al. Vehicle emissions and driving cycles: comparison of the Athens driving cycle (ADC) with ECE-15 and European driving cycle (EDC). Global NEST Journal, Greece, v. 8, n. 3, p. 282-290, 2006.

WANG, L.; WEN, X. Dynamic match and optimizing design of electric vehicle powertrain. In: IVEC'99 - IEEE International Vehicle Electronics Conference, 1999, Changchun, China. Proceedings of the IEEE international vehicle electronics conference. [S.I.: IEEE], 1999, v. 1, p. 387-390.

WANG, L. Hybrid electric vehicle design based on a multi-objective optimization evolutionary algorithm. Walter J. Karplus Summer Research Grant Report 2005. [S.I.: IEEE], 2005, 16 p.

WEST, J. G. W. DC, induction, reluctance and PM motors for electric vehicles. Power Engineering Journal, [London: IEE], v. 8, issue 2, p. 77-88, apr. 1994. 
WIKIPEDIA. Government incentives for plug-in electric vehicles. Disponível em $<$ http://en.wikipedia.org/wiki/Government incentives for plug-in electric vehicles >. Acesso em: 29 ago 2012.

$\mathrm{XU}, \mathrm{W}$. et al. Survey on electrical machines in electrical vehicles. In: IEEE International Conference on Applied Superconductivity and Electromagnetic Devices, 2009, Chengdu, China. Proceedings... [S.I.: IEEE], 2009, p. 167-170.

XUE, X. D.; CHENG, K. W. E.; CHEUNG, N. C. Selection of electric motor drives for electric vehicles. In: AUPEC 2008 - Australasian Universities Power Engineering Conference, 2008, Sydney. Proceedings...[S.I.: s.n.], 2008, p. $1-6$.

YANG, Y. P.; WANG, T. J. Electronic gears for electric vehicles with wheel motor. In: IECON 2005 - Annual Conference of IEEE Industrial Electronics Society, 31., 2005, Raleigh. Proceedings of the $31^{\text {st }}$ annual conference of IEEE industrial electronics society. [S.I.: IEEE], 2005, p. 2644-2648.

YOUNG Jr., W. R.; WILSON, W. Monitoring electric vehicle performance. In: SOUTHCON/95, 1995, Fort Lauderdale. Conference Record. [S.I.: s.n.], 1995, p. 298-302. 